Pace University

DigitalCommons@Pace

$1-1-1993$

\title{
The Exclusion of Pregnant, Pregnable, and Once-Pregnable People (a.k.a. Women) from Biomedical Research
}

Vanessa Merton

Elisabeth Haub School of Law at Pace University

Follow this and additional works at: https://digitalcommons.pace.edu/lawfaculty

Part of the Bioethics and Medical Ethics Commons, and the Law and Gender Commons

\section{Recommended Citation}

Vanessa Merton, The Exclusion of Pregnant, Pregnable, and Once-Pregnable People (A.K.A. Women) from Biomedical Research, 3 Tex. J. Women \& L. 307 (1994), http://digitalcommons.pace.edu/lawfaculty/161/.

This Article is brought to you for free and open access by the School of Law at DigitalCommons@Pace. It has been accepted for inclusion in Pace Law Faculty Publications by an authorized administrator of DigitalCommons@Pace. For more information, please contact dheller2@law.pace.edu. 


\title{
The Exclusion of Pregnant, Pregnable, and Once-Pregnable People (a.k.a. Women) from Biomedical Research ${ }^{\dagger}$
}

\author{
Vanessa Merton††
}

The barriers to women's participation as subjects in biomedical research are currently being challenged as a matter of legislative policy, medicine, and law. This Article catalogs the ways in which women have been disadvantaged by their exclusion and recent developments to redress them, and goes on to dissect the underlying rationales for excluding women from clincial trials. The author reveals the 'fundamental misconception' behind exclusionary rationales, and argues that research sponsors in fact have more to fear in the way of potential liability from the exclusion of women, even pregnant women and women of child-bearing capacity, than from their inclusion. Finally, the Article suggests strategies for achieving reform of these exclusionary practices.

† This title is of course a tribute to the Supreme Court's astute distinction between pregnant and nonpregnant persons in Geduldig v. Aiello, 417 U.S. 484 (1974). See infra notes 237, 252 and accompanying text.

This article is dedicated to the memory of Carol H. Lefcourt, founding partner of Lefcourt, Kraft and Arber, the first all-woman law firm in New York; General Counsel to the New York State Division of Women; co-founder, Coalition on Women's Legal Issues; editor, WOMEN AND THE LAW (1984), named "Best Law Book of 1984" by the American Association of Publishers; recipient in 1990 of the Susan B. Anthony Award of the National Organization for Women. Carol died from breast cancer on August 25, 1991, at the age of 47 .

$+\dagger$ Vanessa Merton, Associate Dean for Clinical Education and Professor of Law, Pace University School of Law; B.A., Radcliffe College, 1971; J.D., N.Y.U. School of Law, 1973. I appreciate the helpful comments of Professors Lissa Griffin, Robert Levine, and John Robertson on earlier versions of this paper. I also wish to acknowledge the important assistance provided by Pace law students Kathleen Gill and Annie Mok, and by the staff of the Pace University Law Library, especially the extraordinary efforts of David Williams, Margaret Murray, and Susan Nossier. Iris Mercado, assistant administrator of the Pace Law Clinic, did a superlative job of editing and producing an endless progression of drafts, for which I am most grateful.

This work was supported in part by Pace University Law School and in part by funding from the Office for Protection from Research Risks (OPRR), National Institutes of Health, Public Health Service, U.S. Department of Health and Human Services. The OPRR does not assume responsibility for the completeness or accuracy of the document. The ideas or conclusions expressed herein are solely those of the author.

Completion of this article would not have been possible without the patient encouragement of my life partner and colleague, Steven Godeski, and the cooperation of Darrow and Rebecca Godeski Merton. 
"Clinical trials have concentrated almost exclusively on middle-class white men."

Charles Hennekens, M.D., Harvard School of Public Health ${ }^{1}$

"One of the most important things we must do is to insist on the political content of science and on its political role. The pretense that science is objective, apolitical and value-neutral . . obscures the political role that science and technology play in underwriting the existing distribution of power in society. Science and technology always operate in somebody's interest and serve someone or some group of people."

Ruth Hubbard, Ph.D., Professor Emerita of Biology, Harvard University ${ }^{2}$

"Mice have a better chance of getting experimental AIDS drugs than women."

Poster, ACT UP and Women's Health Action and Mobilization demonstration at the New York University AIDS Clinical Trial Unit on International Women's Day, March 8, $1990^{3}$

"[R]esearch on women's health is an issue whose time has come."

Ruth L. Kirschstein, M.D., Acting Associate Director, Office of Research on Women's Health, National Institutes of Health ${ }^{4}$

\section{WHAT IS THE PROBLEM?}

The problem is that women, and the health needs and concerns of women, have largely been excluded from biomedical research. This has occurred in two ways. First, women have been barred from participating as subjects in clinical trials, both de jure (explicit exclusion criterion in the protocol) and de facto ("inadvertent" failure to recruit women or to conduct the trial in a manner that realistically permits women to participate) ${ }^{5}$ Second, the

I Gina Kolata, In Medical Research, Equal Opportunity Doesn't Always Apply, N.Y. Times, Mar. 10, 1991 , at E16.

2 Ruth Hubbard, Science, Facts and Feminism, in Feminism and Science 1 19, 128 (Nancy Tuana ed., 1989).

${ }^{9}$ Risa Denenberg. Treatment and Trials, in Women, AIDS, AND ACrivism 68 (The ACT UP/ New York Women and AIDS Book Group ed., 1990).

${ }^{4}$ Ruth L. Kirschstein, Research on Women's Heallh, 81 Am. J. Pub. Health 291, 293 (1991).

${ }^{5}$ See U.S. General Accounting Office, GaO/HRD-93-17, Women's Health: fDA Needs to Ensure More Study of Gender Differences in Prescription Drug Testing (October 1992). This GAO survey of drug manufacturers that obtained FDA approval of new drugs from January 1988 through June 1991 concluded that gender-related differences in response do exist for many drugs; that women are generally under-represented in clinical trials; and that even when women are included in drug trials, the investigators do not analyze trial results to detect genderrelated differences.

See also U.S. Dep't Health \& Human Servs., Pub. No. (PHS) 88-50206, Report of Public Health Service Task Force on Women's Health Issues, Vol. II (October 1985); Mark V. Nadel, General accounting Office GaO/T-HRD-90-38, National Institutes of Health: Problems in Implementing Policy on Women in Study Populations (1990) (Testimony before the House Subcommittee on Health and the Environment, June 18, 1990); Society fOr THE Advancement of Women's Health Research, Toward a Women's Health Research Agenda: 
allocation of resources in biomedical research has been enormously skewed toward the investigation of health problems in and for men, and a huge list of health problems that primarily affect women has been neglected and unexplored. ${ }^{6}$

Findings of the Scientific Advisory Committee (1991); and the collected testimony at the public hearings before the NIH Task Force on Opportunities for Research on Women's Health on June 12-13, 1991 of more than sixty witnesses (transcripts of the testimony of forty-six witnesses are on file with the author); Paul Cotton, Is There Still Too Much Extrapolation from Data on Middle-Aged White Men?, 263 JAMA 1049 (1990); Jerry H. Gurwitz et al., The Exclusion of the Elderly and Women from Clinical Trials in Acute Myocardial Infarction, 268 JAMA 1417 (1992); Celia Hooper, Some Drug Trials Show Gender Bias, 2 J. NIH Res. 47 (1990); Evlin L. Kinney et al., Underrepresentathon of Women in New Drug Trials, 95 Annals InTernal Med. 495 (1981); Kolata, supra note 1, at E16; Earl Lane, The Gender Gap in Medical Research, NEwSDAY, June 25, 1991, at 63 (citing as examples the Physicians' Health study of aspirin prophylaxis for myocardial infarction in 22,071 men, no women; dietary study of recovery from heart attack in 2033 men, no women; study of behavioral link with heart disease in 3154 men, no women); Mary Lake Polan, Medical Researchers, Heal Thyselves of Gender Bias, L.A. Times, Feb. 24, 1991, at M2; Shigeko Segawa, Clinical Trials: It's Still a Man's World, 345 NATURE 754 (1990).

With respect to mental health and developmental research, the picture is much the same. "The study of adolescence has been the study of males," noted psychologist Carol Gilligan in reference to the ongoing work of the Harvard University Project on the Psychology of Women and the Development of Girls. Lindsay Van Gelder, The Importance of Being Eleven: Carol Gilligan Takes On Adolescence, Ms., July-Aug. 1990, at 77; see also U.S. Dep't Health \& Hum. Servs., Pub. Health Serv., Alcohol, Drug Abuse, and Mental Health Admin., Pub. No. (ADM) 86-1447, Women and Drugs: A New Era for Research v (Barbara Ray \& Monique Braude eds., 1986) ("The history of drug abuse research shares with other sciences a relative paucity of knowledge about females in particular and about gender effects in general. This bias in knowledge stems from the tradition of using male subjects for animal and human experiments and an unexamined assumption that gender is not an important experimental variable."); Chris Raymond, Recognition of the Gender Differences in Mental Illness and Its Treatment Prompts a Call for More Healih Research on Problems Specific to Women, Chron. Higher Educ., June 12, 1991, at A5.

Like so many other issues of clinical research, this phenomenon has been particularly remarked upon in the context of the AIDS pandemic. See Jeannette R. Ickovics \& Judith Rodin, Women and AIDS in the United States - Epidemiology, Natural History, and Mediating Mechanisms, 11 Health Psychol., Jan. 1992, at 1 (although women represent more than one-third of all cases of AIDS globally and die significantly sooner after diagnosis than men with AIDS, and despite important gender differences in all phases of the disease process, from prevention and exposure to diagnosis and treatment, women are still excluded from most biomedical and psychosocial research); Institute of Medicine, Expanding Access to Investigational Therapies for HIV InFECTION AND AIDS 64 (1991) (white males predominate in almost all clinical AIDS trials); Kenneth Mayer \& Charles Carpenter, Women and AIDS, 266 ScI. AM. 118 (1992) (marked underrepresentation of women in HIV-related clinical research); Gina Kolata, AIDS Research on New Drugs Bypasses Addicts and Women, N.Y. Times, Jan. 5, 1988, at C1, C7. That this was no oversight is well-documented in Gena Corea, The Invisible Epidemic: The Story of Women and AIDS (1992) (recounting the heroic, but unsuccessful, efforts of leading epidemiologist Dr. Zena Stein to get funding from NIH and the American Foundation for AIDS Research to study the disease in women).

The problem of exclusion is not confined to United States research. See Robert Walker, Heart Studies Ignore Women, Calcary Herald, Oct. 19, 1991, at B2 (report on presentations at the annual meeting of the Canadian Cardiovascular Association); Caroline Mallan, MDs Assume Men Need Better Care, Toronto Star, July 26, 1991, at A26 (Canadian men over the age of 45 more than twice as likely as women with similar heart disease to undergo diagnostic angiography and three times as likely to have bypass surgery; doctors don't offer heart surgery to women because they may believe that women don't need to return to work after heart attacks).

${ }^{6}$ See attached Toward A Women's Health Agenda, Appendix A. This still quite incomplete list was generated from the written testimony offered by witnesses at the NIH Hearing on the Task 
My objective is to explore some of the barriers to women's participation as subjects in biomedical research. These barriers are under siege: Witness the following constellation of events, all within the last three years: in September 1990 the National Institutes of Health ("NIH"), the federal complex of research institutes and premier funding source for biomedical research in this country, opened a new Office of Research on Women's Health; ${ }^{7}$ in 1992 , the prestigious Institute of Medicine of the National Academy of Sciences convened a working group on the inclusion of women in clinical trials, whose report is due in December $1993 ;^{8}$ and in the summer of 1993 , Georgetown University Medical Center sponsored the first major Continuing Medical Education conference on the inclusion of women in clinical trials. ${ }^{9}$ The spring and summer of 1993 also saw the inauguration of the first large-scale study of women's health, the Women's Health Initiative, a fifteen-year, $\$ 625$ million study projected to involve more than 160,000 female subjects. ${ }^{10}$ In June of 1993, President Clinton signed an NIH appropriations bill that codified as statute several policies supporting the participation of women in research both as subjects and as investigators. ${ }^{11}$ Finally, on July 22, 1993, the Food and Drug Administration ("FDA") issued proposed new regulations that revise its guidelines for the drug development process in favor of the inclusion of women. ${ }^{12}$

The symbolic and real importance of these developments should not be minimized, but neither should their impact be overestimated. Careful scrutiny of the text of the new law and regulations, ${ }^{13}$ or for example the WHI protocol, ${ }^{14}$ reveals that women still are regarded as add-ons, requiring special and different treatment than the male standard. Historically, "special" treat-

Force on Opportunities for Research on Women's Health (June 12-13, 1991); of reports created by the new Society for the Advancement of Women's Health Research; and of legislative committee reports on the proposed Women's Health Equity Act. A more definitive list may be found in the recent National Institutes of Health, U.S. Dep't Health \& Hum. Servs., Pub. No. 923457A, Report of the National Institutes of Health: Opportunities for Research on WomEn's Health (1992). See also National Women's Health Network, Research To Improve Women's Health: An Agenda for Equity (Dec. 1991) (on file with author).

7 Philip J. Hilts, N.I.H. Starts Women's Heallh Office, N.Y. Times, Sept. 11, 1990, at C9. In March 1993 the Office held two days of public hearings on issues in the recruitment and retention of women in clinical trials. See 58 Fed. Reg. 12,366-67 (Mar. 4, 1993). The National Institutes of Health Revitalization Act of 1993 codifies the creation of this office and defines its mandate as promoting research on women's health. 42 U.S.C.A. $§ 201 d$ (West Supp. 1993); see infra notes $11,276$.

8 The report entitled Women and Health Research: Ethical and Legal Issues of Includinc Women in Clinical Studies (on file with author) was issued as this article went to press.

${ }^{9}$ Georgetown University Medical Center, Conference on the Inclusion of Women and Minorities in Clinical Research (June 28-29, 1993) (brochure on file with author).

10 U.S. Health Study to Involve 160,000 Women at 16 Centers, N.Y. Times, Mar. 31, 1993, at A21; Sandra Freidland, A Medical Study on Older Women, N.Y. Times, Apr. 4, 1993, at NJ1, NJ16.

11 The National Insitutes of Health Revitalization Act of 1993, 42 U.S.C.A. $\& 201$ (West Supp. 1993); see infra note 276.

12 Guideline for the Study \& Evaluation of Gender Differences in Clinical Evaluation of Drugs, 58 Fed. Reg. 39,406 (July 22, 1993).

13 See infra notes $97-128,276-287$ and accompanying text.

14 All the women in the WHI will be post-menopausal: between the ages of 50 and 79 . See Freidland, supra, note 10 . While there is some scientific logic to the age range, in that the study is trying to identify causal factors of heart disease, cancer, and osteoporosis, which usually become 
ment for female subjects has translated into poorer medical care for women. This article argues that while all these initial steps are heartening, they are far from sufficient to redress the secondary status women have endured in the world of biomedical research.

\section{WHY WOMEN HAVE BEEN EXCLUDED FROM RESEARCH}

Arguably, among the most significant practical reasons for this exclusion has been the gender identity of those conducting and funding clinical research, and their preoccupation, not always conscious, with medical problems that resonate for them. ${ }^{15}$ On a more sociological or perhaps political level,

manifest during those years, many suspect that once again, women of child-bearing potential are being systematically excluded.

${ }^{15}$ In the eloquent phrase of Representative Patricia Schroeder, the Congressional leader who has perhaps done more than anyone else to make this issue visible, "[Y]ou fund what you fear. When you have a male-dominated group of researchers, they are more worried about prostate cancer than breast cancer." Ellen Goodman, A Health-Research Bias, Boston GlobE, June 21 , 1990, at 15. This widely distributed column was, I believe, the first to make the point that even basic animal research is generally conducted with male white rats. One particularly graphic exhibit attached to the NIH Task Force on Opportunities for Research on Women's Health testimony of the Interstitial Cystitis Association of America, Inc., compared NIH expenditures on male and female urological research. NIH Task Force on Opportunities for Research on Women's Health (exhibit to testimony of the Interstitial Cystitis Ass'n of America, Inc.). The annual expenditure of NIH research dollars on predominantly male urologic disease was $\$ 6.49$ per person affected; the comparable expenditure on predominantly female urologic disease was $\$ .35$ per person affected. (Appendix A, attached.)

More women than ever have entered the profession of medicine. Female first-year medical school enrollment has steadily grown, from $4 \%$ in 1930 , to $9 \%$ in 1969 , to over $40 \%$ in 1990 . But women remain under-represented in the ranks of academic medicine, the major locus of training and nurturing of clinical investigators. See Bernadine Healy, Women in Science: from Panes to Ceiling, 255 Science 1333 (1992). One dean of an American medical school is female. Three per cent of all department chairs are female. Women comprise about $22 \%$ of medical school faculty, but they are clustered in the lower ranks; on average, male faculty are promoted twice as fast as women. See Feminist Majority Foundation and American Medical Women's Association, EmpoWering Women in Medicine 2 (1991); AMA Council on Ethical and Judicial Affairs, Gender Discrimination in the Medical Profession, 4 Women's Health Issues 1 (1994). Although in 1987 women earned $35 \%$ of all doctorates in life sciences, and $17 \%$ in physical sciences, a recent blue-ribbon panel on the crisis in funding of research projects strongly recommended creation of more programs to encourage more women and minorities to pursue careers in health sciences and academic medicine. See Report of the Committee on Policies for Allocating Health Sciences Research Funds of the Institute of Medicine, in Funding Health Sciences Research (Floyd E. Bloom \& Mark A. Randolph eds., 1990) at 13, 123.

Women who do seek careers in research experience the same obstacles as women in other non-traditionally-female career paths. See, e.g., Maggie Garb, U.S. Health Instilutes Face Sex Discrimination Suits, 24 Am. MEd. News 4 (1991); Rorie Sherman, Claims of Bias at NIH Bolstered, NAT'L L.J., Dec. 9, 1991, at 3, 35 (\$225,000 verdict against NIH for sex discrimination against senior scientist; three other sex discrimination cases pending against NIH). The NIH, in particular, has an abysmal record in this regard. In 1986, a GAO report found that NIH takes longer than any other Public Health Service agency to resolve discrimination complaints and did not comply with four of eight Equal Employment Opportunity Commission requirements. See Alisa Solomon, Snake Pit, Mirabella, Apr. 1993, at 140-44. The draft report of an internal task force convened in 1991 "to assess the career development and status of intermural women scientists at NIH" found that women make up only $18 \%$ of the tenured scientists, although they constituted $30 \%$ of the last decade's post-docs (the traditional track to senior status). Extensive reports by female scientists of anti-woman bias at NIH range from denial of lab time and other resources, rejection of project proposals, and less desirable assignments, to display of degrading images of women in 
this phenomenon may also reflect the across-the-board tendency in so many spheres of life, from the grammatical to the occupational, to define and perceive the male as generically human and the female as a special subgroup. ${ }^{16}$

Important practical barriers are often cited to explain the much lower rate of participation of women even in trials that do not formally exclude them. Women are far more often the principal caregivers for babies, children, disabled and elderly family members or neighbors, and have much less mobility and ability to take "time off" to attend to their own medical needs. ${ }^{17}$ Women still are far more likely to have to "account" to their male partners for where they go, whom they see, what they do, and how they spend their time than vice-versa. Women's disadvantaged economic position ${ }^{18}$ means

the office and the use of terms like "wicked witch," "dragon lady," and "booby lady" to refer to women researchers. In 1992, a Washington, D.C. television station ran a six-part investigative report that featured dozens of female NIH researchers alleging discriminatory treatment. See id.; Scott Greenberger, Science Friction: The Struggle of Female Researchers at NIH, WASH. Post, July 11, 1993, at C3; NIH, Under Increased Scrutiny for Sex Discrimination, Seeks to Ban Researcher from Campus, Corp. Crime RePorter, Oct. 26, 1992, at 8, 16; and Interview with Margaret Jensvold, M.D., Director, Institute for Research on Women's Health, CoRP. CRIME REP., Oct. 26, 1992, at 8, 16. On April 1, 1994, a female researcher won the first jury verdict ever against the National Institutes of Mental Health for denial of opportunities afforded her male counterparts and retaliation for filing an EEOC complaint. Lack of Mentoring for Female Physician Considered Sex Bias by Federal Jury, 1994 Daily Lab. Rep. (BNA) No. 64, at D-11 (April 5, 1994). Recall also the case of Dr. Frances Conley, the prominent neurosurgeon who resigned her tenured position at Stanford University Medical School to protest the administration's failure to curb the relentless sexism and harassment she and other women professionals had experienced in that institution. See generally THE OUTER CiRCle: Women in the Scientific Community (Harriet Zuckerman et al. eds., 1991).

16 Thus, in the popular press one finds still ubiquitous references to the "woman firefighter" or "woman sportscaster" or, for that matter, the woman doctor or lawyer, while the gender of men in the same roles is never mentioned. In medical school, to pick a more salient example, students learn the anatomy and physiology of the "70-kilogram man:" what his urine output is, what dosages of medication he should get. A study reviewing eight major anatomy texts used in medical schools found that identifiably male bodies and body parts constitute $64 \%$ of the illustrations, while female bodies were used only for $11 \%$ of the illustrations (the gender of the balance was indeterminate) - except, of course, in the chapter on reproductive anatomy. Carol Tavris, The Mismeasure of Women 96-98 (1992); see also Kay Weiss, What Medical Students Leam About Women, in Seizing Our Bodies: The Politics of Women's Health 212 (Claudia Dreifus ed., 1978), for a collection of extraordinary excerpts from standard contemporary gynecology texts.

[P]redominantly male ... researchers, policy makers, and practitioners . . have typically dealt with differences among types of clients by placing everyone, except White middleaged ... men, in special population categories [cit. omit.]. . . This special population approach provides a way to incorporate data and experience that is inconsistent with general expectations .... but reduces the need to examine and revise the fundamental assumptions that define the standard for normal . . . services.

Reed, Developing Women-sensitive Drug Dependence Treatment Services: Why So Difficult?, 19 J. PsychoacTive Drugs 151, 152.53 (1987); see also Rebecca Dresser, Wanted: Single, White Male for Medical Research, 22 Hastings Center Rep. 24, 28 (Jan.-Feb. 1992) (biomedical researchers define "the white male as the normal, representative human being").

17 See Judith D. Auerbach, Ph.D., Testimony on behalf of the Consortium of Social Science Associations before the Task Force on Opportunities for Research on Women's Health of the Advisory Committee to the Director of National Institutes of Health 4-5 (June 12, 1991) (on file with author).

18 "Women make up more than half the world's population, yet perform two thirds of its work, receive one tenth of its income and own less than one hundredth of its property." United Nations, Office of Public Information, United Nations Decade for Women 1976-1985, Really Only a 'Beginning', 22 UN Chron., July-Aug. 1985, at ii. In the United States, the tiresome truth re- 
that they have less to spend on transportation or other relatively minor ancillary expenses. The powerful effect of providing minimal support in the form of child care, for example, has been demonstrated by the experience of the few substance-abuse programs that have instituted child-care facilities. Women's attendance and utilization increase dramatically. ${ }^{19}$

All these factors surely make it more difficult for women to participate in some protocols. But the focus of this paper is neither the psychological nor the social structures that foster concern with male medical problems. Instead I seek to catalog the explicit justifications that have been used for the exclusion of women from biomedical research; to examine the validity of those rationales for future research decisions; and to suggest that Institutional Review Boards, research funding sources, and others concerned with the conduct of biomedical research have an ethical and perhaps a legal duty to educate, persuade and provide incentives for clinical investigators and their sponsors to stop excluding women.

Part I describes the benefits that accrue to participants in a clinical trial, and conversely the variety of ways in which women have been disadvantaged by their exclusion. In Part II, I analyze the law-related arguments that have sustained exclusionary practices, and evaluate their legitimacy. Part III sets forth a proposal for genuinely equitable treatment of women in research, and Part IV reviews some different strategies that might accomplish that goal.

\section{THE IMPACT OF EXCLUSION FROM RESEARCH: WOMEN'S HEALTH AND WHAT WE DO NOT KNOW ABOUT IT}

The exclusion of potential subjects from consideration for clinical protocols has rarely been identified as a bioethical issue. This has not been for lack of interest in the general topic of research ethics; experimentation with human subjects (the eponymous title of one of the very first textbooks in the area) ${ }^{20}$ has been a central focus of bioethical inquiry, having spawned at least one journal devoted exclusively to the subject. ${ }^{21}$ Indeed it might well be characterized as the fountainhead of what can now fairly be called the bioethics movement (or industry, depending on one's perspective). In reviewing both the original "codes" of research ethics 22 and the literature of

mains that college-educated women on average have lower annual income than men with high school diplomas. Depression Affects Productivity, Causes Workplace Accidents, Experts Say, Daily Lab. Rep. (BNA) No. 141, at A-3 (July 23, 1991), and that women employed outside the home make 74c for every dollar of salary paid men. Louis S. Richman, The Truth About the Rich and the Poor, Fortune, Sept. 21, 1992, at 135; Earnings Increased 3.3 Percent for Wage, Salary Workers, Daily Lab. Rep. (BNA) No. 24, at B-4 (Feb. 5, 1992) (median earnings of full-time paid women workers 74.2 percent of full-time male workers).

${ }^{19}$ Andrea Savage-Abramowitz et al., Serving Women: The Impact of Program Structure and Resources, in 1 Drug Dependence and Alcoholism 849 (Arnold J. Schechter ed., 1981); Elaine Carmen et al., Inequality and Women's Mental Health: An Overview, 138 Aм. J. Psychiatry 1319, 1328 (1981); see also Kathleen Teltsch, In Detroit, A Drug Recovery Center That Welcomes the Pregnant Addict, N.Y. Times, Mar. 20, 1990, at Al4.

20 Jay Katz et al., Experimentation with Human Beings (1972).

21 IRB: A Review of Human Subjects Research, published by the Hastings Center and now in its fifteenth volume.

22 The major ethical codes for research scientists speak only to requiring informed consent and ensuring the freedom to refuse to serve as a subject. See, e.g., The Nuremberc Code, Rule 1 
the early years, ${ }^{23}$ as well as the definitive texts of the present, ${ }^{24}$ I have found almost no mention of the notion of a right to be considered for a research protocol or a corresponding duty not to exclude would-be subjects. The first report of The National Commission for the Protection of Human Subjects of Biomedical and Behavioral Research, ${ }^{25}$ does state that the principle of justice:

gives rise to moral requirements that there be fair procedures and outcomes in the selection of research subjects. . .

... Individual justice in the selection of subjects would require that researchers exhibit fairness: thus, they should not offer potentially beneficial research only to some patients who are in their favor or select only "undesirable" persons for risky research. ${ }^{26}$

(1949); World Medical Association, Declaration of Helsinki: Recommendations Guidinc Medical Doctors in Biomedical Research Involving Human Subjects, § III, Rule 3b (1975). Both are reprinted in Robert J. Levine, Ethics and Regulation of Clinical Research 425, 427 (2d ed. 1988) [hereinafter Levine, Ethics and Regulation].

23 E.g., Bernard Barber et al., Research on Human Subjects: Problems of Social. Control in Medical Experimentation (1973); Henry K. Beecher, Research and the Individual (1970); Renée C. Fox, Experiment Perilous (1959); Paul Freund, Experimentation on Human Subjects (1970); Charles Fried, Medical Experimentation: Personal Integrity and Social Policy (1974); Alvan R. Feinstein, Medical Ethics and the Architecture of Clinical Research, 15 Clinical Pharmacology \& Therapeutics 316 (1974); Hans Jonas, Philosophical Reflections on Experimenting with Human Subjects, 98 DaEdalus 219 (1969); LeRoy Walters, Some Ethical Issues in Research Involving Human Subjects, 20 Persp. Biology \& Med. 193 (Winter 1977); see also President's Commission for the Study of Ethical Problems in Medicine and Biomedical and Behavioral Research, Implementing Human Research Regulations (1983); President's Commission for the Study of Ethical Problems in Medicine and Biomedical and Behavioral Research, Protecting Human Subjects (1981). But see Robert J. Levine, Appropriale Guidelines for the Selection of Human Subjects for Participation in Biomedical and Behavioral Research, in The National Commission for the Protection of Human Subjects of Biomedical and Behavioral. Research, The Belmont Report: Ethical Principles and Guidelines for the Protection of Human Subjects of Research, DHEW Pub. No. (OS) 78-0013, Appendix I (1978) (hereinafter, The Belmont RePORT APPENDIX I]; Robert J. Levine \& Karen Lebacqz, Ethical Considerations in Clinical Trials, 25 Clinical Pharmacology and Therapeutics 728 (1979). Levine early on identified the potential benefit to subjects, not of the innovation on trial, but of the quality of care in the research environment.

24 Probably universally recognized as the premier comprehensive treatment is LEviNE, ETHics and Reculation, supra note 22. As noted above, Levine is one of the few ethicists to comment on this issue, although his discussion in this text is not extensive. See id. at 89-90.

25 National Commission for the Protection of Human Subjects of Biomedical and Behavioral Research, Dep't Health, Educ. \& Welfare, Pub. No. 78-0012, Ethical Principles and Guidelines for the Protection of Human Subjects Research (1978) [hereinafter BelMONT REPORT].

$26 \mathrm{Id}$. at 18 (emphasis added). The Belmont Report goes on to point out:

Injustice may appear in the selection of subjects, even if individual subjects are selected fairly by investigators and treated fairly in the course of the research. This injustice arises from social, racial, sexual, and cultural biases institutionalized in society. Thus, even if individual researchers are treating their research subjects fairly, and even if IRBs are taking care to assure that subjects are selected fairly within a particular institution, unjust social patterns may nevertheless appear in the overall distribution of the burdens and benefits of research. Although individual institutions or investigators may not be able to resolve a problem that is pervasive in their social setting, they can consider distributive justice in selecting research subjects.

Id. at 19 (emphasis added). It is fair to conclude that the authors of the Belmont Report may have meant by the emphasized phrase more the ultimate knowledge derived from the research than any immediate advantage from the experience of participation; nonetheless, the provocative, and 


\section{A. The Immediate Benefits of Trial Participation That Women Do Not GET}

The concept of just allocation of access to research has not been developed. It has taken the AIDS epidemic and the consequent seismic changes, both in the public's awareness of the conduct of clinical trials and the government's approach to them, to focus attention on the question of achieving "access" to experimental drugs or innovative therapies by serving as a research subject. ${ }^{27}$ With the battlecry of "Trials are treatment," AIDS advocates have pretty much single-handedly made obsolete the sacrosanct assumptions of "null hypothesis" and "clinical equipoise"28 that had been the bedrock of research ethics.

I would like to unpack, as the philosophers say, this rather facile-sounding slogan and suggest the extent to which it contains more truth than propaganda. There are at least three ways that clinical trials are treatment, although certainly there are many ways in which they are not. ${ }^{29}$ First, even in this era of "compassionate use," "Treatment INDs," "parallel track," and "buyer's clubs," 30 it is still the case that the average American can obtain genuinely

still unusual, focus of the Belmont Report on the need to consider patterns of subject selection when evaluating the ethics of research design bears repetition and reflection today.

27 See, e.g. , Harold Edgar \& David J. Rothman, New Rules for New Drugs: The Challenge of AIDS to the Regulatory Process, in A Disease of Society: Cultural and Institutional Responses to AIDS 84, 94-98 (Dorothy Nelkin et al. eds., 1991); James J. Eigo, Expedited Drug Approval Procedures: Perspective from an AIDS Activist, 45 Food Drug Cosm. L.J. 377 (1990).

28 In clinical trials, one group of subjects receives the intervention on trial - a drug, procedure, or device - while another similar group ("the control group") does not. The health outcomes of both groups are analyzed to detect statistically significant differences - that is, differences that are highly unlikely to be the product of chance or coincidence. Traditionally, clinical trials have been considered ethically permissible if and only if at the inception of a trial, no one, especially the scientist-investigator, knows whether the intervention to be tested is better, worse, or the same as whatever will be received by the control group (placebo, standard therapy, alternative experimental therapy, no intervention). In other words, the tested intervention must be in "clinical equipoise" with the placebo or standard therapy or alternative experimental therapy. Based on the information available at the outset, the control group should be as likely to benefit as the subjects receiving the innovative therapy. See Benjamin Freedman, Equipoise and The Ethics of Clinical Research, 317 NEw ENG. J. MED. 141 (1987).

Likewise, the "null hypothesis" standard for clinical trials dictates that the hypothesis on trial - that a given drug will reduce blood pressure, for example - must be as likely to be false as it is true. See Eugene Passamani, Clinical Trials - Are They Ethical?, 324 NEw ENG. J. MEd. 1589, 1591 (1991). In reality, of course, many investigators begin trials with a strong suspicion that the tested intervention will prove efficacious, whether or not they feel comfortable saying so. Despite the ritual disclaimers of informed consent, few subjects, especially sick subjects, believe that their devoted physicians would subject them to experimentation unless the doctors "knew" it would help them. See Samuel Hellman \& Deborah S. Hellman, Of Mice But Not Men: Problems of the Randomized Clinical Trial, 324 NEw ENG. J. MED. 1585 (1991); Robert J. Levine, Clinical Trials and Physicians as Double Agents, 65 Yale J. Biolocy \& Med. 65 (1992). Here, as in the law, the lines between "hope," "intend," and "desire," on the one hand, and "believe" and "know," on the other, are often tenuous.

${ }^{29}$ Because of the uncertainty, presumed or real, about the safety or efficacy of an experimental intervention, trials have typically been defined as non-beneficial and not intended to provide treatment; rather, they are pure vehicles of data-gathering and information acquisition.

${ }^{30}$ All these terms denote exceptions to the general rule that a drug not approved for marketing in the United States cannot be provided to patients, other than those enrolled in a protocol. "Compassionate use" is an FDA-approved administration of a nonstandard therapy, whether or 
new, unlicensed drugs only by serving as a research subject. ${ }^{31}$ Second, patients are also interested in therapies that are licensed for one indication, but hoped to be useful for another. Trial participants can get these therapies free, while non-subjects have to pay for them, often without insurance or Medicaid reimbursement because of their "unlicensed" status. ${ }^{32}$ Patients are actually beginning to pay for the privilege of serving as research subjects witness the Parkinson's patients who have paid $\$ 30,000$ to be experimental fetal tissue transplant recipients. ${ }^{33}$

For patients, getting drugs free is better than paying for them, and if for no other reason, participation in a trial is a benefit. Skeptics who find the null hypothesis still viable or even compelling may reject the would-be subject's perception as ignorant or illogical - especially if there is a placebo arm to the trial. ${ }^{34}$ But there are other reasons to characterize trial participation as a valuable treatment option. First, for a large segment of the American population, clinical trials are the best available source of quality health care. ${ }^{35}$

not it is under investigation, to an individual patient, and requires agency review on a case-bycase basis. Treatment INDs ("Investigational New Drug') are limited to drugs intended to treat an "immediately life-threatening" disease and which are already well along the drug development pipeline. See 21 C.F.R. $\$ \$ 312.34$ (a) \& 314.35 (1993). "Parallel track" is a means for people with life-threatening diseases who are unable to tolerate or benefit from standard approved therapies, and who cannot, for reasons of exclusionary criteria or geographic inconvenience, enroll in protocol, to gain early access to promising, but non-approved, agents. See Expanded Availability of Investigational New Drugs Through a Parallel Track Mechanism for People with AIDS and other HIV-Related Diseases, 57 Fed. Reg. 13,250 (April 15, 1992); Expanded Availability of Investigational New Drugs Through a Parallel Track Mechanism for People with AIDS and other HIV-Related Diseases, 55 Fed. Reg. 20,856 (April 2, 1990). See generally Bret L. Lansdale, Essay, A Procedural Due Process Attack on FDA Regulations: Getting New Drugs to People with AIDS, 18 Hastings Const. L.Q. 417 (1991); Frank E. Young et al., The FDA's New Procedures for the Use of Investigational Drugs in Treatment, 259 JAMA 2267 (1988). "Buyer's clubs" are organizations of patients, primarily people living with AIDS, who pool knowledge and resources to import pharmaceuticals approved elsewhere but not yet available in the United States, which is permitted so long as the imported substance is for personal use only. See Philip J. Hilts, U.S. Issues Rules on Medicine Clubs, N.Y. Times, May 26, 1993, at A18. While these mechanisms may permit earlier access to an unproven drug, they do not provide the care and other benefits associated with participation in a clinical trial. See infra part I.B.

${ }^{31}$ My comment with respect to the average American is even more apt for the average nonAmerican. For a brief reference to this notion in the international context, see Laurence Gostin, Ethical Principles for the Conduct of Human Subjects Research: Population-Based Research and Ethics, 19 L., Med. \& Health Care 191, 196 (Fall-Winter 1991).

32 Pharmaceutical companies may charge "cost" for drugs used in Treatment INDs and parallel track; it is not yet clear whether "cost" will be interpreted to include R \& D, not just production. Public and private insurers generally do not cover "experimental" therapies, even if the drug is licensed for use for a different indication. See generally Mary Griffin, AIDS, Drugs and the Pharmaceutical Industry: A Need for Reform, 17 AM. J.L. \& MED. 363 (1991); Grace Powers Monaco \& M. Gail Gottlicb, Treatment INDs: Research for Hire?, 258 JAMA 3296 (1987).

33 Gina Kolata, Patients Paying to Be Subjects in Brain Study, N.Y. Times, May 24, 1992, at 1; see also E. Haavi Morreim, Patient-Funded Research: Paying the Piper or Protecting the Patient?, IRB: Rev. Hum. Surjects Res., May-June 1991, at 1.

34 See discussion of "the therapeutic misconception" in Paul S. Appelbaum et al., False Hopes and Best Data: Consent to Research and the Therapeutic Misconception, Hastings Center ReP., Apr. 1987, at 20.

${ }^{35}$ For an example, see physician and ethicist Kathleen Nolan's comment with respect to HIV-infected children:

AZT and other treatments should be widely available as "standard therapy." Unfortu- 
Second, for women, exclusion from the clinical trials has meant less efficacious health care even for those who can afford their choice of private physician. ${ }^{36}$

\section{B. How Trials Are Treatment}

As biologist Alvin Novick has observed:

Many . . . subjects recognize that as trial participants they will be regularly examined and evaluated by a health care provider, in an organizational setting. Appointments will be made and subjects will be treated decently. Those are compelling benefits for many indigent and marginalized persons. . . . [M]any of these persons will volunteer for clinical trials to receive basic health care. ${ }^{37}$

Clinical investigators themselves realize that regardless of the outcome in terms of the value of the intervention on trial, there are many therapeutic aspects to being a subject. In the candid words of a standard text:

The very nature of protocols, which require standardized and frequent observations to follow outcome, provides the patient with a better assessment of therapeutic result, more safety checks, more attention from the physician and staff, and more access to the medical system. The screening process provides an excellent overall health assessment. ... The physicians undertaking the research, the consultants, and the laboratories are usually among the best in the community and provide state-of-the-art diagnosis and advice. As a part of the process of encouraging continuation in the study, the attitudes of health providers shift from acting as though they are doing the patient a favor to seeking to please the patient who is doing them a favor. This shift is reflected in waiting time, friendliness, and overall efficiency in using the patient's time. ...

...

... In almost all situations, the study population does better than patients who are not under protocol study largely because they get more attention and close monitoring of the major abnormality. ${ }^{38}$

nately programs to care for children with AIDS remain poorly funded, and it is tragically true that only "participation in investigational treatment programs ensures that a child will receive state-of-the-art care for all symptoms and any complicating illness in addition to HIV disease, thus reducing morbidity and improving quality of life."

Kathleen Nolan, AIDS and Pediatric Research, 14 Evaluation Rev. 464, 477 (1990) (citing Dep't of Health \& Human Servs., Secretary's Work Group on Pediatric HiV Infection and Disease: FinAL. REPORT 24 (1988)).

36 See infra notes 39-77 and accompanying text.

37 Alvin Novick, Noncompliance in Clinical Trials: I. Subjects, 5 AIDS \& PUB. PoL'y 94, 94 (1990); see also Barbara Brotman, Any Volunteers? Being a Human Guinea Pig Has Its Risks and Its Rewards, CHI. TRIB., May 19, 1992, at Cl (most people become research subjects to obtain free medical care; in cancer medicine, clinical trials regarded as best care available).

38 Frank L. Iber et al., Conducting Clinical. Trials 110-111, 121 (1987). This text actually has a table of "Advantages to the Subject in Research Participation:"

Possible therapeutic advantage

Better outcome of disease

Closer monitoring than in routine practice

Getting attention for other ailments 
Without exploring why this quality of care is not routinely available outside protocols (even if the patient can afford expensive private physicians), or suggesting that it represents the norm within protocols, the basic point remains: exclusion from trials, regardless of whether the intervention on trial turns out to be efficacious or the subject receives nothing but placebo, is tantamount to denial of a special quality of care.

\section{The Research Not Done}

A final sense in which trials are the equivalent of treatment (or at least, that exclusion from trials translates into exclusion from treatment) is that women become guinea pigs once a new therapy hits the marketplace. As far as women are concerned, these therapies have not really been tested. Even women who can pay for their health care lose out because their physicians can offer care with only limited knowledge about the operation of "standard" therapies in female bodies. ${ }^{39}$

It is increasingly well-understood that both the pharmacokinetics ${ }^{40}$ and pharmacodynamics ${ }^{41}$ of drugs are frequently different in women than in men. ${ }^{42}$ That means that optimal doses arrived at through testing in male subjects may be ineffective or dangerous for women. It has been demonstrated repeatedly that both female menstrual cycles, and the exogenous estrogens used in contraceptives and hormone replacement therapy, can dramatically affect the utilization of a wide range of drugs, including diazepam, insulin,

\footnotetext{
Better physical and laboratory health check

Superior physicians, labs, and testing

More contact with the providers

Access to contacts for future health information

Remuneration

The opportunity to make new friends

Contributions to society
}

Id. at Table 13. The text goes on to describe "Techniques that Enhance Recruitment and Retention of Patients," including, inter alia, training of all receptionists, technicians, and telephone personnel to provide "friendly, informed contacts that reflect the importance and uniqueness of the patient[!]"; locating and recruiting former research subjects to talk with and reassure potential new subjects; noting in the chart specific information about the subject (e.g., new grandchild, new job, gardening, cooking) so that the subject can be asked about them at the next visit, to "demonstrate to each patient his uniqueness"; and if anxiety is detected about an unrelated health problem, prompt evaluation of symptoms by the principal investigator. Id. at 120-21 (emphasis added). How often do we expect such tender treatment from an ordinary health care provider?

${ }^{39}$ Gurwitz, supra note 5, at $142 \mathrm{I}$; Nanette K. Wenger, Exclusion of the Elderly and Women From Coronary Trials - Is Their Quality of Care Compromised?, 268 JAMA 1460 (1992) (editorial). "For many if not most drugs on the market, no one really knows whether they behave any differently in women. Nobody really knows what their role is or should be in pregnancy." Drug Testing on Men Only, Wash. Post, Dec. 8, 1992, at Z14 (quoting Nancy Buc, former General Counsel at Food and Drug Administration).

40 Pharmacokinetics refers to the concentration over time of an ingested substance in body tissues and blood, i.e. the "bioavailability" of the substance as it is absorbed, metabolized, and excreted. See Ruth B. Merkatz et al., Women in Clinical Trials of New Drugs: A Change in Food and Drug Administration Policy, 329 New Enc. J. Med. 292, 292 (1993).

41 Pharmacodynamics means the body's response to a particular concentration of ingested substance. Id. at 293.

$42 I d$. at 293 and references cited therein. 
tetracycline, rifampin, and anticonvulsants. ${ }^{43}$ Even when women have been included in clinical studies, researchers have consistently failed to explore these issues or even to attempt to discover these effects. In 1988, the Food and Drug Administration adopted a policy calling specifically for such gender breakdowns and analyses of safety and effectiveness data in all applications submitted for marketing approval of a new drug. ${ }^{44}$ An audit by the General Accounting Office and subsequent FDA self-study revealed that by the middle of 1992, these analyses were being performed between 50 and 60 percent of the time. ${ }^{45}$ But no application was turned down, or held up, as a result. The FDA now maintains that in the future it "may consider" deferring review of an application if the sex-specific analyses are lacking. ${ }^{46}$

Women as a class also are harmed by the paucity of research about health problems that primarily afflict them, and because we know almost nothing about therapeutics for pregnant women. Almost twenty years ago Robert Levine succinctly laid out the dilemma that confronts women who need medical care:

It is the custom in the United States to develop new drugs based upon testing of their safety and efficacy almost exclusively in adults who are incapable of becoming pregnant. . . . As a consequence, most drugs must contain on their . . labels a statement to the effect that their safety and/or efficacy have not been established in children and/or pregnant women. In fact, it might be more appropriate to include in such statements that the safety and/or efficacy of the drug has not been established in women who are capable of becoming pregnant. ...

....

It is common practice in this country to administer drugs approved for use in non-pregnant adults to pregnant women and children. Such administration is conducted according to the usual standards of medical practice without rigorous testing of safety and/ or efficacy. In this way we have a tendency to distribute the unknown risks of such activities not randomly but rather capriciously. In addition, we have no assurance that, should the risks materialize as harm, they will be detected. 47

The irony of this is evident: because researchers ${ }^{48}$ are so skittish about the risk of fetal harm, ${ }^{49}$ they bar women who might be pregnant - which to them includes every fertile female - from their research. But when it comes time to prescribe, market, and profit from drugs, drug companies do not bar

43 Id. at 293.

44 FDA, Guideline for the Format and Content of the Clinical and Statistical Sections of New Drug Applications, 53 Fed. Reg. 39,524 (1988).

45 Merkatz, supra note 40, at 294.

$46 \mathrm{Id}$. This is not exactly a vigorous enforcement stance. On the disappointing lack of teeth in the proposed new FDA guideline, see infra notes $116-128$ and accompanying text.

47 The Belmont Report Appendix I, supra note 23, at 4-65 \& 4-66 (emphasis added).

48 Throughout this paper, I use the term "researcher" generically, to include both the investigator scientist and the institutional/corporate sponsor. When it is useful to differentiate the two, I will.

49 See infra notes $139-97$ and accompanying text. 
women, including women of child-bearing capacity. Researchers sidestep responsibility by making the true statement that they have no information about the risk to the child of a pregnant woman who takes the drug. (They also generally have no information about the risk to children of women who took the drug before conception or to children of men who either are taking or have taken the drug prior to or at the time that they impregnate someone.)

As a result, women who are not pregnant (or not thought to be pregnant), as well as some women who know that they are pregnant, may take drugs with no real basis for predicting their effects. Or they may be unnecessarily deterred from taking a drug they need for fear of those untested effects. This may have serious implications for their health or the ultimate health of their children. Meanwhile, men take the same drug without realizing that it may have unknown, unstudied consequences for the children they father. ${ }^{50}$

\section{Disparity in Recognition and Treatment of Women's Health Problems}

Women do not receive the same quality of health care that men do. Physicians respond to presenting symptoms in women with less aggressive diagnostic procedures and more conservative treatment. Part of the problem is that the data to support aggressive intervention in women is absent. ${ }^{51}$

Even the American Medical Association has recognized this disparity, and concluded that it could not be accounted for by pertinent biological differences between women and men. 52 The AMA Council on Ethical and Judicial Affairs found that

medical treatments for women are based on a male model, regardless of the fact that women may react differently to treatments than men or that some diseases manifest themselves differently in women than in men. The results of medical research on men are generalized to women without sufficient evidence of applicability to women. ${ }^{53}$

It went on to recommend that "[r]esearch on health problems that affect both sexes should include male and female subjects. Sound medical and scientific reasons should be required for excluding women from medical tests and studies, such as that the proposed research does not or would not affect the health of women." 54

For example, some of the strongest evidence yet that moderate drinking protects against heart disease was published in August 1991. Funded by the National Institutes of Health, a study of 51,529 American male doctors, den-

\footnotetext{
50 See infra notes 140-46 and accompanying text.

51 Paul Cotton, Examples Abound of Gaps in Medical Knowledge Because of Groups Excluded from Scientific Study, 263 JAMA 1051, 1055 (1990); Marguerite Holloway \& Philip Yam, Reflecting Differences: Health Care Begins to Address Needs of Women and Minorities, Scr. Am., Mar. 1992, at 13; Laurence Altman, Study Finds Heart Treatment Differs for Men and Women, N.Y. Times, Nov. 13, 1991, at 18: see also Toward Healthy Women. N.Y. Times, Sept. 9, 1991, at A14.

52 Council on Ethical and Judicial Affairs, AMA, Gender Disparities in Clinical Decision Making, 266 JAMA 559, 559 (1991); see also Carl M. Kjellstrand, Age, Sex and Race Inequality in Renal Transplantation, 148 Archives Internal Med. 1305 (1988).

${ }^{53}$ Council on Ethical and Judicial Affairs, supra note 52, at 559.

54 Id. at 562.
} 
tists, pharmacists, and veterinary surgeons "provide[s] strong evidence for the hypothesis that alcohol intake is inversely associated with coronary artery disease." 55 In response to this study, the cardiologist Arthur Klatsky observed "It would be fair to say if there was a procedure or medication as effective as moderate drinking which was perceived as having no important risk, it would be a very, very major form of therapy for coronary disease." 56

But we know almost nothing about the effect of alcohol consumption on coronary disease in women. Nor do we know whether women should be on the new anticholesterol drugs, or whether putting some women on the "stepped care" regimen for mild hypertension may actually kill them, as has been suggested in one article criticizing the Hypertension Detection and Follow-Up study. ${ }^{57}$

Women are far more likely than men to experience adverse reactions to prescribed drugs. ${ }^{58}$ They are twice as likely to die from side effects as men, possibly because the dosage levels have been determined by testing in men. ${ }^{59}$ Yet women are prescribed antidepressants much more often than men also suffering from depression. ${ }^{60}$ Although twice as many women as men suffer at least one episode of serious clinical depression, ${ }^{61}$ Wellbutrin, and many other promising antidepressant agents, have been studied almost exclusively in men. ${ }^{62}$ Only in practice did physicians learn anecdotally that women have seizures on the drug, especially if they suffer from bulimia. ${ }^{63}$ Women use over ninety percent of "diet pills," but nearly all of the testing was done in

55 Eric B. Rimm et al., Prospective Study of Alcohol Consumption and Risk of Coronary Disease in Men, 338 LANCET 464, 467 (1991). Harvard School of Public Health researchers found that men who have up to two drinks per day enjoy a $26 \%$ reduction in risk for heart disease compared with those who drink little or not at all. It may be that the risk is also reduced by about $40 \%$ in men who have two or three drinks per day, but the sample at that level is too small to permit confidence, Id. at 465-68.

${ }^{56}$ Richard Saltus, Study Affirms Alcohol Curbs Heart Ills, Boston Globe, Aug. 23, 1991, at 1, 16.

57 Peter L. Schnall et al., An Analysis of the HDFP Trial: Evidence of Adverse Effects of Antihypertensive Treatment on White Women with Moderate and Severe Hypertension, 84 N.Y. ST. J. MED. 299 (1984). The article reported that this large study included women, but failed to analyze the data indicating that $168 \%$ more of the European-American women aged thirty to sixty-nine with diastolic blood pressure $>105$ died on treatment than on control. Interestingly, the critical article that performed this data analysis was turned down by the New England Journal of Medicine, the Journal of American Medical Association, and the Lancet, allegedly because it was too "hot," and was ultimately accepted by the New York State Journal of Medicine only after review by twice the usual number of readers. See Barbara Berney, In Research, Women Don't Matter, The Progressive, Oct. 1990, at 24.

58 Jean Hamilton \& Barbara Parry, Sex-Related Differences in Clinical Drug Response: Implications for Women's Health, 38 J. Am. Med. Women's Ass's 126 (1983).

59 See Annette Kornblum, Are Women Being Ignored?, N.Y. Newsday, Jan. 16, 1990, Discovery Section, at 5 .

60 Sue V. Rosser, Is There Androcentric Bias in Psychiatric Diagnosis?, 17 J. Med. \& PhIL. 223 (1992).

61 Andrew C. Leon et al., Continuing Female Predominance in Depressive Illness, 83 AM. J. Pub. Health 754 (1993); The Women's Health Data Book: A Profile of Women's Health in the United States 63 (Jacqueline A. Horton ed., 1992).

62 Patricia Anstett, Medical Groups and Congress Are Facing Elusive Issues, CH1. Trib., June 23, 1991, at 12 (Interview with Margaret Jensvold, M.D., Director of the Institute for Research on Women's Health).

63 Id. 
male subjects. ${ }^{64}$

When women are misdiagnosed because of deficiencies in research, the consequences may be more than physical. Until January 1, 1993, the presumptive definition of AIDS used by the Centers for Disease Control and Prevention ("CDC") failed to include the different manifestations of the infection in women (pelvic inflammatory disease, cervical cancer, genital herpes, vulvovaginal candidiasis). This inaccurate definition in the primary surveillance tool for all public health purposes worked to women's disadvantage by skewing statistics and surveillance data used to allocate the distribution of AIDS resources and services and by making it appear that the low number of women participating in AIDS Clinical Trial Group studies (funded and administered by the National Institute of Allergy and Infectious Diseases) is less disproportionate than in fact it is. ${ }^{65}$ Moreover, since 1983 the Social Security Administration ("SSA") had treated CDC-defined AIDS as a "Listing" - a medical condition that presumptively entitled claimants to automatic disability benefits and related medical care coverage. ${ }^{66}$ But women who in reality were suffering from what ought to have been classified as AIDS did not qualify for these-services.

Finally, in response to legal challenge, ${ }^{67}$ the CDC proposed a new, more inclusive case definition in November 1991. The SSA promptly followed suit by proposing a new, more inclusive "HIV Infection Listing." 68 However, simultaneously the SSA changed its rules so that now no one with HIV infection, male or female, automatically qualifies for benefits. ${ }^{69}$ The new listing also fails to include pelvic inflammatory disease, chronic genital ulcers, Stage I cervical cancer, or recurrent herpes. Its divergence from the CDC definition will be confusing for the physicians asked to verify their patients' symptomology and diagnoses.

\section{E. Guesswork About the Health Needs of Pregnant Women}

Ironically, given the close correlation between the health of the pregnant woman and that of her child, research on the health needs of pregnant wo-

64 Jeannette R. Ickovics \& Elissa S. Epel, Women's Health Research: Policy and Practice, IRB: REv. Hum. Subjects Res., July-Aug. 1993, at 1, 3.

${ }^{65}$ For a careful analysis of this claim, see Carol Levine \& Gary L. Stein, What's In A Name? The Policy Implications of the CDC Definition of AIDS, 19 L., MED. \& HealTh Care 278, 280-82 (FallWinter 1991); see also Office of Technology Assessment, Pub. No. OTA-BP-H-89, The CDC's Definition of AIDS: Implications of the Proposed Revisions (1992). As of September 1991, only $6.9 \%$ of the 15,563 patients enrolled in AIDS Clinical Trial Group protocols were adult women. By comparison, almost $20 \%$ of the enrollees in the Community Programs for Clinical Research on AIDS protocols were women - indicating that it is hardly impossible to recruit and retain female subjects in AIDS protocols. As of February 1992, women constituted $11 \%$ of the AIDS cases in the United States, even diagnosed under the male-based definition. See Centers for Disease Control, HIV/AIDS Surveillance 12 (Feb. 1992). Eighty-five per cent of women with AIDS are diagnosed during childbearing years (age 15-44 years). Tedd V. Ellerbrock et al., Epidemiology of Women with AIDS in the United States, 1981 through 1990, 265 JAMA 2971 (1991).

6656 Fed. Reg. 65,702, 65,703 (1991).

67 See S.P. v. Sullivan, No. 90 Civ. 6294 MJC (S.D.N.Y. filed Oct. 1, 1990) (class action brought by MFY Legal Services and the Lambda Legal Defense and Education Fund).

68 See 56 Fed. Reg. 65,702 (1991).

69 See OfFice of Technology Assessment, supra note 65, at 4-5, $31-48$. 
men has been virtually prohibited. Again, the HIV-infection epidemic provides stark examples of an attitude that prioritizes protection of a fetus from uncertain risk over even probable benefit to the pregnant woman. There was the recommendation of the Centers for Disease Control that rejected as "inadvisable" the use of aerosol pentamidine as prophylaxis for the potentially fatal opportunistic infection Pneumocystis carinii pneumonia in HIV-infected pregnant women, ${ }^{70}$ although "[c]learly, women with AIDS, especially pregnant women with AIDS, have a more fulminant course than men."71 There was the reported decision not to offer the same prophylactic AZT regimen to pregnant or breast-feeding health-care providers who have been exposed to HIV infection that is routinely offered to male and nonpregnant female health-care providers. ${ }^{72}$ There was Ortho Pharmaceutical's exclusion of pregnant women from its protocols and treatment IND for erythropoietin, a genetically engineered hormone analogue with few side effects, now approved for treatment of AZT-induced anemia. ${ }^{73}$ Conscientious physicians treating pregnant patients with AIDS feel compelled to struggle with the "familiar yet unique dilemma" posed by the absence of good information about the consequences of treatment and non-treatment options both for potential mother and potential child. ${ }^{\mathbf{7 4}}$

Despite the absence of adequate studies of the safety and efficacy of prescription drugs for pregnant women, physicians prescribe, and pregnant women take, a surprisingly large number of drugs. ${ }^{75}$ There is good reason to believe that the efficacy of these drugs is affected by the patient's pregnancy, but very little data about how, how much, or why. ${ }^{76}$ Without systematic re-

70 Centers for Disease Control, U.S. Dep't of Health \& Human Serv., Guidelines for Prophylaxis Against Pneumocystis Carinii Pneumonia for Persons Infected with Human Immunodeficiency Virus, MORTALity \& Morbidity Rep.: Recommendations \& Rep. (No. S-5), June 16, 1989, at 1, 6.

${ }^{71}$ Machelle Harris Allen, Primary Care of Women Infected with the Human Immunodeficiency Virus, 17 Obstetrics \& Gynecology Clinics N. Am. 557, 558 (1990).

72 The director of infection control for the University Hospital at Stony-Brook in New York, Dr. William Greene, was quoted as recommending this exclusion at a conference on HIV-infected health care providers. See Lambda Legal Defense and Education Fund, Inc., 4 AIDS UpDate 25 (1991). In a conversation with me on May 28, 1992, Dr. Greene indicated that his reluctance was generated in part by uncertainty about the efficacy of AZT for post-exposure prophylaxis in the general population (by which I gather he meant men and infertile women), as well as by some concern about potential liability to offspring. However, it was based primarily on the absence of safety and efficacy data for pregnant women. Now that several hundred HIV-positive women have used AZT (in the perinatal transmission trial) without evidence of gross anatomical anomalies in their children, Dr. Greene suggested that he would be substantially more comfortable with the participation of pregnant women in a prophylaxis protocol.

${ }^{73}$ Carol Levine, Women and HIV/AIDS Research, 14 Evaluation Rev. 447, 448 (1990). Er. ythropoietin is on the market with the usual warning for drugs never tested in pregnant women: "There are no adequate and well-controlled studies in pregnant women. [Erythropoietin] should be used during pregnancy only if potential benefit justifies the potential risk to the fetus." PHYsIcians' Desk Reference 593 (3d ed. 1992).

${ }^{74}$ Howard L. Minkoff \& Jonathan D. Moreno, Drug Prophylaxis for Human Immunodeficiency Virus-infected Pregnant Women: Ethical Considerations, 163 Aм. J. Obstetrics \& Gynecology 1111 , 1113 (1990). Fortunately, some physicians like Dr. Minkoff recognize "the mother's rightful primacy both as fetal champion and as the focus of her physician's concern." Id. at 1113 .

75 See Levine, supra note 73, at 457.

76 See, e.g., Leon D. Sabath et al., Ethics and the Use of Drugs During Pregnancy, 202 Science 540, 540 (1978) (pregnant physician who was prescribed ampicillin for her bronchitis, with no result- 
search on the effects of the drugs in pregnant women, physicians and their pregnant patients engage in a kind of Russian roulette, courting the "random disaster . . . of inadequately investigated drugs." 77 The patient risks the unknown health consequences of the drug, not just to her offspring but to her body, and the physician risks legal consequences if the adequacy of warnings to the patient come into question.

\section{F. Reinforcement of Societal Images of Women}

Women are struggling to escape their secondary status, a status in no small part attributable to the constant identification of women as those who bear and rear children. ${ }^{78}$ Men are almost never defined primarily by their parental role or their procreative potential. Biomedical researchers, in particular, seem nearly obsessed with the possibility of pregnancy among female subjects, yet oblivious to the reproductive status or activities of their male subjects. The exclusionary criteria in research protocols not only reflect, but reinforce, a stereotype that is in itself a distinct harm to the interests and progress of women. ${ }^{79}$

ing therapeutic effect, measured her blood level of the drug and found it lower than the predicted level; when she later conducted a small study, in pregnant women who were planning elective abortions, of the absorption of erythromycin and clindamycin by measuring levels in recovered fetal tissue, she was indicted under an 1814 Massachusetts grave-robbing statute).

At a presentation on treatment of pregnant women suffering from hypertension, a very knowledgeable expert reviewed the broad spectrum of drugs available to treat this serious condition: peripheral alpha-one blockers, beta blockers, calcium channel blockers, hydralazine, labetalol, and the drugs of choice for hypertension-associated heart failure, sodium nitroprusside and diazoxide. Again and again the expert had to say that she could find no data on the safety and efficacy of these drugs in pregnant women, although they necessarily are used in that population. Patricia A. Howard, Pharm. D., Pharmacotherapy of Hypertension in Pregnancy, Presentation at St. Louis University School of Medicine, (Oct. 13, 1993) (distributed materials on file with the author). Dr. Howard also described the horrible experience with ACE-inhibitors (angiotensin-converting-enzyme inhibitors), which a vigilant practitioner had found produced fatal neonatal renal malfunction after the FDA had approved the drugs for marketing and they had been widely used by, among others, pregnant women. Id; see also Merkatz, supra note 40, at 295.

77 Bernard L. Mirkin, Drug Therapy and the Developing Human: Who Cares?, 23 Clinical Res. 106, 110 (1975); see also Bernard L. Mirkin, Impact of Public Policy on the Development of Drugs for Pregnant Women and Children, 23 CLinical Res. 233 (1975). On the paucity of information about the activity of approved drugs in pregnant women, see Kinney, supra note 5 , at $495,496$.

78 The historical "protection" of women by the law, which has meant upholding the legality of their exclusion from occupations and legal functions such as estate administration, and their loss of jobs, seniority, and vital benefits because of pregnancy and forced maternity leave, has always been justified by the "unique" status and role of childbearer. See, e.g., Muller v. Oregon, 208 U.S. 412 (1908) (citing reproductive health concerns in allowing women to work a maximum of 10 hours per day); Bradwell v. Illinois, 83 U.S. 130, 141 (1873) ("The natural and proper timidity and delicacy which belongs to the female sex evidently unfits it for many of the occupations of civil life.").

79 For expanded discussion, see Vanessa Merton, Ethical Obstacles to the Participation of Women in Biomedical Research, in Feminism And Bioethics: Beyond Reproduction (Susan Wolf ed., 1994) [hereinafter Merton, Ethical Obstacles]. 


\section{WHY ARE WOMEN EXCLUDED FROM CLINICAL TRIALS?}

Through my participation on two Institutional Review Boards ${ }^{80}$ for eight years and my continuing research on various aspects of human subject experimentation since 1980 , I have developed a reasonably clear understanding of the rationales invoked to justify the exclusion of women from clinical research. ${ }^{81}$ The formulation that follows is intended to present these arguments in their most positive and persuasive light. Let me emphasize that the difficulty of this issue is that these are by no means specious arguments. In fact, from a male-centered perspective, they make a fair degree of sense. From a woman-centered perspective, however, their limitations and fallacies are apparent and compelling. It is that analysis that I seek to present here. ${ }^{82}$

\section{A. The Fundamental Misconception: All Women Are Always Pregnable (Pregnant)}

One central concept is at work in producing all these rationales. The researchers who espouse them do not consciously prevaricate, but they do not realize how connected each and every one is to what I will call the fundamental misconception (the oblique pun is unintended): All women are always pregnable and therefore (through the magical operation of the mind characteristic of unconscious sexism) always pregnant. ${ }^{83}$

${ }^{80}$ For a discussion of the function of Institutional Review Boards, see infra notes 255-62 and accompanying text.

81 Parallel arguments were identified by a planning panel of the Institute of Medicine of the National Academy of Sciences. See National Academy of Sciences, Planning Panel of the Institute of Medicine, Division of Health Sciences Policy, Issues in the Inclusion of Women in Clinical Trials 4 (1991) (on file with author).

82 Some readers may ask why I do not aspire instead to an "objective" or "human" perspective. The short answer is that I do not believe it possible, for me or for anyone else in this so heavily engendered society, to analyze problems that have different impact on women and men "objectively" - if by that is meant an absolute, determinable reality independent of the multitude of forces that shape and qualify human perception. For a useful discussion of the "objectivist illusion," see Evelyn Fox Keller, Feminism and Science, in Sex and Scr. Inquiry 233, 233-46 (Sandra Harding \& Jean O'Barr eds., 1987). Keller includes an excerpt from Jean Piaget's The Child's Conception of the World that offers a different definition of objectivity:

Objectivity consists in so fully realizing the countless intrusions of the self in everyday thought and the countless illusions which result - illusions of sense, language, point of view, value, etc. - that the preliminary step to every judgement is the effort to exclude the intrusive self. Realism, on the contrary, consists in ignoring the existence of self and thence regarding one's own perspective as immediately objective and absolute. Realism is thus anthropocentric [and, I would add in this context, androcentric] illusion, finality - in short, all those illusions which teem in the history of science.

Keller, supra, at 238 (quoting Jean Piaget, The Child's Conception of the World 1972). Or, as biologist Ruth Hubbard put it:

After all, facts aren't just out there. Every fact has a factor, a maker. The interesting question is: as people move through the world, how do we sort those aspects of it that we permit to become facts from those that we relegate to being fiction - untrue, imagined, imaginary, or figments of the imagination - and from those that, worse yet, we do not even notice and that therefore do not become fact, fiction, or figment? In other words, what criteria and mechanisms of selection do scientists use in the making of facts?

Hubbard, supra note 2 at 119.

${ }^{83}$ I find some corroboration in the medical adage cited and commented on by British physi- 
I know that this sounds outlandish; even to suggest it makes researchers angry and defensive, and insist that their exclusionary justifications in no way rely on such an absurd premise. I have no desire to provoke that reaction, and I concede immediately that my hypothesis is not capable of independent verification. I can say only that I have been left with this distinct impression from probably close to two hundred dialogues with investigators and sponsors and study coordinators and academics who study the conduct of research - at conferences and meetings, in negotiations over the IRB approval of protocols, in correspondence and in idle conversation. The undertone, the motif that keeps cropping up, is always: but what if the women are pregnant? Treat this observation as data, not fact. It has, however, some explanatory power with respect to the behavior of researchers. ${ }^{84}$ If its enunciation here serves no other purpose than to make the possibility of such subtle influence salient, and perhaps inspire a modicum of self-examination, I am content. In addition, it frames the parameters of my analysis; because I believe that every issue about the exclusion of women from research eventually collapses back into the question of pregnant women, I believe also. that until and unless that question is resolved, the seemingly larger issue will remain open. Thus a substantial part of my analysis of the ethics of exclusion of women from research depends on recognition of a basic principle: that women have the right - the same right as men - to decide for themselves (and therefore, implicitly, for their potential offspring), whether it is prudent and morally right for them to participate in a given protocol, and that women do not lose that right when they become pregnant. ${ }^{85}$

\section{B. The Justifications for ExClusion of Women}

Three principal justifications are offered for barring women from clinical biomedical studies. The first two are essentially assertions of principle and value: that a researcher's commitment to quality science and/or reverence for fetal life requires women's, or at least pregnant women's, exclusion. While I summarize these arguments briefly below, in another paper $^{86}$ I discuss the fatal flaws of these rationales in much greater detail.

The third reason for exclusion of women purports to be grounded not in researchers' own inherent values but rather in the dictates of the law. Researchers are not able to include women in their protocols because of either government regulation, or risk of liability to the offspring of female subjects, or both. This article addresses this contention and demonstrates that re-

cian Sue Roberts. See Sue Roberts, All Women Are Pregnant Until Proved Otherwise, Lancet, July 8 , 1978, at 89 (physicians' tendency to focus on female biological roles both of women colleagues and women patients; role-conflict of inadequate helpmate/sexual object and competent doctor and decision-maker).

84 Not to mention the behavior of, for example, employers whose policies exclude all nonsterile females aged 5 [sic] to 63 from certain jobs in the name of "fetal protection." See Wright v. Olin Corp., 697 F.2d 1172, 1182 (4th Cir. 1982); discussion infra note 248.

85 The ethical underpinnings of this asserted right are discussed at some length in Merton, Ethical Obstacles, supra note 79. See infra notes 249-50 and accompanying text and part II.B.1; Uriel Halbreich \& Stanley Carson, Drug Studies in Women of Child Bearing Age: Ethical and Methodological Considerations, 9 J. Clinical Psycholopharmacology 328, 331 (1989); see also supra pp. 39.40.

86 Merton, Ethical Obstacles, supra note 79. 
searchers have much more to fear, legally speaking, from their failure to include women in protocols. ${ }^{87}$

\section{Scientific rigor and the researcher's duty to protect fetal life}

To condense what might be called the researcher's utilitarian and deontological arguments: the first contention is that women and men are so physiologically and biochemically different, it is slower and more expensive, if not impossible, to get "clean" data from gender-integrated trials. In the long run, everyone is better off with the "more efficient" single-gender approach, because therapies will become available sooner and cost less. ${ }^{88}$

This argument refutes itself: ${ }^{89}$ if the information generated from a mixed population of subjects is so different from that generated by studying only men, then how can the results of the latter be generalized to a real world of women and men? If the activity of the drug is different enough in women to skew the results, then from a female point of view, the data from a male-only trial is neither "cleaner" nor more efficiently obtained; it is largely irrelevant. Similarly, for a pregnant woman, the data from a non-pregnant-person trial is of scant use. Moreover, if researchers wish to continue insisting that data from subjects of one gender is scientifically preferable, then the question arises, why has that gender historically been the male?

Finally, the quest for "purity" in data seems to be extremely limited in focus. Researchers are rarely so meticulous about eliminating a multitude of other potentially conflating variables - prior individual and family health history, body weight and proportion of body fat, health-related behaviors and attitudes, access to health care outside the trial, and so on. Typically, these factors are controlled for through the devices of sample size and randomization - that is, the random assignment of a sufficient number of subjects to the study groups being compared to ensure a random distribution of these attributes throughout both control and treatment groups of subjects. To select gender as one of the very few exclusionary criteria for a protocol cannot logically be defended unless other, equally significant parameters are screened for and screened out. ${ }^{90}$

The second ethical argument is that some researchers believe that it is their moral duty to avoid the infliction of fetal harm, regardless of whether legal responsibility would ever be imposed, and that inclusion of women of child-bearing potential presents too great a risk of causing such harm. My response to this is twofold. First, on the legalistic level: technically, as a matter of federal law, researchers are privileged to refuse to conduct any research

\footnotetext{
${ }^{87}$ See infra notes 203-32 and accompanying text.

88 For an interesting recent exposition of this argument, see Benjamin Wittes \& Janet Wittes, Group Therapy, New Republic, Apr. 5, 1993, at 15. 79.

89 For a more extensive discussion of this argument, see Merton, Ethical Obstacles, supra note

90 A particularly potent confounder is the usage of other medication by subjects, especially the use of the medication on trial by members of the control or comparison group. This phenomenon has been acknowledged as rampant in the field of AIDS research. See, e.g., Peter S. Arno \& Karyn L. Feiden, Against the Odds: The Story of AIDS Drug Development, Politics, And Profits (1992); Jay A. Gold, Is There A Right to Experimental Treatment? 5 Bioethics Bull. 1, 3 (1992). However, there is no basis for believing that it occurs only in that context.
} 
to which that researcher conscientiously objects, and may not be fired or disciplined as a result.91 More important, however, researchers do not have the right to arrogate to themselves the determination of when participation in a protocol may create a greater risk of harm to the fetus than chance of benefit. I do not say that this calculation should not be made; the issue is, who should make it? My answer is, this is a judgment to be made by the pregnant or potentially pregnant woman. Unless and until comparable restrictions are placed on the judgments of men who engage in reproductive activity, in reckless disregard of the unknown, but possible, risks to their offspring, to hold otherwise is to inappropriately invalidate the competence and the freedom of women to make such decisions.

But what about the legal arguments? Their analysis follows.

2. The legal constraints on inclusion of women in research

\section{a. Federal regulations}

Biomedical research has been the province of extensive federal regulation for over thirty years, first from the FDA ${ }^{92}$ and then from the Department of Health and Human Services ("HHS"). ${ }^{93}$ FDA regulates research intended to obtain approval for commercial distribution of a new drug or device (or of an approved drug/device for a new indication). Since the mid-seventies, HHS has regulated the vast majority of other research with human subjects, including all research funded by that department's many arms. In 1991, a new "Federal Policy for the Protection of Human Subjects" replaced the HHS "Basic Policy for Protection of Human Research Subjects."94 Fifteen other federal agencies and departments have also subscribed to the new policy, which applies to research conducted, funded, or in any way sponsored by these agencies. However, Subpart B of the original HHS regulations, a section that specifically governs research with pregnant women, has not been replaced by the new policy. ${ }^{95}$ Researchers frequently point to the federal regulations as the basis for their exclusion of women from protocols. Unquestionably, these regulations have contributed to the problem, but a close reading of their text reveals that they provide plenty of latitude to conduct research with female subjects. In July 1993, in response to growing political pressure and a Citizen Petition, ${ }^{96}$ the FDA proposed to substantially revise one of its regulations. ${ }^{97}$ This revision, if adopted, will make the "regulatory

91 See 42 U.S.C. $\S 300 \mathrm{a}-7$ (d) (1992). Again, this point is elaborated in Merton, Ethical Obstacles, supra note 79.

92 See Louis Lasagna, Congress, the FDA, and New Drug Development: Before and After 1962, 32 Perspectives in Biology \& Med. 322, 322-23 (1989).

9345 C.F.R. 46 (1974).

9456 Fed. Reg. 28,002 (1991); see also Joan Porter, The Federal Policy for the Protection of Human Subjects, IRB: Rev. Hum. Subjects Res., Sept.-Oct. 1991, at 8.

95 Technically, this section applies only to research conducted or supported in whole or in part with HHS funds. Most nongovernmental researchers, however, generally adhere to HHS rules even when they are not applicable.

96 See infra note 269.

97 See Notice of Proposed Guidelines for the Study and Evaluation of Gender Differences in the Clinical Evaluation of Drugs, 58 Fed. Reg. 39,406 (July 22, 1993) [hereinafter Proposed FDA Guideline]. 
excuse" even more difficult to assert, although it fails to address the exclusion of pregnant women. But even in their original form, FDA rules were not the barrier to inclusion of women subjects that researchers claimed them to be. Below, I discuss first the original regulations - which continue in effect until the revised rules are formally adopted - and then the proposed revision.

\section{(1) Current FDA regulations}

The exclusionary criterion most often found in protocols prohibits the participation of "pregnant and lactating women and women of child-bearing potential." This formulation appears to be derived from the FDA's Guidelines for researchers, adopted in 1977 (Guidelines). ${ }^{98}$ While the Guidelines are not legally binding, research conducted in accordance with the Guidelines qualifies for FDA consideration in a New Drug Application, ${ }^{99}$ and most investigators take the Guidelines seriously. ${ }^{100}$ Certainly no prudent attorney would recommend their cavalier disregard, since they might well be deemed a "standard of care" for the research community. ${ }^{101}$

The Guidelines state that women of child-bearing potential should be barred from large-scale (Phase III) clinical trials until all three segments of the FDA Animal Reproduction Studies ${ }^{102}$ have been completed, and that women may be included in Phase II (controlled trials in several hundred subjects) studies only if "segment II and the female part of segment I of the FDA

98 FDA, Pub. No. 77-3040, General Considerations for the Clinical Evaluation of Drugs (1977) [hereinafter FDA Guidelines]

9921 C.F.R. $\$ 10.90$ (b) (1993) (research conducted in good faith pursuant to Guidelines will be accepted by FDA for review). "A person may rely upon a guideline with assurance that it is acceptable to FDA." id. at $\$ 10.90$ (b)(1)(i); see also 21 C.F.R. $\$ 312.145$ (1993).

100 Obviously the entire discussion in this section bears only on research intended to obtain approval for a new drug or a new indication for an approved drug.

101 Knowing iis visceral impact, I prefer to avoid using the word "malpractice" in a paper that I hope will be read by health professionals, but this reference should be explained for those unfamiliar with the phrase "standard of care": a patient or a client in a professional relationship who seeks to hold the professional responsible for a bad outcome must prove, among other things, that the harm would not have occurred had the professional not breached a professional "standard of care"; that is, did not provide care within the broad range of choices that a competent professional might reasonably consider under the circumstances. Protocols and standards issued by professional organizations and governmental agencies sometimes are utilized as sources of the "standard of care." See, e.g., Steven E. Pegalis \& Harvey F. Wachsman, AmeriCan Law of Medical Malpractice $\$ 3: 1-\$ 3: 13$ (2d ed. 1992).

In this paper I have not taken on the question whether the "trials as treatment" theory expounded above has any implications for professional liability, in the sense of transforming the duties of researcher to subject into something more analogous to those of a physician for a patient - an interesting issue, but one not different for male and female subjects, and thus not germane. See discussion supra notes 37-38 and accompanying text.

102 The FDA has never published a protocol for the Animal Reproduction Studies referenced in the Guidelines, but after several telephone calls to FDA sources, I was sent a copy of a document identified as the pertinent standard. See William D'Aguanno, Guidelines for Reproduction Studies for Safety Evaluation of Drugs for Human Use (undated) (on file with the author). Segment I covers gonadal function, effects of estrous cycles/mating behavior, and early gestation; segment II, teratogenesis; and segment III, the drug's effect on late fetal development, labor and delivery, lactation, and newborn health. In a switch from the typical toxicology studies, conducted primarily in male animals, here most of the testing, and all of it pertaining to intergenerational effects, is done exclusively in females. The interest in male animals is confined to the impact on their fertility. 
Animal Reproduction Guidelines have been completed."103 Remarkably, the Guidelines are silent on the question of how the results of the Animal Reproduction Studies ought to affect inclusion or exclusion of women. Probably in 1977 it never occurred to the authors that researchers might offer women a chance to participate even if adverse reproductive effects were indicated.

The catch is that there is no mandate to perform any of the Animal Reproduction Studies ever, and certainly not prior to the conduct of Phase II or III trials. ${ }^{104}$ The regulation that describes what applications for new drug approval must contain says only that the application should include nonclinical "studies, as appropriate, of the effects of the drug on reproduction and on the developing fetus." 105 Whether under this standard the FDA could ever approve a New Drug Application without animal testing for reproductive effect has never been determined by a court, but the FDA does not appear ever to have required such studies to precede Phase III trials. ${ }^{106}$ There is no practical way to research this, but I would bet that the FDA has never interpreted "as appropriate" to require animal studies that would elicit adverse reproductive effects mediated through the male animal. ${ }^{107}$

What this boils down to is that pharmaceutical companies can choose to market drugs with no information about their reproductive impact, so long as the label makes this clear. ${ }^{108}$ Further, the animal studies which the FDA

109 FDA, 1977 Guidel.ines, supra note 98, at 10. For a good description of the Phase I-Phase II-Phase III categories, see David Kessler, The Regulation of Investigational Drugs, 320 NEw ENG. J. MED. 281, 282-83 (1989). Phase I, the first set of clinical studies, is supposed to use fewer than 100 healthy volunteers to detect gross safety problems and establish the parameters for proper dosages to be tested. Phase II, typically done in a couple of hundred patients, begins to evaluate efficacy and identify side effects, if any. Phase III studies may be conducted in thousands of patients and should be designed to elaborate on therapeutic value and elicit longer-term adverse effects. It is important to note that since Phase I is when dosage parameters are set, and safety issues are defined, the data generated in Phase I is critical to the design - the doses to be tested and the variables to be monitored - in Phase II and Phase 11I. See 21 C.F.R. $\$ 312.21$ (1993) ("During Phase I sufficient information about the drug's pharmacokinetics and pharmacological effects should be obtained to permit the design of well-controlled, scientifically valid Phase II studies.").

104 Some texts and treatises seem to assume that this testing is necessary for a New Drug Application. See, e.g., Donald E. Vinson \& Alexander H. Slaughter, Products Liability: Pharmaceutical Drug Cases $\$ 5.04$ (1988 \& Supp. 1991). However, nothing in the language of the regulations or the FDA Guidelines is couched in mandatory rather than precatory terms.

10521 C.F.R. $\$ 314.50$ (d)(2)(iii) (1991) (emphasis added).

106 Dr. Robert Temple, Director of the Office on Drug Evaluation of the Food and Drug Administration, has stated that no one at the FDA is responsible for determining whether animal reproduction studies are actually conducted. Response to question at Institute of Medicine seminar on inclusion of women in clinical trials, June 23, 1992.

107 The Guidelines do suggest that when testicular or spermatogenetic abnormalities have been observed in animals (which is not to say animal studies to evoke these responses must be done), or when chromosomal abnormalities are anticipated, the inclusion of males in all three Phases of trials depends on a constellation of factors: the nature of the abnormalities, the "importance" of the drug, etc. Compare this textured, case-by-case, only-if-reason-for-concern-hasbeen-demonstrated, approach to the categorical language of the rule about women of child-bearing potential. There is also no mention of a need to discuss contraception with male subjects in these circumstances. See infra notes 267-68 and accompanying text.

10821 C.F.R. \& 201.57 (1991), which governs labeling of human prescription drugs, requires a statement of critical information, if known, but does not create any independent duty to acquire the information. For example, under subsection (f)(5), the label must specify whether "adequate 
defines as a necessary precursor to large-scale clinical trials with female subjects may never be conducted at all or may be done only in parallel with, not in advance of, clinical testing.

To compound this, the FDA, and thus clinical investigators, define the Guidelines' key phrase "of childbearing potential" in a way that envisions all women as "constantly poised for reproductive activity." 109 "A woman of childbearing potential is defined as a premenopausal female capable of becoming pregnant. This includes women on oral, injectable, or mechanical contraception; women who are single; women whose husbands have been vasectomized or whose husbands have received or are utilizing mechanical contraceptive devices." 110

The breadth of this definition of child-bearing potential makes it tantamount to "all fertile women." In an echo of the fundamental misconception, 111 the FDA limits the universe of women subjects right up through Phase III trials to

women who have been surgically sterilized, women who are postmenopausal, and women who are infertile ... provided they [infertile women] are willing to use an effective form of contraception during the study, or have been evaluated by a fertility expert and have been found to be infertile, and have been so for greater than five years

to quote one research manual's interpretation. ${ }^{112}$

The FDA Guidelines do, however, expressly recognize an exception that offers researchers some substantial latitude: the use of the drug as a life-saving or life-prolonging measure. ${ }^{113}$ "Life-prolonging" seems a quite elastic phrase that could cover many situations of clinical research. So long as the lack of reproduction studies is pointed out during the informed consent process, and the woman of child-bearing potential is tested for pregnancy and advised of contraceptive measures, she may participate in such studies. Even the nursing mother is specifically mentioned as a potential subject, with analysis of the excretion of the drug or its metabolites in the milk to be determined "when feasible."114 And the one reference to pregnant women in the Guidelines (probably in 1977 it never occurred to anyone to explicitly state that

and well-controlled studies in pregnant women" have or have not demonstrated a risk to the fetus, and describe the results of animal reproduction studies, if available. But it is perfectly acceptable to label a drug Pregnancy Category $C$, in the event that there are no animal reproduction studies and no studies in humans, and state that "It is also not known whether (name of drug) can cause fetal harm when administered to a pregnant woman or can affect reproduction capacity. (Name of drug) should be given to a pregnant woman only if clearly needed." Even under the category of nonteratogenic effects, there is no requirement to provide either information, or a warning of the absence of information, about the drug's reproductive impact in men. Compare subsection (f)(7), which requires a clear statement of the absence of data about effects on childbirth, and subsection $(f)(8)$, which requires a clear statement if it is not known whether a particular drug is contained in the milk of nursing mothers.

109 Vanessa Merton, Community-Based AIDS Research, 14 Evaluation Rev. 502, 519 (1990) [hereinafter Merton, Community-Based].

110 FDA, 1977 Guidelines, supra note 98.

111 See discussion supra notes 83-86 and accompanying text.

112 IBER ET AL., supra note 38, at 179.

113 FDA, 1977 Guidelines, supra note 98 , at 10.

114 Id. at 11. 
pregnant women were not allowed to be subjects) merely states that fetal follow-up should be carried out if a subject becomes pregnant while on the protocol; 115 it does not say anything about immediately terminating the woman from the protocol, a provision frequently found in research design.

\section{(2) Proposed new guidelines}

The head of the FDA's Office on Drug Evaluation, Dr. Robert Temple, maintains that the Guidelines should never have been interpreted by researchers to require the exclusion of women from protocols. ${ }^{116}$ This observation is a welcome one, but apparently it was neither widely disseminated nor widely shared. ${ }^{117}$ As is acknowledged in FDA's proposed revision of the Guidelines,

Although the 1977 guideline has not resulted in a failure to include adequate numbers of women in the later phases of clinical trials, it has restricted the early accumulation of information about response to drugs in women that could be utilized in designing phase 2 and 3 trials, and has perhaps delayed appreciation of gender-related variation in drug effects. . . .

The agency is, therefore, withdrawing the restriction on the participation of women of childbearing potential in early clinical trials $\ldots{ }^{118}$

Regrettably, the Proposed Guideline merely removes what has always been, in theory, a highly permeable barrier to the inclusion of women in clinical trials. It does nothing affirmative. ${ }^{119}$ It appears, in spots, to hover on the verge of demanding actual change in the conduct of biomedical research, but always it draws back to precatory language of recommendation and encouragement and vague notions of "reasonable representativeness" in subject populations. ${ }^{120}$ Its straightforward acknowledgement of the phenomenon of women's exclusion from trials, and the impact of that phenomenon, is help-

$115 \mathrm{Id}$.

116 Diane Rehm, Is There Gender Bias in Drug Testing?, FDA Consumer, Apr. 1991, at 8 (Interview with Robert Temple and Margaret Jensvold); see also Levine, supra note 73, at 455.

117 In a confidential 1991 survey of 33 major pharmaceutical houses, conducted by the Pharmaceutical Manufacturers Association, 79\% reported that FDA reviewers had required them to exclude women of child-bearing potential from their protocols. Lionel D. Edwards, Design and Conduct of Research in Women: To Include or Exclude: A Pharmaceutical Industry Physician's Perspective 17 (Feb. 1992) (unpublished manuscript on file with author).

118 Proposed FDA Guideline, supra note 97, at 39,408.

119 It also, of course, has no effect whatsoever on the substantial body of research, behavioral and otherwise, that is not governed or influenced by FDA standards. But this limitation of any FDA action is inescapable.

120 The Proposed Guideline "urges" that "reasonable numbers" (not defined precisely) of women be included in studies of new drugs. It expresses the agency's "expectation" that women will be included in numbers sufficient to allow for differential data analysis. It "stresses the importance" of assessing potential pharmacokinetic differences. In light of its recognition that the failure to include women in early (Phase I and Phase II) trials may negatively affect the design and dose selection of "the pivotal controlled trials [Phase III]", see 21 C.F.R. § 312.21(a)(1) (1993), the FDA "encourages" the inclusion of women of all ages in early trials. Merkatz, supra note 40, at 294; Proposed FDA Guideline, supra note 97, passim.

While admitting that "in some cases, there may be a basis for requiring participation of women in early studies," and that "under these circumstances, clinical protocols should not place unwarranted restrictions on the participation of women," Proposed FDA Guideline, supra note 
ful. ${ }^{121}$ Some of the rhetoric about a woman's right to make her own decisions in this area is positively progressive. Reading the Proposed Guideline, one keeps waiting for the punch line. It never comes. In the end it amounts to a "pretty please" to the pharmaceutical houses, with a gratuitous abandonment of regulatory authority ${ }^{122}$ that is both unwarranted as a matter of law and not too smart as a matter of strategy.

What should the FDA's Proposed Guideline have done? Well, to begin with, it might have better been issued as a regulation, with clear legal status, rather than in the ambiguous nether world of "guideline." Second, it entirely fails to deal with the anomaly of an agency intensely preoccupied with preventing fetal exposure to drugs and adverse reproductive outcomes, but which does not require basic animal reproductive studies prior to testing drugs in humans (not only women, but the males whose offspring can be just as damaged.) ${ }^{123}$

Third, it could have utilized its existing regulations far more effectively to address this problem. The FDA could, pursuant to 21 C.F.R. $\S 312.23(a)(3)(i v)(e)$, and/or (a)(6)(i), require a statement of the number of women and men in every trial, and a statement of the reasons for any nongender-neutral exclusion, pursuant to $\$ 312.23(6)$ (c). It could have refused to agree that a researcher has adequately determined the proper dosages to be administered to women, as is required under 21 C.F.R. \$ 312.23(6)(iii)(e), in the absence of pharmacokinetic and pharmacodynamic data in women.

Sections $312.23(5)(i i)^{124}$ and (8) ${ }^{125}$ of 21 C.F.R. could easily be interpreted to require reproductive toxicology studies; how can the FDA say that toxicology work-up of impact on the liver, the kidneys, the central nervous system, every organ in fact, can be required, but not for the reproductive system? In section 312.23(8)(ii), the FDA purports to require a description of

97, at 39,409 , the Proposed Guideline never translates these observations into an unambiguous con: dition for FDA approval.

121 Id. at 39,408 .

122 The agency recognizes that this change in FDA's policy will not, by itself, cause drug companies or IRB's to alter restrictions that they might impose on the participation of women of childbearing potential. We do not at this time perceive a regulatory basis for requiring routinely that women of childbearing potential be included in particular trials.

Proposed FDA Guideline, supra note 97, at 39,408.

The FDA has previously demonstrated the "regulatory authority" to prescribe in fulsome detail every jot and tittle of protocols to be submitted for its approval. Its statutory duty to ensure "adequate and well-controlled investigations ... on the basis of which it could ... be concluded . . . that the drug will have the effect it purports . . to have" prior to drug approval offers plenty of room to define "adequate" to include testing in women when women will be consumers of the drug. 21 C.F.R. § 314.126 (1988); see 21 U.S.C. $\$ 355$ (1972 \& Supp. 1993). The FDA's inability to "perceive" its own power when it comes to protecting the rights and interests of women suggests that it may be more of a captive agency than some of us had thought and most of us had hoped.

123 See discussion infra notes $140-46$ and accompanying text.

124 Sponsors are required to provide clinical investigators with brochures that describe, inter alia, "the pharmacological and toxicological effects of the drug in animals . . ." 21 C.F.R. $\S 312.23(5)$ (ii) (1993).

125 A New Drug Application must contain "adequate information about pharmacological and toxicological studies of the drug involving laboratory animals . . ." Id. at $\$ 312.23(8)$. Depending on the nature of the drug and the phase of the investigation, the description is to include the "results of ... tests of the drug's effects on reproduction and the developing fet.us." Id. at $\S 312.23(8)$ (ii). 
"tests of the drug's effects on reproduction and the developing fetus." That should mean reproductive consequences for both male and female consumers of the drug. ${ }^{126}$ Without such data, what is the value of all the emphasis in the Proposed Guideline on advising would-be subjects about reproductive risk prior to their enrollment? ${ }^{127}$

Unfortunately, once again, the FDA has defined reproductive risk exclusively in terms of fetal toxicity and possibly reduced fertility. Contraception or abstinence from reproductive behavior is identified as an issue only for female subjects. Animal studies that address fetal toxicity and unknown fetal risks are to be relayed to the subjects; nothing at all is said about male-mediated reproductive outcomes. The result is predictable; women, who may well be more concerned about such questions than men are to begin with, will be more reluctant to participate, and the difficulties in recruitment and retention of women subjects that researchers often refer to as an obstacle to their inclusion will be exacerbated, in a self-fulfilling prophecy.

The FDA's proposal essentially leaves women where they have been: presumed to be constant reproducers, while men never reproduce at all; the victims of bad science that does not generate knowledge of use to women, especially pregnant women; objects of random, meaningless, post-marketing "experimentation" from drugs that should have been fully and properly tested under the FDA's statutory mandate. Restrictions on women's participation in clinical trials continues to substitute for adequate preclinical studies that could provide the basis for a genuinely informed decision on the part of potential subjects, male and female, about the risk to future offspring. The FDA, in sum, has punted. ${ }^{128}$

126 See also 21 C.F.R. $\$ 312.32$ (a) (defining adverse experiences that must be reported to the FDA to include "any experience suggesting a significant risk for human [not only female] subjects, including any finding of mutagenicity, teratogenicity, or carcinogenicity.").

127 See Proposed FDA Guideline, supra note 97, at 39,411. Note that this concern appears to be limited to fetal toxicity and women subjects.

128 For a more detailed analysis of the shortcomings of the Proposed Guideline, see HIV Law Project \& NOW Legal Defense and Education Fund, Memorandum on the FDA's Proposed Guideline for the Study and Evaluation of Gender Differences in the Clinical Evaluation of Drugs (Oct. 18, 1993) (on file with author) [hereinafter Memorandum on FDA's Proposed Guideline]. Another troubling example of recognizing the problem but doing nothing to rectify it is the recently completed International Ethical Guidelines for Biomedical Research Involving Human Subjects of the Council of International Organizations of Medical Sciences and the World Health Organization (on file with the author). Guideline 11 acknowledges that:

Women in most societies have been discriminated against with regard to their involvement in research. Women who are biologically capable of becoming pregnant have been customarily excluded from formal clinical trials . . . owing to concern about undetermined risks to the fetus. Consequently, relatively little is known about the safety and efficacy of most drugs, vaccines, or devices for such women, and this lack of knowledge can be dangerous. ...

A general policy of excluding from such clinical trials women biologically capable of becoming pregnant is unjust in that it deprives women as a class of persons of the benefits of the new knowledge derived from the trials. Further, it is an affront to their right of self-determination. . . .

Premenopausal women have also been excluded from participation in many research activities ... in case the physiological data associated with various phases of the menstrual cycle would complicate interpretation of research data. Consequently, much 


\section{(3) HHS limitations on research with pregnant women}

The FDA guidelines, then, especially after their revision, can be parsed to have relatively little impact on women's participation in research, unless the researcher wants them to. The relevant HHS regulations, on the other hand, appear to be a far greater constraint. However, they deal exclusively with the pregnant, rather than merely pregnable, woman. (But let us remain mindful of how easily those categories conflate.)

Subpart B of Part 46 of Title 45 of the Code of Federal Regulations is entitled "Additional Protections Pertaining to Research, Development, and Related Activities Involving Fetuses, Pregnant Women, and Human In Vitro Fertilization." Promulgated in the mid-seventies, Subpart B prohibits research "involving" pregnant women unless: 1) "appropriate" studies on animals and nonpregnant individuals have been completed;129 2) the purpose of the research is "to meet the health needs" of the woman; and 3) the fetus will be placed at minimal risk or at risk to the minimum extent necessary to meet the woman's health needs. ${ }^{130}$

A further provision tries to require that the "father" of the fetus (to use the loaded language of the section) ${ }^{131}$ give his informed consent to the pregnant woman's participation in the research. Presumably unintentionally, however, the drafters rendered this provision meaningless. The various exceptions to the progenitor-consent requirement are stated in the disjunctive; that is, any one of them permits departure from the rule. One exception is identical to a previously defined precondition for the pregnant woman's participation in any research that may pose more than a minimal risk to the fetus: that the purpose of the research be to meet the pregnant woman's health needs. Since any research that poses more than minimal risk is permissible only if its purpose is to meet the pregnant woman's health needs regardless of progenitor consent, this exception will almost always subsume the apparent requirement of such consent. ${ }^{132}$ Progenitor consent is actually necessary

less is known of women's than of men's normal physiological processes. This, too, is unjust in that it deprives women as a class of persons of the benefits of such knowledge.

Id. at 33-34. Despite its recognition of these injustices, Guideline 11 categorically excludes pregnant or nursing women from protocols, unless the research carries no more than minimal risk for the fetus or infant, its objective is new knowledge about pregnancy or lactation, and women who are not pregnant or nursing would not be suitable subjects. It utterly ignores the right of women to make their own risk-benefit calculus. The International Ethical Guidelines impose no such restrictions on fertile and reproductively active male subjects.

12945 C.F.R. $\$ 46.206(a)(1)$ (1975). Other conditions, intended to ensure that no inducements or pressures to terminate the pregnancy are part of the research design, are also enumerated in this section.

13045 C.F.R. $\$ 46.207$ (a) (1992). Section 46.205 imposes various special obligations, mostly pertaining to informed consent, on IRBs that review protocols involving pregnant women and fetuses. All these provisions may be waived or modified by the Secretary of Health and Human Services on request of a researcher, 45 C.F.R. $\$ 46.211$, but virtually no requests have been made, possibly because since 1980 an indispensable participant in the waiver process, an Ethical Advisory Board within HHS, has not been funded or appointed. See Levine, Ethics and RegulaTION, supra note 22 , at 319-20.

131 See 45 C.F.R. $\$ 46.207$ (b). A pregnant woman is not yet a mother, and her impregnator is not yet a father. See Renee Solomon, Note, Future Fear: Prenatal Duties Imposed by Private Parties, 17 AM. J.L. \& MED. 411,417 n.37 (1991).

132 Given the recent Supreme Court decision in Planned Parenthood of Southeastern Pa. et 
only when: 1) the risk to the fetus is minimal (or less); and 2) the research can in no way be characterized as directed toward the woman's health needs.

So how significant a barrier for the pregnant woman are these regulations? To begin, let us consider the first requirement: completion of "appropriate" studies in animals and nonpregnant people (presumably, under current FDA Guidelines, not studies in women of childbearing potential). "Appropriate" is what lawyers call a weasel word, a word that gives the decisionmaker in a situation great discretion. ${ }^{133}$ Perhaps this is a reference to teratogenicity studies? General clinical pharmacology studies for toxicity? Or perhaps the sort of in vitro work or uncontrolled case reports that one would ordinarily expect to foreshadow clinical research? It is hard to imagine the government's succeeding in imposing sanctions on a researcher for violating this amorphous provision unless absolutely no work had been done on the intervention on trial at all before the pregnant woman was permitted to participate.

More troubling is the requirement that the research be intended to "meet the health needs of the mother [sic]." I will not try to improve on Robert Levine's trenchant exposition of the conceptual murkiness of the terms "therapeutic research" and "nontherapeutic research" and their especially problematic usage in this context. ${ }^{134}$ Suffice it to say, this is another phrase that gives the researcher considerable scope. I have reviewed above the many ways and situations in which participation in research in and of itself may serve a subject's health needs. ${ }^{135}$ I will add only that from the standpoint of psychic health, it takes a severe toll for a pregnant woman (or for any woman) to be told that after having been fully informed of the risks to her potential offspring, she cannot be trusted to decide whether to participate in a protocol, while no restrictions of any kind are placed on the decisions of her male counterpart, whose offspring may be at equal risk.

As for the requirement that the risk to the fetus must be "minimal," again we find an ill-defined and comparative term. ${ }^{136}$ And who should be making

al. v. Casey, 112 S. Ct. 2791 (1992), it is hard to see how this paternal consent condition, if ever applied, could be upheld against constitutional challenge. The only one of the set of anti-choice state restrictions struck down in Casey was the husband notification provision, because "[i]t is an inescapable biological fact that state regulation with respect to the child a woman is carrying will have a far greater impact on the mother's liberty than on the father's." Id. at 2830 . If paternal notification cannot be required for an abortion that will kill the fetus, the constitutionality of requiring paternal consent for a much lesser risk to the fetus is dubious.

The other exceptions to this requirement also might be applicable to many pregnant research subjects: when the father cannot be identified or found, or the pregnancy resulted from rape.

133 See discussion infra notes 278-80 and accompanying text.

134 Levine, Ethics and Regulation, supra note 22, at 8-10, 298.

135 See discussion supra notes 27-79 and accompanying text.

136 See John C. Fletcher \& Joseph D. Schulman, Fetal Research: The State of the Question, HasTings Center ReP., Apr. 1985, at 6 and Karen Lebacqz, Fetal Research: A Commissioner's Reflection, IRB: REv. HUM. SUbJECTS RES., May 1979, at 7, for varied approaches to assessing risk in this context. "Minimal risk" is defined elsewhere in the regulations to mean that the danger anticipated from the research is not greater, considering both probability and magnitude, than the danger of ordinary daily life or routine physical or psychological tests. 58 Fed. Reg. 28,002, 28,013-14 (June 18,1981). For a fetus, isn't an amniocentesis, with its half-percent chance of miscarriage, now a routine test? What about chorionic villi sampling? Ultrasound? Wouldn't the 
this assessment? Always the assumption seems to be that the researcher, or perhaps the IRB member, or perhaps a federal bureaucrat is the best choice to judge the net of harm and benefit, risk and advantage, that would result from a pregnant woman's participation in a protocol. Always the assumption is of maternal-fetal conflict, a male perspective that ignores the inextricable link between pregnant woman and conceptus at any stage of its development, and denies the woman's inherent responsibility for the fate of that part of her body that may be born a child. ${ }^{137}$ As the HHS regulations require, the woman must and should be fully informed about the risks, known and unknown, to her fetus. But nowhere do the regulations say, and no fair and rational reading can impute, that the judgment as to the requisite level of risk, and its proper weight in light of the woman's health needs, should be made by anyone other than her. ${ }^{138}$

risk of ordinary daily life include the risk of a mother or father who smokes or who works where smoking is permitted? Drinks socially? Eats food containing additives? Disregards the prenatal care provider's advice? See Kentucky v. Welch, 864 S.W.2d 280, 283 (Ky. 1993) ("What if a pregnant woman drives over the speed limit, or ... does not wear the prescription lenses she knows she needs to see the dangers of the road?").

On the latter point, see Barbara K. Rothman, When a Pregnant Woman Endangers Her Fetus, Hastings Center Rep., Feb. 1986, at 25, describing what a typical "fetal abuse" case of twentyfive years ago might have sounded like:

[The pregnant woman], a diabetic, refused her DES treatment, prescribed as especially important in the prevention of miscarriage among diabetics. Further, although she was eleven pounds overweight at the time of conception, she refused to limit her weight gain over the course of the pregnancy to under thirteen pounds. She compounded the problem by not taking the diuretics prescribed, and twice refused to show up for scheduled $\mathrm{X}$-rays, citing a distrust of medications and radiation. Her irrational refusal to comply with her doctor's advice, plus her unwillingness or inability to limit her weight gain, indicate fetal abuse.

See Merton, Ethical Obstacles, supra note 79.

187 The subject of "maternal-fetal conflict," and the fallacious and invidious premises packed into that term, are ably dissected in Dawn Johnsen, Shared Interests: Promoting Healthy Births without Sacrificing Women's Liberty, 43 Hastings L.J. 569 (1992). Surprisingly, the American College of Obstetricians and Gynecologists (hardly a radical feminist outfit), while buying into the "conflict" paradigm, has recognized that "Obstetricians should refrain from performing procedures that are unwanted by a pregnant woman. The use of judicial authority to implement treatment regimens in order to protect the fetus violates the pregnant woman's autonomy." Opinion from the Committee on Ethics, American College of Obstetricians and Gynecologists, Opinion No. 55, "Patient Choice: Maternal-Fetal Conflict" (1987); see also AMA Board of Trustees Report, Legal Interventions During Pregnancy, 264 JAMA 2663 (1990).

138 See Nat'l Commission for the Protection of Human Subjects of Biomedical and Behavioral Research, Dep't Health Education and Welfare, Pub. No. (OS) 76-127, Research ON THE FETUS 65 (1975):

Therapeutic research directed toward the pregnant woman may expose the fetus to risk for the benefit of another subject and thus is at first glance more problematic. Recognizing the woman's priority regarding her own health care, however, the Commission concludes that such research is ethically acceptable provided that the woman has been fully informed of the possible impact on the fetus and that other general requirements have been met. Protection for the fetus is further provided by requiring that research put the fetus at minimum risk consistent with the provision of health care for the woman. Moreover, therapeutic research directed toward the pregnant woman frequently benefits the fetus, though it need not necessarily do so. In view of the woman's right to privacy regarding her own health care, the Commission concludes that the informed consent of the woman is both necessary and sufficient.

In general, the Commission concludes that therapeutic research directed toward the 
The absence of either administrative or judicial review of this question, as well as of the other questions raised by the HHS regulations, underscores my conclusion that it is not federal regulations that are trammeling researchers who in their eagerness to recruit and accept women subjects have been testing the boundaries of the law.

\section{b. The real explanation: tort phobia}

The central preoccupation of researchers asked to consider the inclusion of women in clinical trials is the risk of liability to their offspring. Any innovative therapy may affect some aspect of the development of the patient's offspring, whether because of damage to the germ cells prior to conception or because of mutagenic or teratogenic effects. The fear is that if it can be demonstrated that the therapy on trial injured the child of a subject, the researcher will be sued and have to pay damages. ${ }^{139}$

The assumption of researchers seems to be that this chain of events can only occur with regard to female subjects. But this assumption flies in the face of rapidly developing scientific understanding of the impact of the male germ cell on the physical and psychological development of offspring. ${ }^{140}$ Research in this area reached sufficient critical mass to precipitate a full-scale Conference on Male-Mediated Developmental Toxicity in September 1992 at the School of Public Health of the University of Pittsburgh. ${ }^{141}$ One of the

health condition of either the fetus or the pregnant woman is, in principle, ethical. Such research benefits not only the individual woman or fetus but also women and fetuses as a class, and should therefore be encouraged actively.

Id.

139 The usually unstated but logically necessary final step of the argument is that such accountability and responsibility would be wrong and unjust. For a discussion of the thesis that it may be precisely the just outcome, see infra notes 198-202 and accompanying text.

140 One of the most frequently cited compilations on this subject is Lester F. Soyka \& Justin M. Joffee, Male Mediated Drug Effects on Offspring, in Drug and Chemical Risks to the Fetus and NEwBorn 49 (Richard Schwartz \& Sumner Yaffe eds., 1980). Literature reviews have focused on occupational exposures. See, e.g., Joanna Haas \& David Schottenfeld, Risks to the Offspring from Parental Occupational Exposures, $21 \mathrm{~J}$. Occupational MEd, 607 (1979). (chromosomal aberrations in men exposed to vinyl chloride and benzene); David Savitz \& Joanna Chen, Parental Occupation and Childhood Cancer: Review of Epidemiologic Studies, 88 Envtl. Health Persp. 325 (1990) (in review of 24 case-control studies, no specific parental occupational exposure established as cause of childhood cancer, but several paternal occupations associated with childhood leukemias and nervous system tumors); see also Children's Cancer Tied to British A-Plant Workers, N.Y. Times, Feb. 18, 1990, at 27, reporting six-fold elevated risk of leukemia in offspring of male workers at nuclear plant. "The main finding was of a raised risk for those children whose fathers worked at Sellafield, in particular fathers with the highest recorded exposures to external ionizing radiation before their child's conception." Id. (emphasis added); see also M.J. Gardner et al., Results of Case-control Study of Leukaemia and Lymphoma Among Young People Near Sellafield Nuclear Plant in West Cumbria, 300 BRIT. MED. J. 423 (1990).

Male toxic exposures ranging from lead and other heavy metals to dibromochloropropane (DBCP) and chlordecone (Kepone) also have been demonstrated to affect the likelihood both of conception and of spontaneous abortion. See Michael Castleman, Toxics and Male Infertility, SIERRA Club Bull., Mar.-Apr. 1985, at 49; Kari Hemminki et al., Spontaneous Abortions in an Industrialized Community in Finland, 73 Am. J. Pub. Health 32 (1983); M. Donald Whorton, Adverse Reproductive Outcomes: The Occupational Health Issue of the 1980's, 73 Am. J. Pub. Health 15 (1983) (editorial).

141 See the announcement in The Nation's Health, May-June, 1992, at 17; Bulletin of the Conference on Male-Mediated Developmental Toxicity (Sept. 1992) (on file with the author). 
first large-scale record reviews, a case-control study of over 14,000 birth defects, conducted with careful procedures to avoid the methodological problems of some earlier studies, demonstrates numerous associations between various paternal occupations and specific anomalies, including increased incidence of spina bifida in the children of male logging workers, painters, and gas-station attendants; of heart defects in the children of male firefighters, metalworkers, and janitors; and of cleft palate in the children of male painters, miners, foundry workers, and mechanics. ${ }^{142}$ Many other studies link paternal exposures to serious problems in offspring. ${ }^{143}$ Paternal use of tobacco and alcohol has repeatedly been found to affect a wide range of functional abilities, low birth-weight, and neonatal survival in the offspring both of male rats and of male humans. ${ }^{144}$

The potential role of male-mediated risk factors has not been extensively investigated, probably largely because of the prevailing view that male-mediated effects are unlikely. ... [L]ittle is known of the epidemiology and biology of potential male-mediated birth defects and this has hindered the development of a definitive model or

142 Andrew Olshan et al., Paternal Occupation and Congenital Anomalies in Offspring, 20 AM. J. INDUS. MED. 447 (1991).

143 An earlier study from the same group, controlling for maternal age, found elevated relative risk of Down syndrome in the offspring of fathers employed as janitors, mechanics, metalworkers, and sawmill workers. Andrew Olshan et al., Paternal Occupational Exposures and the Risk of Down Syndrome, 44 AM. J. HuM. Genetics 646, 649 (1989). The children of male anesthesiologists also experience increased congenital abnormalities. Alastair A. Spence et al., Occupational Hazards for Operating Room-based Physicians: Analysis of Data From the United States and United Kingdom, 238 JAMA 955 (1977). Carbon disulfide and ionizing radiation have repeatedly been linked to malformations in the children of exposed men. See Joan Bertin, Reproductive Hazards in the Workplace, in Reproductive Laws for the 1990's 277-305 (Sherrill Cohen \& Nadine Taub eds., 1989); Elaine Draper, Risky Business 69 (1991). Dr. Ellen Silbergeld, a toxicologist at the University of Maryland, found defects in the brain development of the offspring of male rats exposed to lead at levels equivalent to those experienced by many factory workers. One form of retirioblastoma, Wilm's tumor, and Prader Willi syndrome all have been associated with paternal exposure or spermal mutation. Sandra Blakeslee, Research on Birth Defects Shifts to Flaws in Sperm, N.Y. Times, Jan. 1, 1991, at A1, C36. "Researchers have found several childhood cancers that primarily arise from new mutations traced to sperm, never to eggs." Id. at 36. Reduced body weight, delayed maturation, and learning and behavioral problems have been observed through four generations of paternal exposure of rodents to opioids and nitrous oxide. Gladys Friedler, Behavioral Effects in Offspring of Male Mice Injected with Opioids Prior to Mating, 11 Pharmacology \& BIochemical Behav. 23 (1979); Gladys Friedler, Effect of Limited Paternal Exposure to Xenobiotic Agents on the Development of Progeny, 7 Neurobehavioral. Toxicology \& Teratology 739 (1985).

144 See Susan Katz Miller, Warning: Smoking May Damage Your Sperm, 136 New Scientist 13 (1992) (even sperm with gross abnormalities may have same chance as healthy sperm of reaching and penetrating ovum; men should be encouraged to abstain from alcohol and tobacco and avoid other chemical exposures prior to reproduction); Anne Merewood, Sperm Under Siege: More Than We Ever Guessed, Having a Healthy Baby May Depend on Dad, 23 Heal.TH 53 (1991) (children of fathers who smoke close to time of conception $20 \%$ more likely to develop brain cancer, lymphoma, and leukemia); Jane E. Brody, Possible Links Between Babies' Health and Fathers' Habits and Working Conditions, N.Y. Times, Dec. 25, 1991, at 64; Devra L. Davis, Fathers and Fetuses, N.Y. Times, Mar. 1, 1991, at A27; see also Perry M. Adams et al., Male-transmitted Develipmental and Neurobehavioral Deficits, 4 Teratogenesis Carcinogenesis Mutagenesis 149 (1984); Ruth E. Little \& Charles F. Sing, Association of Father's Drinking and Infant's Birth Weight, 314 New linc. J. Med. 1644 (1986) (association between paternal preconceptual alcohol consumption and birthweight); J. Makin et al., A Comparison of Active and Passive Smoking During Pregnancy: Long-term Effects, Neurotoxicology \& Teratolocy, Jan. 1991, at 5. 
mechanism. However, recent work is beginning to suggest possible pathways that might explain associations between paternal exposures and congenital anomalies in offspring. These include direct effects on sperm DNA, producing mutation or chromosomal abnormalities, indirect effects by transmission of agents to the mother via the seminal fluid, and maternal exposure to agents brought home by the father. ${ }^{145}$

Until very recently, scientists and policy-makers have simply been unwilling to acknowledge the connection between paternal exposures or behavior and the well-being of offspring. Accordingly, the legal risk has been denied. As the evidence of paternal transmission accumulates, ${ }^{146}$ one would expect to see ready accommodation to this new reality in the form of stringent restrictions on the participation of fertile men in research. Yet, for example, the proposed FDA policy revision discussed above makes no mention whatsoever of this issue. ${ }^{147}$

(1) How real is the risk of liability to researchers if women are included in trials?

Given existing and foreseeable legal authority, what is the chance that researchers will be held liable for harm to their female subjects' children?

It is hard to exaggerate the complexity of the legal analysis required to determine whether there is a realistic basis for the liability fears of the research sponsors who exclude women who are or may become pregnant from their trials. Because the analysis is so complex, it is easy to understand that the legal advisors to research sponsors - by and large, in-house counsel to pharmaceutical companies and major medical centers - have contented themselves with concluding that there is ample room for possible liability in

145 Olshan, supra note 142, at 448. Cocaine and methadone have been found in semen; see Ricardo A. Yazigi et al., Demonstration of Specific Binding of Cocaine to Human Spermatozoa, 266 JAMA 1956 (1991).

146 See Devra Davis et al., Male-mediated Teratogenesis and Other Reproductive Effects: Biologic and Epidemiologic Findings and A Plea for Clinical Research, 6 Reproductive Toxicolocy 289 (1992) (more than 60 different compounds identified as increasing risk to offspring from male-mediated exposures; lack of extensive human evidence a deficiency in research, not absence of effect); Barbara Hales et al., Increased Postimplantation Loss and Malformations among the F2 Progeny of Male Rats Chronically Treated With Cyclophosphamide, 45 TERATOLogY 671 (1992) (edema, syndactyly, gigantism and dwarfism observed in second-generation offspring of exposed male rats); Susan Katz Miller, Can Children Be Damaged by Fathers' Cancer Therapy?, 135 New Scientist 5 (1992) (male cancer patients advised against using semen collected after start of chemotherapy because of "potentially drastic mutagenic effect"); Researchers Find Pre-Development of Cancer Could Start Before Birth, Cancer W KLY, July 20, 1992, at 10 (National Cancer Institute study confirms that exposure of sperm to carcinogens can make offspring more susceptible to cancers); see also Sins of the Fathers, 318 Economist 87 (1991); Sandra Blakeslee, Father Figures: the Male Link to Birth Defects, 10 AM. Health 54 (1991). See generally Gladys Friedler, Developmental Toxicology: Male-mediated Effects, in Occupational and Environmental Reproductive Hazards: A Guide for Clinicians 52-59 (Maureen Paul ed., 1993).

147 There is one oblique reference to the need for special study if animal data indicates a risk of decreased sperm production, and a general reference to risk-benefit calculation when people (presumably meaning men) of reproductive age participate in a study of a drug that has demonstrated reproductive toxicity, but the emphasis remains on harm to offspring of female, not male, subjects. Proposed FDA Guideline, supra note 97, at 39,411. 
this area, that their clients and bosses cannot be advised that liability is impossible, and that since their professional responsibility is to minimize the risk not only of liability but of litigation, the most prudent course is to recommend that researchers stay away from women. ${ }^{148}$

Why, then, do I bother to engage, and seek to engage the reader, in this analysis? It is not possible for me to demonstrate conclusively that liability could never be found. Nor can I categorically state that optimistic litigators will always find the state of the law so inhospitable that bringing a claim will seem prohibitively expensive or ripe for sanction, and so conclude that no claim would be worth the potential of a nuisance settlement. As lawyers always find themselves saying when asked by non-lawyers, "Could I be sued?" I have to say "Yes, anyone can sue anyone else for anything." The more useful questions are how likely and how provable are such claims; what kind of damages would they entail; and what kind of defenses are available for the researcher? That is what $I$ explore in the next section.

But first let me return to a baseline issue: Why should researchers incur even a small legal risk, if they can avoid it by not including women? Because, for three reasons, they cannot avoid legal risk, and their continued exclusion of women will actually exacerbate rather than reduce that risk:

1. In fact, even were researchers able to continue excluding all pregnable women, unless they confine their subject populations to irreversibly sterilized men, they will have to grapple with preconceptual liability. Slowly and painfully over the next decades, the causal connection between male exposure to gametotoxins and harm to offspring will continue to be demonstrated and recognized. The paternal-exposure preconceptual injury case will someday succeed.

2. Researchers are going to face legal responsibility for injury flowing from their refusals to include pregnant and pregnable women in their clinical trials based on the developing "duty to test." Courts will hold drug researchers accountable for failing to investigate in women side-effects and efficacy problems that should have been caught prior to marketing the drug. Even if the FDA approved the drug, that will not, in and of itself, immunize the researcher.

3. As the purpose and function of clinical trials, especially largescale Phase III and Phase II-III trials, increasingly become defined as a means of providing health care - not just innovative therapies, but basic health care - public-sector researchers will confront sex discrimination claims by excluded women.

In the following section I will explain how through each of these three

148 A similar dynamic led to the "fetal protection" policies barring non-sterile women from lucrative though possibly fetotoxic jobs in many industries. See Valerie Mark, The Flip Side of Fetal Protection Policies: Compensating Children Injured through Parental Exposure to Reproductive Hazards in the Workplace, 22 Golden GATE U. L. REv, 673, 674-75 (1992). It is noteworthy that the one reported decision on employer liability to employee offspring for toxic workplace exposure involved the developmentally disabled son of a man exposed to mercury on the job. See Skelly v. Firestone Tire \& Rubber Co., 20 O.S.H. Rep. (BNA) 1040 (1990). But see Widera v. Ettco Wire and Cable Corp., 1994 WL 167738 (N.Y. App. Div. 1994) (no common law or OSHA cause of action against father's employer for infant prenatally injured by father's toxic exposure on the job). 
impending developments in the law, researchers are exposed to liability at least as significant as what they now seek to avoid by the exclusion of women.

(a) Liability for prenatal and preconceptual injury

American law did not recognize any legal duties to an unborn child until relatively recently. Killing a fetus in utero was not a crime; abortion only became widely illegal by about 1900 . Now, eighteen states have "feticide" statutes, ${ }^{149}$ and it is the rule in every state that negligent or intentional injury to a fetus may, under certain circumstances, give rise to an action in tort by or on behalf of the child, after its live birth. ${ }^{150}$ Some jurisdictions still purport to require proof that the fetus was viable at the time of the injury, but that requirement has been soundly criticized and largely abandoned in practice. ${ }^{151}$

Although liability founded on preconceptual tortious conduct and injury to the subsequently born child has generally been precluded as a matter of "public policy," 152 that is not universal. A few courts have entertained such actions. ${ }^{153}$ Review of this handful of decisions and the larger number that

149 Solomon, supra note 131 , at 413 \& n.6.

150 See Roland F. Chase, Annotation, Liability for Prenatal Injuries, 40 A.L.R.3d 1222 (1971); W. Page Keeton et al., Prosser \& Keeton on Torts \$ 55, at 367 (5th ed. 1984 \& Supp. 1988). Almost a half-century ago the District of Columbia became the first jurisdiction to recognize a civil right of action for prenatal injury. Bonbrest v. Kotz, 65 F. Supp. 138 (D.D.C. 1946).

151 Horace B. Robertson, Jr., Toward Rational Boundaries of Tort Liability for Injury to the Unborm: Prenatal Injuries, Preconception Injuries, and Wrongful Life, 1978 Duke L.J. 1401, 1412 (1978).

152 E.g., in New York the leading decisions of New York's highest court in Enright v. Eli Lilly \& Co., 570 N.E.2d 198 (N.Y.), cert. denied 112 S. Ct. 197 (1991) (no cause of action for "third generation" DES effects, i.e. cerebral palsy attributable to premature birth caused by mother's DES-caused defective reproductive organs); Albala v. City of New York, 429 N.E.2d 786 (N.Y. 1981) (no cause of action for child's injury due to negligently perforated uterus prior to conception); Catherwood v. American Sterilizer Co., 498 N.Y.S.2d 703 (Sup. Ct. 1986) (no cause of action for child's Down's syndrome attributed to maternal preconceptual exposure on the job to ethylene oxide), affd, 511 N.Y.S.2d 807 (App. Div.), appeal dismissed, 515 N.E.2d 908 (N.Y. 1987); see also Becker v. Schwartz, 386 N.E.2d 807, 814 (N.Y. 1978), overruling Park v. Chessin, 387 N.Y.S.2d 204 (Sup. Ct. 1976) (negligent advice to mother of child with polycystic kidneys that congenital defect would not recur led her to become pregnant and bear second polycystic child who died).

Other decisions that have rejected preconceptual tort liability include Sorrells v. Eli Lilly \& Co., 737 F. Supp. 678 (D.D.C. 1990) (applying Maryland law)(dismissal of third-generation DES claim); Hegyes v. Unjian Enterprises, Inc., 286 Cal. Rptr. 85 (Cal. Ct. App. 1991) (dismissal of claim for premature delivery necessitated by mother's lumbo-peritoneal shunt, resulting from automobile collision caused by defendant), reh'g denied, No. B047481, 1991 Cal. App. LEXIS 1220 (Cal. Ct. App. Oct. 10, 1991), review denied, No. S023723, 1992 Cal. LEXIS 264 (Cal. Jan. 16, 1992); McAuley v. Wills, 303 S.E.2d 258 (Ga. 1983) (dismissal of claim for child's postpartum death caused by mother's paraplegia, resulting from automobile collision caused by defendant); McNulty v. McDowell, 613 N.E.2d 904, 907 (Ma. 1993) (summary judgment for defendant granted because "mere fact that most women of child-bearing age are . . capable of becoming pregnant does not impose duty of care on their physicians to any later-conceived children"); Loerch v. Abbott Labs., 445 N.W.2d 560 (Minn. 1989)(en banc) (upholding lower-court dismissal of third-generation DES claim by split vote); Grover v. Eli Lilly and Co., 591 N.E.2d 696 (Ohio 1992) (dismissal of third-generation DES claim).

${ }^{159}$ It is unquestionably possible for a child or its parents to recover for injuries to the child, once born alive, resulting from pre-conceptual negligent or intentional conduct. See, e.g., Bergstresser v. Mitchell, 577 F.2d 22 (8th Cir. 1978) (applying Missouri law) (action permitted on claim that uterine rupture caused by negligent prior Caesarean section resulted in premature birth and hypoxia to second child); Jorgensen v. Meade Johnson Laboratories, Inc., 483 F.2d 237 


\section{have rejected such claims indicates great hesitation to recognize preconcep-}

(10th Cir. 1973) (applying Oklahoma law) (strict liability action permitted on claim that preconception use of oral contraceptives caused chromosomal damage resulting in birth of Down's Syndrome twins); Renslow v. Mennonite Hospital, 367 N.E.2d 1250 (Ill. 1977) (action permitted on claim for child's permanent injury resulting from negligent pre-conceptual transfusion of $\mathbf{R h}$ negative blood into Rh-positive mother); Monusko v. Postle, 437 N.W.2d 367 (Mich. App.), $l v$. app. denied, 433 Mich. 869 (1989) (action permitted on claim for failure to test rubella status of mother and immunize her prior to conception of injured child); Lazevnick v. General Hospital of Monroe Country, 499 F. Supp. 146 (M.D. Pa. 1980) (applying Pennsylvania law) (action permitted for error in blood test record during first pregnancy that resulted in paralysis and brain damage of second child), apparenily overruling Morgan v. U.S., 143 F. Supp. 580 (D.C.N.J. 1956) (applying Pennsylviania law) (dismissing claim that transfusion to woman two years prior to birth of child caused harm to child); Harbeson v. Parke-Davis, Inc., 656 P.2d 483 (Wash. 1983) (action permitted on claim for pre-conceptual failure to inform mother of risks of taking Dilantin during pregnancy).

One lower Philadelphia court, in an unreported decision, permitted a "third generation" DES case to proceed, but will require the plaintiff to prove that defendant manufacturers knew of the risk of the injury to the reproductive systems of the second generation, in order to establish the foreseeability of harm to the third generation - a formidable burden. Rorie Sherman, New DES Front, Nat'l L.J., Mar. 12, 1990, at 1, 27. See also Pitre v. Opelousas Gen. Hosp., 530 So. 2d 1151 (La. 1988) (no liability to child for negligent tubal ligation resulting in child's birth with congenital albinism, but dictum left open possibility of child's pre-conceptual claim on showing of foreseeability of specific defect).

Note that Bergstresser and Renslow both represent the speculation of the federal courts as to how state courts would construe their law. Renslow and Bergstresser also have been roundly criticized for their reliance on prenatal precedent, in particular the overruled New York decision in Park v. Chessin, 387 N.Y.S.2d 204 (Sup. Ct. 1976), to support their recognition of pre-conceptual liability. See supra note 152; Hegyes v. Unjian Enterprises, Inc., 286 Cal. Rptr. 85, 94 (Cal. Ct. App. 1991), review denied, Jan. 16, 1992.

Not considered here are the so-called "wronglful pregnancy" or "wrongful conception" cases where parents seek compensation for the birth of a healthy child after a negligently performed sterilization. See generally Russell G. Donaldson, Annotation, Recoverability of Cost of Raising Normal, Healthy Child Born as Result of Physician's Negligence or Breach of Contract or W'arranty, 89 A.L.R.4th 632 (1991). Although obviously the harm alleged is the result of pre-conceptual tortious conduct, a failed sterilization is in no way analogous to the conduct of biomedical researchers.

Two other distinct categories of claim have given rise to pre-conceptual tort liability, but are hardly instructive as to the potential of such liability for researchers. One group, the Rh-factor cases, all arise from a physician's failure to detect or treat the Rh-negative status of a woman during her care for one pregnancy, with the result that children born subsequently are severly damaged or die because of the "sensitization" of the mother and her production of antibodies lethal to the fetus. These decisions emphasize the extraordinary factors tilting toward liability in Rh-negative cases: not just the routine nature of the blood-typing procedure, but the fact that failure to treat an Rh-negative woman is malpractice per se, and that the resulting heınolytic disease and death of the child is "overwhelmingly preventable." Graham v. Keuchel, 847 P.2d 342, 364 (Okla. 1993).

As the courts determining these claims reiterate, the whole focus of the information or treatment not provided is protection of "those who, although unconceived at the time of [the woman's] treatment, are anticipated and foreseeable." Id. at 365. "The same duty is owed both the mother and her unconceived child - i.e., the duty to prevent the mother's sensitization ...." Id. at 365 n.130. See also Yeager v. Bloomington Obstetrics and Gynecology, Inc., 585 N.E.2d 696 (Ind. App.), aff'd, 604 N.E.2d 598 (Ind. 1992); Walker v. Rinck, 604 N.E.2d 59 (Ind. 1992) (in both cases, action permitted on claim for failure to determine Rh-negative status of mother during prior pregnancy); accord, Empire Casualty Co. v. St. Paul Fire and Marine Insurance Co., 764 P.2d 1191 (Colo. 1988); Lough v. Rolla Women's Clinic, Inc., 866 S.W.2d 851 (Mo. 1993).

The second distinctive category of pre-conceptual injury are claims resulting from negligent genetic investigation and counseling following the birth of a child with serious anomalies. In 
tual liability. One reason for this judicial reluctance clearly is the difficulty of establishing the causal link between a child's health problem and the defendant's preconceptual conduct. The courts also express lingering unease with the notion that conduct which inflicts no injury and violates no duty at the time it is undertaken - because the person it will eventually harm does not exist in any sense - later can be judged negligent, or in the case of strict liability claims, injurious.

\section{(b) Causation in the preconceptual injury decisions}

It is not possible, in a few sentences, to cogently decipher the required element of causation in a tort claim. ${ }^{154}$ A plaintiff must prove not only literal causation, sometimes called "causation-in-fact" - that the defendant's conduct (meaning both acts and omissions to act) was a substantial factor in bringing about the result complained of - but also must establish that it was the "proximate cause" or "legal cause" of the harm. The latter concept is used to limit the otherwise infinitely-regressive chain of preceding, overlapping, contributing, necessary but not sufficient, or sufficient but not necessary events and conditions that could be subsumed under the rubric of "cause." To oversimplify crudely, when a court thinks that imposing responsibility on a particular defendant would go just too far, seem too unfair and too impractical, often the court resorts to finding no proximate cause, ${ }^{155}$ or along the lines that I suggest below, to finding that something the parent did relieves the defendant of responsibility.

The Georgia Supreme Court's analysis in McAuley $v$. Wills, ${ }^{156}$ for example, turned heavily on causation. A child conceived after a mother's paralysis in a car accident died shortly after birth, allegedly because of a problematic

these cases, physicians reassured the parents that they had no genetic defects and could safely conceive other children, only to discover after the birth of a similarly damaged sibling that their reassurances were wrong, and negligently so. Again, the courts have permitted these preconceptual claims to stand, but the defendants in these cases bear no resemblance to medical researchers, unless the latter provide their subjects with undue reassurances. E.g., Gallegher v. Duke University, 852 F.2d 773 (4th Cir. 1988) (applying North Carolina law); Lininger v. Eisenbaum, 764 P.2d 1202 (Colo. 1988); Kush v. Lloyd, 616 So.2d 415 (Fla. 1993). But see Bruggeman v. Schimke, 718 P.2d 635 (Kan. 1986) (although court found that physician provided negligent genetic counseling, and that a physician consulted about the possible hereditary defects owes duty of care not only to parents, but to unconceived children, child's "wrongful life" claim rejected as a matter of law).

154 Speaking of the causation issue, and citing more than a score of lengthy law review articles on the subject, Prosser says: "There is perhaps nothing in the entire field of law which has called forth more disagreement, or upon which the opinions are in such a welter of confusion." KEETON ET AL., supra note 150 , at $\$ 41$.

155 To achieve the same outcome, courts also use the terms "duty," "foreseeability," and "negligence," all of which turn out to be inextricably intertwined with the analysis of proximate cause.

"Proximate cause," in short, has been an extraordinarily changeable concept. "Having no integrated meaning of its own, its chameleon quality permits it to be substituted for any one of the elements of a negligence case when decision on that element becomes difficult. . . No other formula . . so nearly does the work of Aladdin's lamp."

Keeton et AL., supra note 150 , at $\$ 42$, quoting, Leon Green, Proximate Cause in Texas Negligence Law, 28 TEX. L. REV. 471 (1950).

I56 303 S.E.2d 258 (Ga. 1983). 
delivery caused by the mother's paraplegia. Dismissing the case against the driver on the pleadings, prior to trial, the Georgia court found that the parent's decision to proceed with a pregnancy, having been warned of the risks, constituted an intervening act that broke the causal link between the original car accident and the child's death. ${ }^{157}$ This break in the link of causation was critical. As a later court found, building on the McAuley analysis, "if the doctor did warn [the woman] of the risks associated with becoming pregnant, and [the woman] nonetheless decided to proceed with pregnancy, her voluntary and knowing act was an intervening intentional act, breaking the chain of causation." 158 Similarly, a researcher's lawyer could argue, the decision of the fully-informed subject to proceed on a protocol, once advised that there are known and unknown risks to future offspring, severs the causal chain.

\section{(c) Duty and foreseeability}

Even when the causal linkage is quite clear and strong, courts find it hard to impose liability on someone for harm to a person not yet conceived at the time of the defendant's action. Often the question becomes defined as one of "duty": was there a relationship between the actor and the plaintiff that created a legal obligation "for the benefit of" the plaintiff? That, in turn, is partially a function of foreseeability - whether it is foreseeable that the actor's conduct may create a risk of harm to the plaintiff. ${ }^{159}$ When a plaintiff did not exist in any sense, even in utero, at the time of the defendant's conduct, injury to her could not have been foreseen. Absent foreseeability of harm, there can be no responsibility to avoid the harm. "[P]laintiff at the time of the conduct was in no sense a separate entity to whom the traditional duty of care could be owed." 160

While foreseeability may be necessary, it alone will not suffice. "[T]he creation of a legal duty requires more than a mere possibility of occurrence since, through hindsight, everything is foreseeable." 161 In the decisions that reject preconceptual injury claims, frequently the courts determine that although the plaintiff's injury might have been foreseeable (in the sense that

157 Id. at 260.

158 Hegyes, 286 Cal. Rptr. at 99. But see Walker v. Rinck, 604 N.E.2d 59 (Ind. 1992). In a 3-2 decision, Walker reversed an intermediate appellate court's determination that a parent's decision to conceive more children, after having been informed that her physician had negligently failed to ascertain and appropriately medicate her Rh-negative condition, was an intervening cause of the harm to her subsequently born children. Id. at 596. The majority ruled that the later pregnancies were "totally foreseeable" and that the very purpose of the physician's care had been "to protect future fetuses." Id. at 595. The court was at pains, however, to avoid recognizing "a duty ... [that] might lead physicians to forego treatment that might benefit the mother but pose a risk to later children," thus placing them "in a direct conflict between their moral duty to patients and the proposed legal duty to ... hypothetical future generations." Id. at 595 (quoting Albala v. City of New York, 429 N.E.2d 786 (N.Y. 1981)). It found that administration of the proper medication for Rh-negative blood "neither benefits nor harms the mother; It is given only to protect potential fetuses not yet conceived." Id. In the research context, the court's analysis of causation, which was strongly criticized by its to dissenters, id. at 598 , has limited utility.

${ }^{159}$ See, e.g., Monusko v. Postle, 437 N.W.2d 367, 369 (Mich. App.), lv. app. denied, 433 Mich. 869 (1989).

160 Renslow v. Mennonite Hosp., 367 N.E.2d 1250, 1254 (Ill. 1977)(child injured by preconception transfusions to mother).

161 Hegyes, 286 Cal. Rptr. at 103. 
the defendant could have anticipated the chance that a child would later be conceived, injured, and born), as a matter of public policy they would not recognize "a duty to the unconceived." 162

The major exception to this principle occurs when it is clear that the birth of the afflicted child is not merely theoretically foreseeable, but actually foreseen - for example, contemplated and desired as the sole objective of a physician's intervention. In the so-called "wrongful life" cases, where birth with injurious genetic defects has followed negligent preconceptual testing and counseling by a physician, liability for this preconception tort is based on the "special relationship" between the physician and the parental patient. ${ }^{163}$ In Monusko v. Postle, ${ }^{164}$ for example, the rubella test and immunization that the defendant physician ought to have done would have prevented precisely the harm that the plaintiff suffered (rubella syndrome), and the court carefully confined its recognition of preconceptual liability to that unique circumstance.

In Hegyes v. Unjian Enterprises, Inc., ${ }^{165}$ a California court dismissed the claim as legally insufficient because no such relationship was involved. The plaintiff's mother had a lumbo-peritoneal shunt as a result of a car accident. The shunt became compressed by the fetus during her pregnancy, and to protect the mother the fetus had to be delivered prematurely. Plaintiff, the child, was suing for injuries resulting from the premature delivery, based on the preconceptual car accident that had led to implantation of the shunt. ${ }^{166}$

In its persuasive opinion, the Hegyes court emphasized the distinct, sui generis nature of situations in which the whole goal and function of a preexisting relationship between the plaintiff's parent and the defendant was the birth of a healthy child, and the culpability of the physician in negligently depriving the parent of the opportunity to choose not to conceive a child. ${ }^{167}$ It categorically refused to enlarge responsibility for preconceptual harm beyond the realm of professional negligence or products liability - the latter not because of any "special relationship," but because liability for a defective product by definition extends to all persons affected by the product, regardless of privity, foreseeability or due care. ${ }^{168}$

The very first preconceptual injury decision, Renslow v. Mennonite Hospi-

162 Catherwood v. American Sterilizer Co., 498 N.Y.S.2d 703, 706 (Sup. Ct. 1986), affd, 511 N.Y.S.2d 805 (App. Div.), appeal dismissed, 515 N.E.2d 908 (1987).

163 See, e.g., Turpin v. Sortini, 643 P.2d 954 (Cal. 1982) (negligent failure to diagnose sibling's hereditary defect); Curlender v. Bio-Science Labs., 165 Cal. Rptr. 477 (Cal. Ct. App. 1980) (negligent testing for gene for Tay-Sachs disease). But see Smith v. Cote, 513 A.2d 341, $351-55$ (N.H. 1986) (refusing to recognize "wrongful life" claim of child prenatally injured by negligent failure to test mother for rubella) and cases discussed therein.

164437 N.W.2d 367 (Mich. App.), lv. app. denied, 433 Mich. 869 (1989).

165286 Cal. Rptr. 85 (Cal. Ct. App. 1991).

166 Id. at 86-87.

167 " A duty is easily recognized where ... the parents consulted the physician for the express purpose of determining whether to conceive a child or to terminate an existing pregnancy ... [when] a medical professional's conduct ... is directly and intentionally related to whether a child is conceived or born." Id. at 100-01.

$168 \mathrm{Id}$. at $89 \mathrm{n} .4$; see discussion of strict liability law, infra notes 178-88, 204-34 and accompanying text. 
tal, ${ }^{169}$ remains one of the more fertile for analysis, in part because of its several opinions and dissents. A bare majority of the Illinois Supreme Court refused to conclude as a matter of law that the defendant could not have foreseen the harm to plaintiff, a child born with hyperbilirubinemia because of the negligent sensitization of her mother's Rh-negative blood, given the state of medical knowledge about the effects of $\mathbf{R h}$-factor incompatibility at the time of her mother's transfusion in 1965. The precise form of the harm, or the exact identity of the person harmed, need not be foreseeable; it is "[ $t]$ he likelihood of harm in some form to a class of persons . . ."170 that generates a duty to exercise care to prevent the harm. In any event, as the concurring opinion found, it was easily foreseeable that the adolescent girl transfused "would grow up, marry and become pregnant."171

Renslow goes on to posit "a right to be born free from prenatal injuries foreseeably caused by a breach of duty to the child's mother."172 Although the conduct was preconceptual, the injury was prenatal, and because the conduct was negligent with respect to the plaintiff's mother, the court invoked the concept of "transferred negligence" to support its conclusion that the wrong to the mother was also a violation of duty to the child. However, the Renslow court was careful to limit its holding to one generation, noting that the damage here was not self-perpetuating, ${ }^{173}$ not the sort of "hereditary defect" or "genetic injury" that the dissenters feared would extend traditional tort liability to the "freakish and the fantastic." 174 And once again, this was not a case in which the mother had been fully informed of risks and proceeded despite warning; a duty to her had been breached, and it was this breach, not her independent decision, that caused the harm to her child - hence, the physician's liability. ${ }^{175}$

What does this analysis of the current state of the law tell us about the likelihood of researcher liability to the unconceived child of a subject? Unlike in Hegyes and McCauley, there is a relationship, and perhaps one that could be characterized as professional, between the researcher and the subject-parent. But the purpose of that relationship is not the prevention of impairment of

169367 N.E.2d 1250 (Ill. 1977).
$170 I d$. at 1258.
171 Id.
$172 I d$. at 1255 (emphasis added).
173 Id.
174 Id. at 1262 (Ryan, J., dissenting) (quoting William L. Prosser, Palsgraf Revisited, 52 Mrch. L. REv, 1, 27 (1953)).

${ }^{175}$ Cf. Graham v. Keuchel, 847 P.2d 342 (Okla. 1993). One of the negligent Rh-negative senitization cases, Graham reversed a verdict because the court did not direct the jury to find a defense of supervening cause only if the mother's conception of the injured child had been intentional or in reckless disregard of her awarenewss of the risk to the child. Id. at 354, n.55. However, it also determined that if a woman knew of her Rh-sensitive status, had been adequately warned of the dangers of conception in that condition, and completely understood the medical risk, then the "forces set in motion by the doctors' failure to give her [the treatment] may be said to have become passive .... If she undertook unreasonable risks by becoming pregnant in her sensitized condition, the harm . . . is not attributable to the doctors, but to the normal risks of pregnancy for a woman who has been sensitized." Id. at 352-53. "The doctors . . would not be held accountable for foreseeing that an adult female patient, who is sui juris, would willfully conceive in the face of substantial risk of known and appeciated danger of severe disability or death to the child." Id. at 351. 
the subject's offspring, or assisting the subject in producing healthy future progeny, as in Monusko or the wrongful life cases. Nor will a researcher, simply by including a subject in a protocol, breach any independent duty of care to the subject-parent, as did the negligent transfusing doctor in Renslow. ${ }^{176}$ The logical appeal of the limited "special relationship" exception, the intervening causation of the subject's decision to proceed, and the context of outright rejection of preconceptual liability for lack of legal duty convince me that the chances of researcher liability on a negligence theory are minuscule. ${ }^{177}$

\section{(d) Strict liability preconceptual claims}

Of the preconceptual injury decisions extant, Jorgensen $v$. Meade Johnson Labs., Inc. , ${ }^{178}$ is perhaps the closest on its facts to the scenario feared by researchers contemplating the inclusion of fertile women in their trials. Alone among the decisions upholding a preconceptual claim, Jorgensen was pleaded in strict liability and express warranty; the court did not need to reach issues of duty or foreseeability. The plaintiffs were twin girls born with Down's syndrome, one of whom died at the age of three and the other who was severely impaired. Their condition was attributed to chromosomal damage sustained by their mother's taking birth control pills just prior to becoming pregnant. Without accepting as proven the alleged causal link between the pills and the child's condition, the court held that if such a connection could be proven, the fact that the defendant's conduct - the manufacture and sale of the pills - occurred prior to conception, in and of itself, would not defeat the action. ${ }^{179}$

The appellate court emphasized that "[w]e are persuaded that the Oklahoma courts would treat the problem of the injuries alleged here as one of causation and proximate cause, to be determined by competent medical proof." 180 In other words, the trial court erred in ruling out preconceptual injury claims per se; it should have focused on the element of causation, in both its factual and legal senses, to decide whether defendant was responsible. The appellate court did not dictate what the lower court should do, and as with so many of these cases, it seems to have been settled post-appeal, so we do not know what the trial court would have concluded on that issue.

But we do know that far from having been advised or warned of any risk of chromosomal damage from the contraceptive, Alta Jorgensen was told that the pills were safe and fit and received no warning of any potential harm from

176 If a researcher does breach a duty to a subject, either by concealing information or misreading tests or departing from the protocol, and harm ensues to the subject's children whether they are unconceived, conceived, born, or grown-up - all bets are off. The researcher may be responsible for that harm - as, I would hope, everyone would agree is only fair. That, however, has no bearing on the quite different question whether the researcher's inclusion of a subject, without any negligence, could in and of itself subject the researcher to liability to the subject's future offspring for unavoidable harm.

177 For a very similar conclusion with respect to employer liability for harm to workers' offspring, based on an intervening causation analysis, see Mark, supra note 148, at 695-97.

178483 F.2d 237 (10th Cir. 1973).

${ }^{179} I d$. at $238,240$.

180 Id. at 240. 
their use (or so says her complaint, which the court had to accept as true for purposes of this ruling). Whether she could have proved this warranty and lack of warning, and then proven that the pills caused an alteration in her chromosomes, is not at all clear. No researchers, however, will guarantee a subject the "fitness" of an intervention on trial; quite the contrary, the reasonable researcher will warn that there may be substantial risk both to the subject and the subject's children. Researchers, in fact, could choose to routinely inform all subjects that chromosomal damage might result from a protocol.

The law has not yet developed in this area, but it seems clear that such warnings would extinguish the strict liability claims of both subjects and their children, for either prenatal or preconceptual harm. Unlike the purveyor of goods who is held to a standard of strict liability, the research sponsor generally is not selling a product. Extensive warnings of known and unknown risks are provided, and the subjects expressly assume those risks. It is often said that contributory negligence and assumption of the risk are not defenses to strict liability. ${ }^{181}$ In the field of products liability, a special subset of strict liability,

virtually all courts have seemingly agreed that the conduct or misconduct of another, including an intermediate seller, the claimant, or anyone else, may be of such nature or kind as to constitute a superseding cause. ...

....

[For example], voluntary and unreasonable (negligent) use with knowledge of the defective condition and appreciation of its danger. ${ }^{182}$

So let us return to the causation theme that pervades the jurisprudence of preconceptual and prenatal tort: who really caused the harm to the child? Is it the researcher who allows the competent, fully informed, adult ${ }^{183}$ parent-tobe to participate? I would argue, no; it is the subject whose voluntary, deliberate, intervening actions have superseded and eclipsed any responsibility the researcher might otherwise have had.

In none of the instances described above did a court face a tortfeasor who had been honest with a woman about potential risks to her offspring which she then chose to assume for reasons of her own. The issue should properly be viewed not as a question of waiver but rather of superseding cau-

181 There is also definitely some question as to whether a subject's assumption of the risk (or in some circumstances, contributory negligence) in proceeding with the protocol would be imputed to and binding on the as-yet-unborn or unconceived child. This issue is discussed more extensively below under the question of waiver of liability. See infra note 302.

182 KEETON ET AL., supra note $150, \S 102$ (emphasis added).

189 Different issues arise when the subject is a minor limited in capacity to consent to anything, including medical treatment. This topic deserves its own monograph and cannot be addressed here. However, it should be noted that those whom the law calls "mature minors" or "emancipated minors" - because of their actual independence from their parents, through employment, marriage, or parenthood - do not fall into this category, because they can generally consent both to medical treatment and to research participation. See JAMES M. MorfisseY ET AL., Consent and Confidentiality in the Health Care of Children and Adolescents 90-92 (1986). 
sation. The harm, if it occurs, to a subject's subsequently-born child has been caused not by the researcher, but by the parent's decision to engage in certain conduct, knowing that it might harm potential offspring. ${ }^{184}$ In this era of onrushing abrogation of parental tort immunity, ${ }^{185}$ the child might seek recompense from the parent, ${ }^{186}$ but the researcher is likely to be shielded by the parent's interception of liability. ${ }^{187}$ Too, it is important to remember the

184 Compare Solomon, supra note 131, at 427:

The first problem is fear of medical malpractice liability, should the fetus develop into a damaged baby. Since few physicians have a clear understanding of malpractice law, this concern is very real to them. Nevertheless, there is a simple response. The doctrine of informed consent, based on the constitutional right to refuse medical treatment, requires that the physician disclose the risks and benefits of any medical procedure to the patient for her decision. Far from forcing or coercing the patient to act in accordance with the physician's orders, the law requires the patient to have the final say. The woman, not the fetus, selects and employs her doctor. Therefore, the physician discharges his legal duty by providing the woman with the required information.

185 KEETON ET AL., supra note 150 , at $\$ 122$.

186 In 1980 , in a plain effort to permit recovery against the mother's insurer, Michigan became the first state to sustain a claim against a child's mother for injuries resulting from her negligent conduct during the pregnancy. Grodin v. Grodin, 301 N.W.2d 869, 871 (Mich. 1980) (action permitted against mother for damage to son's teeth caused by use of tetracycline during pregnancy; must establish whether choice was "reasonable exercise of parental discretion"); see also Bonte v. Bonte, 616 A.2d 464 (N.H. 1992). One other state court considered such a claim and rejected it, at least with respect to unintentional harm, to avoid "State scrutiny [of] all the decisions a mother must make in attempting to carry a pregnancy to term" and the creation of an adversarial relationship between the pregnant woman and fetus from the moment of conception until birth. Stallman v. Youngquist, 531 N.E.2d 355, 355, 360 (Ill. 1988) (child born with intestinal injuries, apparently resulting from automobile collision while mother was five months pregnant). However, one writer believes that at least thirty U.S. jurisdictions have demonstrated their receptiveness to recognition of a woman's duty to her embryo-fetus. See Ron Beal, "Can I Sue Mommy?" An Analysis of a Woman's Tort Liability for Prenatal Injuries to Her Child Borm Alive, 21 SAN Diego L. Rev. 325, 357 (1984). See generally Thomas M. Fleming, Right of Child to Action Against Mother for Infiction of Prenatal Injuries, 78 A.L.R.4th 1082, 1088 (1990) (suggesting that "recognition ... of a mother's liability for injuring her unborn child might involve a duty on her part to properly care for her own body throughout her fertile years, regardless of pregnancy or her knowledge thereof, and render admissible evidence of such self-injurious conduct before conception as heavy drinking or drug use").

Many commentators enthusiastically support the notion of maternal prenatal civil liability. See Joseph S. Badger, Note, Stallman v. Youngquist: 'No, You Can't Sue Mommy In Illinois;' The Illinois Supreme Court Rejects Maternal Prenatal Civil Liability, 11 N. ILL. U. L. REv. 409, 433 n.169 (1991). One even suggests that women should be held liable for perinatal transmission of the human immunodeficiency virus - a concept that stands out, even among academic law reviews, for its stunning remoteness from the real world as well as for its condemnatory attitude toward people living with AIDS. Martha M. Curley, Note, Establishing Relief for the Most Innocent of All AIDS Victims: Liability for Perinatal Transmission of AIDS, 28 J. FAM. L. 271 (1990). No one on this long list of commentators, however, seems to have considered the possibility of paternal liability to a child for prenatal or preconceptual injury.

187 The only contrary analysis that I have found is a footnote in a student note, David $S$. Steefel, Note, Preconception Torts: Foreseeing the Unconceived, 48 U. Colo. L. Rev. 621, 636 n.81 (1977). The author relies on the black-letter language of Section 89 of the Restatement (SECOND) OF TORTS (and other rules) that "normal" and "foreseeable" intervening causes do not supersede a defendant's liability. See KEETON ET AL., supra note 150 , at $\$ 44$. He errs, in my judgment, by focusing on the conception of offspring as the superseding "event;" my argument is, rather, that it is the informed consent of the male or female subject which supersedes the defendant's duty. As Prosser says,

Sometimes the defendant will be free to assume that when a third person becomes aware 
strength of current "public policy" considerations, such as the interest in fostering drug development. ${ }^{188}$ At present, there is still no precedent for imposition of liability for harm to a subject's children on a researcher who obtained properly informed consent from the subject. ${ }^{189}$

In sum, the possibility of liability for prenatal or preconceptual harm to a subject's offspring cannot be negated, but it is hardly inevitable or of colossal proportions. A few researchers may be subject to a prima facie clairn, under theories either of negligence or strict liability, ${ }^{190}$ if the child of a subject is prenatally or preconceptually injured, and it can be convincingly demonstrated that the harm is attributable to the research intervention. For that matter, a researcher could face a loss of consortium ${ }^{191}$ claim from an already existing child whose parent was injured by participating in the research. But how many researchers inquire into whether their subjects, male or female, have children who might make such a claim? Again, the issue is not merely, could such an action in theory be brought, but how serious a threat to the researcher would such a lawsuit be, relative to all other sources of liability inherent in the research enterprise.

By far the most likely scenario for a researcher's liability is failure to adequately inform the parent-subject about some aspect of the experimental procedure: its risks, the non-experimental alternatives available if the subject did not participate in the protocol, the unknown potential for later harm to offspring, and all the other information required by current federal regulations and the general law of informed consent. ${ }^{192}$ Researchers are subjecting

of the danger, and is in a position to deal with it, the third person will act reasonably. It is only where misconduct is to be anticipated, and taking the risk of it was unreasonable, that liability will be imposed for consequences to which such intervening acts contributed.

Id. Without more, the choice to participate in a protocol should not be characterized as "misconduct."

188 See Enright v. Eli Lilly \& Co., 570 N.E.2d 198 (1991) (no cause of action for "third generation" DES effects, in part because of "dangers of overdeterrence - the possibility that research will be discouraged or that beneficial drugs will be withheld from the market").

189 The only tort claims against a researcher for damage to subject's offspring ever brought have been the intentional tort - not negligence - claims against the University of Chicago and Eli Lilly \& Co. for their conduct of the DES trial in which female subjects were deliberately misinformed and misled. See Wetherill v. University of Chicago, 570 F. Supp. 1124 (N.D. Ill. 1983); Mink v. University of Chicago, 460 F. Supp. 713 (N.D. Ill. 1978).

190 If the subject was not paying to participate in the protocol or for the drug administered, quaere whether strict liability for non-negligent conduct, which is limited to those engaged in the business of selling a product, would be applicable. If the research subject is analogized to a "professional tester," it would appear that transfer of products that are still in a testing stage and have not yet "entered the stream of commerce" will not be held to the strict liability standard. See Marshall Shapo, The Law of Products Liability $\S 12-34 \& \$ 12-35$ (1987). It is quite clear that physicians and other providers of health care are not strictly liable for defects in products that they dispense or prescribe. See, e.g., Magrine v. Spector, 24l A.2d 637 (N.J. 1968), affd 250 A.2d 129 (N.J. 1969).

191 "Loss of consortium" is the legal term for the harm of losing the "society and affection" or in the case of a child, the "society, guidance, attention and care" of a family mernber who is injured or killed. It is an item of damages separate from physical injury, medical expenses, pain and suffering, or financial loss. In the last decade, children have been permitted to sue for loss of parental consortium in several states. KEETON ET AL., supra note 150 , at $\$ 125$.

192 See, e.g., Levine, Ethics and Regulation, supra note 22, at 95-153. 
themselves now to incalculable potential liability because they almost never advise male subjects of any possible risk to their children, and never recommend precautionary measures such as avoiding conception while on protocol. ${ }^{193}$ IRBs who approve these deficient protocols are complicit in this failure and may also be held legally responsible. ${ }^{194}$ This practice has far greater potential for devastating liability than the inclusion of women.

As for the extent of any liability, if the circumstances of a particular researcher-subject relationship were analogous to an employer-employee relationship, ${ }^{195}$ the researcher's maximum liability would be the relatively circumscribed recovery of workers' compensation. Through the peculiar operation of that system, which remains the sole legal remedy for any workrelated injury to an employee even if in fact no benefits are available for the specific injury claimed, this theoretical liability may often amount to nothing. For example, a California court recently decided that serious injury to an unborn child, caused by an employee health clinic's failure to diagnose a ruptured uterus, was a work-related injury that would be compensated only by workers' compensation. However, because the California workers' compensation scheme does not cover an employee's child, the child's medical and other expenses were, in the end, paid by no one. ${ }^{196}$ The decision rested in large part on the court's apprehension that otherwise, employers would be tempted to resort to exclusion of pregnant workers from the workplace; similar concern about the impact of barring pregnant or pregnable women from research protocols might animate a court to bar civil liability on policy

${ }^{199}$ In light of developing knowledge of the male contribution to birth defects, such risks are no longer "unforeseeable" and therefore exempt from the product manufacturer's duty to warn. See discussion supra notes $140-46$ and accompanying text.

194 See infra notes 255-65 and accompanying text.

195 For example, if the subject were paid. The vast majority of Phase I subjects - the "normal healthy volunteers" - are paid. Although often characterized as independent contractors, researchers certainly could choose instead to establish an employee-employer relationship. It is noteworthy that the greatest resistance to female subject inclusion seems to focus on Phase $\mathrm{I}$, and the dire risks associated with utterly untried interventions, often when animal data is still quite incomplete. Yet, as Robert Levine recounts, when years ago insurance companies were solicited to give estimates for workers' compensation coverage of a large Phase I testing facility, their per capita cost estimates for insuring the Phase I subjects was about the same as for insuring the facility's secretaries: very low. Workshop on Research Involving Human Subjects, Annual Meeting of the American Society of Law, Medicine and Ethics, October 23, 1993. Study of Phase I subjects in prison found 58 adverse medical events (using a very broad definition) and no deaths or permanent disability in the course of almost 18 billion subject-days of Phase I exposure. LEvine, Ethics and Reculation, supra note 22, at 39-40.

196 Bell v. Macy's California, 261 Cal. Rptr. 447 (Ct. App. 1989), review denied, 1989 Cal. LEXIS 4637 (Cal. Nov. 16, 1989); see also Witty v. American Gen. Capital Distribs., Inc., 697 S.W.2d 636 (Tex. Ct. App. 1985), aff'd in part, rev'd in part on other grounds, 727 S.W.2d 503 (Tex. 1987) (both wrongful death and emotional distress claims of employee whose fetus was killed in work accident barred by workers' compensation). But in the jurisdiction of Louisiana, where the fetus has been statutorily declared a juridical human being with all the rights of any child, the employer may be liable in a civil tort action, not merely in workers' compensation, for negligence that causes the death of an employee's fetus. Adams v. Denny's Inc., 464 So. 2d 876 (La. Ct. App.), cert. denied, 467 So. 2d 530 (La. 1985); see also Namislo v. Akzo Chemicals, Inc., 620 So. 2d 573 (Ala. 1993); Dillon v. S.S. Kresge Co., 192 N.W. 2d 661 (Mich. Ct. App. 1971). See generally, Jean M. Eggen, Toxic Reproductive and Genetic Hazards in the Workplace: Challenging the Myths of the Tort and Workers ' Compensation Systems, 60 Fordham L. Rev. 843, 879-84 (1992); Mark, supra note 148. 
grounds. ${ }^{197}$

(2) If there is a real risk to sponsors from inclusion of women, is it an unjust risk?

Let us assume that liability is possible. The question then shifts to whether the possibility of liability justifies the exclusion of all women on the chance that their unanticipated, undesired, or undisclosed pregnancy might eventually lead to claims against the research sponsor. Let us assume that real harm is done to children and that the sponsors have to pay. Is that necessarily an unjust result?

The closest analogy already developing in the law is fetal protection policy in the workplace. ${ }^{198}$ The Supreme Court has recently refused to countenance a similar justification for the required sterilization of ernployees exposed to lead, in no small part because of the company's abysmal record with respect to protecting or acknowledging the risk to male workers' children from the men's comparably dangerous, or worse, exposures. ${ }^{199}$ The potential for tort liability was the major defense for the discriminatory policy raised by the employer, Johnson Controls, and it was soundly rejected in light of other social costs, including the cost in women's autonomy. ${ }^{200}$

As was the case with Johnson Controls' lack of concern about the exposure of their male workers, the utter disinterest evidenced by most researchers in the possibility of harm to the offspring of male subjects is a telltale sign that their inclusion/exclusion criteria are more about the exclusion of women than about the prevention of harm to unborn children. In fact, it does not seem at all unjust for those who profit from the conduct of research - not only the sponsors, but the investigators who may reap rewards of prestige and professional reputation, with concomitant access to further grants and contracts, salary increases, offers to edit journals or teach - to be held responsi-

197 Contra, Jarvis v. Providence Hosp., 444 N.W.2d 236 (Mich. Ct. App. 1989). But note that in Jarvis, not only did the employer hospital omit to give gamma globulin to the pregnant lab technician exposed to hepatitis, the supervising physician affirmatively misled the woman by telling her that the sample to which she had been exposed had tested negative for hepatitis and that there was no need for concern. Id. at 238. Also, for whatever reason, the employer's attorney failed to raise the defense of exclusivity of remedy with respect to the woman's survivors' action. Id. at 242 n.5. The court in fact engaged in the kind of "causal intervention" analysis that I predict courts will, and found that the woman's intervening conduct - failure to report the exposure for two days and to seek health care elsewhere - did not constitute a proximate cause of the fetal death.

198 Some will argue that the analogy to workplace fetal protection policies falls apart in the face of the differences between employment and participation in research. Getting and keeping a job is seen as an unalloyed benefit, while serving as a subject is if anything a sacrifice. This perspective, grounded in the traditional notions of "the null hypothesis" and "clinical equipoise," and the much-touted distinction between research and treatment, is at best partial. See supra note 28. Employment has its burdens too, and, as the prior discussion reveals, research can offer distinct benefits to its subjects. See discussion supra notes 29-79 and accompanying text.

199 Int'l Union, United Auto., Aerospace and Agric. Implement Workers of Am., UAW, v. Johnson Controls, Inc., 499 U.S. 187 (1991). See discussion supra notes 140-46 and accompanying text.

200 "It is no more appropriate for the courts than it is for individual employers to decide whether a woman's reproductive role is more important to herself and her family than her economic role. Congress has left this choice to the woman as hers to make." Id. at 211 . 
ble for the actual costs to human beings that research entails. Why should research sponsors and investigators be permitted to externalize those costs, if in fact they arise, to subjects and their children? Perhaps if research were truly cooperative and subjects participated in eventual profit or other reward, I might see the question differently, but as the California cell-line case makes clear, researchers resist giving their lay subjects any stake in their success. ${ }^{201}$

The issue here is not fault, in the sense of negligently failing to avoid harm that was preventable. I return to the principle underlying the legal concept of strict liability: even when harm occurs totally without fault, if the choice of who shall absorb that harm is between those who profit from the conduct that caused it, and those who do not, ${ }^{202}$ the right choice is the former.

(3) What is the risk of liability if women are not included in trials?

In addition to the risk of liability to the children of male subjects, ${ }^{203}$ researchers and the IRBs that approve their research face a different set of legal risks if they continue to exclude women from their research. The prudent researcher should be interested in learning about these legal hazards and comparing them with the risks of inclusion.

(a) The most likely source of liability for research sponsors: failure to conduct adequate pre-marketing testing with women and pregnant subjects

i. The duty to provide "safe" products

Under strict liability, a seller of any product "in a defective condition unreasonably dangerous to the user or consumer" is subject to liability for physical harm to the user if the seller is engaged in the business of selling the product and the product reached the user without substantial change in its condition when sold. ${ }^{204}$ Liability may attach even if the seller exercises "all possible care" in preparation of the product and despite the absence of any contractual connection between the user and the seller. ${ }^{205}$ The focus is not

201 See Moore v. Regents of Univ. of Cal., 793 P.2d 479 (Cal. 1990), cert. denied, 499 U.S. 936 (1991) (researchers refuse to share with patient profit from "immortal" cell line cultured from his spleen without his knowledge or consent). By "success" I do not necessarily mean an exciting breakthrough on a particular protocol or development of a particular drug; as with other enterprises, over time those engaged in research have to expect to absorb costs associated with experiments that don't work. And, of course, the trial that fails to disprove a null hypothesis may well be publishable or otherwise translatable into tangible benefit for the researcher.

202 Some may turn around the arguments advanced above about the benefits of being a research subject, and say that those benefits transform the subject into a true joint venturer who, having made a conscious decision to proceed despite (let us assume) awareness of possible if unquantifiable risks to offspring, should bear sole and absolute responsibility for whatever ensues. Rarely, I think, will the incidental advantages of being a subject approach the overall gain of the researcher from the research.

203 See discussion supra notes 140-46 and accompanying text.

204 Restatement (SEcond) of Torts $\$ 402 A$ (1965) [hereinafter Restatement]. A “Restatement" is an authoritative source of general legal rules and principles, not tied to the law of any particular state. In the field of products liability, each state also has its own body of judicial precedent and statutes controlling commercial transactions.

205 It has occasionally been suggested that strict liability would not apply to providers of 
on whether the manufacturer or the seller of the product was at fault, but on whether the product itself was flawed, either in the manufacture of one item or in the design of the whole product line. One rationale for holding manufacturers and sellers of defective products strictly liable, without regard to privity, ${ }^{206}$ foreseeability, or due care, is that they are able to distribute the cost of harm to innocent victims among all who benefit from the product by passing it along to customers.

ii. The duty to warn

Liability may attach if the manufacturer does not take "available and reasonable steps to lessen or eliminate the danger of even a significantly useful and desirable product."207 When the risk is not apparent, product users must be adequately and understandably warned of concealed dangers. In the case of pharmaceutical products, the manufacturer's duty to warn may be discharged by warnings to the physician, not the patient. ${ }^{208}$ Failure to warn of known dangers may be considered either negligence or a kind of defect in the product marketed. If the injured party can make a further showing that the failure to warn caused the injury - that proper warnings would have prevented the injury - damages may be recoverable from the seller of the product. ${ }^{209}$

Unlike most other products, such as an uncrashworthy car with an improperly installed brake, drugs are often dangerous not because of a flaw in their design or careless manufacture, but because of their inherent toxicity for some people. Individuals react differently to drugs, and in some cases those reactions may be idiosyncratic, allergic, or statistically so rare that no premarketing clinical trial of reasonable size or duration could discover the problem. The occurrence of such injuries from a drug that otherwise performs its function does not make the drug "unreasonably dangerous" in the language of the Restatement. Very often courts classify drugs as "Comment k" products, referring back to a section of the Restatement that limits liability to true man-

investigational drugs because usually the drugs are not "sold," i.e., transferred for value, to the consumer-subjects. At least one court rejected this contention summarily, pointing out that the manufacturer testing the drug was "in the business of selling drugs," and that its ultimate goal was the commercially profitable sale of the drug. Gaston v. Hunter, 588 P.2d 326, 338-39 (Ariz. Ct. App. 1978). This defense is particularly problematic because claims of strict liability sound in tort, not contract, and may be maintained by family members, employees, guests, or donees of an original purchaser. See infra note 206. The only other avenue would be statutory or common-law definition of the provision of investigational drugs as a "medical service," rather than distribution of a product, as occurred with respect to processors and providers of blood and blood components. See, e.g., Doe v. Travenol Labs., Inc., 698 F. Supp. 780 (D. Minn. 1988) and authorities reviewed therein.

206 "Privity" is a relationship between two legal actors that gives rise to legal consequences, such as seller-buyer. The concept originally limited the reach of strict liability to those consumers or users who had actually purchased the defective goods, as opposed to their friends or relatives. With some infrequent exceptions, it no longer is significant in the law of strict liability. See Restatement $\$ 402 \mathrm{~A}$, cmt. 1; William L. Prosser, The Fall of the Citadel, 50 Minn. L. Rev. 791 (1966).

207 Brochu v. Ortho Pharmaceutical Corp., 642 F.2d 652, 655 (1st Cir. 1981).

${ }^{208}$ E.g. Basko v. Sterling Drug, Inc., 416 F.2d 417, 426 (2d Cir. 1969); Sterling Drug, Inc. v. Cornish, 370 F.2d 82, 85 (8th Cir. 1966); Grundberg v. Upjohn Co., 813 P.2d 89, 97 (Utah 1991). 209 See, e.g., Ezagui v. Dow Chem. Co., 598 F.2d 727 (2d Cir. 1979). 
ufacturing flaws (such as impurities) and to a negligent failure to warn of those risks that were foreseeable at the time the product was distributed. ${ }^{210}$

Under Comment $\mathbf{k}$, if proper warnings are provided, no liability will attach to the seller if the product is "unavoidably unsafe."

[S]ome products . . . in the present state of human knowledge are quite incapable of being made safe for their intended and ordinary use. These are especially common in the field of drugs .... [This is] true in particular of many new or experimental drugs as to which, because of lack of time and opportunity for sufficient medical experience, there can be no assurance of safety .... .

So, for example, if a child contracts polio from oral Sabin vaccine, the manufacturer of that vaccine will be protected from liability if physicians received adequate warnings of that risk, because the legitimate public interest in the vaccine's availability outweighs the potential harmful effects of the product. ${ }^{211}$

How does one judge the adequacy of a necessary warning? Like the analogous question of the adequacy of the information required to secure valid informed consent to a medical procedure, ${ }^{212}$ this question is intensely fact-dependent, but certain general principles apply. The warnings must be accurate in content and conveyed through an appropriate means and style of communication. ${ }^{213}$ The seller's duty to warn is limited to those risks which were reasonably foreseeable at the time that the drug was prescribed and used. There is no duty to warn of unknown, unforeseeable, or "possible" risks. ${ }^{214}$ However, if the seller realizes that its knowledge of potential adverse effects is limited, it should at least warn the consumer that the product is experimental and may present unknown hazards. ${ }^{215}$

It has been argued that compliance with the FDA minimum requirements with respect to labelling ought to preclude claims that the warnings provided by a drug manufacturer are insufficient. ${ }^{216}$ That concept has largely been

210 Some courts have deemed all prescription drugs, by definition, in this category. See, e.g., Brown v. Superior Court San Francisco County, 751 P.2d 470 (Cal. 1988). Other courts believe that this assessment should be made on a case-by-case basis, considering the real value of and need for marketing of the drug. See, e.g., Hill v. Searle Labs., 884 F.2d 1064 (8th Cir. 1989); Kociemba v. G.D. Searle \& Co., 695 F. Supp. 432 (D. Minn. 1988); Collins v. Eli Lilly \& Co., 342 N.W.2d 37, 52 (Wis.), cert. denied, 469 U.S. 826 (1984).

211 See, e.g., Givens v. Lederle, 556 F.2d 1341 (5th Cir. 1977) (strict liability imposed for failure to warn pediatrician of risk of vaccine-induced polio); Niemiera v. Schneider, 555 A.2d 1112 (N.J. 1989) (sufficient to warn physician of risk of convulsions from DPT vaccine). Compare Davis v. Wyeth Labs., Inc., 399 F.2d 121 (9th Cir. 1968) (necessary to warn consumers of risk because drug administered in a mass vaccination program without the "learned intermediary" of the physician); accord Reyes v. Wyeth Labs., Inc., 498 F.2d 1264 (5th Cir.), cert. denied, 419 U.S. 1096 (1974).

212 See, e.g., Cobbs v. Grant, 502 P.2d 1 (Cal. 1972).

219 See, e.g., Sterling Drug, Inc. v. Yarrow, 408 F.2d 978 (8th Cir. 1969) (unreasonable to fail to instruct "detail men" (sales representatives) who regularly saw prescribing physicians to warn them about drug risks).

214 See, e.g., Doe v. Miles Labs., Inc., 927 F.2d 187, 194-95 (4th Cir. 1991); O'Hare v. Merck \& Co., 381 F.2d 286 (8th Cir. 1967).

215 Singer v. Sterling Drug, Inc., 461 F.2d 288 (7th Cir.), cert. denied, 409 U.S. 878 (1972).

216 See, e.g., Chambers v. G.D. Searle \& Co., 441 F. Supp. 377, 383 (D. Md. 1975), affd, 567 F.2d 269 (4th Cir. 1977) (per curiam). 
rejected with respect to drug manufacturer liability, as it has been with respect to other tort claims based on conduct that met federal regulatory standards, but which a community jury found unreasonably dangerous or negligent. ${ }^{217}$

iii. The duty to test

Could a woman try to establish liability on the part of pharmaceutical manufacturers for their failure to research the specific effects on women of their products?

The law offers two sources of responsibility for adequate testing of pharmaceutical products. First, federal law and Food and Drug Administration regulations require that a New Drug Application demonstrate "adequate, and well-controlled investigations, including clinical investigations . . ."218 and "data demonstrating substantial evidence of effectiveness for the claimed indications,"219 Second, it has long been recognized that the obligation to adequately test drugs before beginning to profit from their marketing can be grounded not only in the FDA's regulations, but in basic tort law principles. Beginning with the debacle of MER/29, the Richardson-Merrell anticholesterol product that blinded many people because the company failed to pursue ocular abnormalities in animals, ${ }^{220}$ courts have penalized companies that do not conduct reasonable testing to determine the potential adverse reactions of their products, even if the testing involved was not required by the FDA. ${ }^{221}$

The most stark cases, of course, have involved deliberate disregard of suggestive data, such as reports from clinicians or in the medical literature. ${ }^{222}$ But even less compelling information, such as indications of a disparate occurrence of an adverse effect in one particular subpopulation of foreseeable users, has been held sufficient to trigger an obligation to conduct further research "reasonably necessary to render the product safe for its users."223

217 See, e.g., Salmon v. Parke, Davis \& Co., 520 F.2d 1359, 1362, 1364 (4th Cir. 1975); Mazur v. Merck \& Co., Inc., 742 F. Supp. 239 (E.D. Pa. 1990); In re Tetracycline Cases, 747 F. Supp 543, 550 (W.D. Mo. 1989); Shanks v. Upjohn Co., 835 P.2d 1189, 1197-98 (Alaska 1992); see also Cipollone v. Liggett Group, Inc., 112 S.Ct. 2608 (1992) (not all failure-to-warn and design defect claims against tobacco manufacturers preempted by federal statutes regulating cigarette advertising and promotion); Silkwood v. Kerr-McGee Corp., 464 U.S. 238, 251 (1984) (federal nuclear safety regulations do not preempt state punitive damage awards).

21821 U.S.C. $\$ 355$ (b)(l)(A) (1988).

21921 C.F.R. $\$ 314.50(\mathrm{~d})(5)(\mathrm{v})(1993)$.

220 Toole v. Richardson-Merrell, Inc., 60 Cal. Rptr. 398 (Ct. App. 1967).

221 Barson v. E.R. Squibb \& Sons, Inc., 682 P.2d 832 (Utah 1984) (manufacturer negligent in not testing for teratogenic effects of injected progestational hormone); see also West v. Johnson \& Johnson Prods., Inc., 220 Cal. Rptr. 437, 448 (Ct. App. 1985) (failure of tampon manufacturer to study the basic microbiology of the human vagina, to test for vaginal infections, and - of particular interest - to include women with a history of vaginitis in the human studies), cert. denied, 479 U.S. 824 (1986).

222 See, e.g., Wooderson v. Ortho Pharmaceutical Corp., 681 P.2d 1038, 1063-64 (Kan. 1984), cert. denied, 469 U.S. 965 (1984) (sustaining award of punitive damages to victim of hemolytic uremic syndrome from oral contraceptive because of Ortho's failure to do further animal research after independent researcher reported finding lesions in vessel walls of autopsied women taking oral contraceptives).

223 Taylor v. Wyeth Labs., 362 N.W.2d 293, 296-97 (Mich. App. 1984) (even absent any study, prudent manufacturer would have explored relationship between blood type and blood- 
"Testing procedures should simulate as closely as possible the anticipated conditions of marketing and use of the product."224 If a product is intended for long-term use, for example, testing it in trials that are short-term and therefore fail to detect a side effect like retinal damage may well subject the manufacturer to liability. ${ }^{225}$ Courts have engaged in quite close scrutiny of the research design of clinical trials and criticized them not only for unreliable technique and sloppy data handling, but for their lack of relevance to actual market conditions. ${ }^{226}$ The FDA's own regulations, too, specifically state that "evidence is also required to support the dosage and administration section of the labeling, and modifications for specific subgroups (for example, pediatrics, geriatrics, patients with renal failure)"'227 and "if evidence is available to support the safety and effectiveness of the drug only in selected subgroups of the larger population with the disease .... the labeling shall describe the available evidence and state the limitations of the usefulness of the drug."228

Thus it would seem that the conscious choice of drug companies to confine their pre-marketing clinical trials to a population quite unrepresentative of their ultimate consumers may invite even more litigation from women (or the elderly, or people of color) injured because of the research not done than could be expected from the decision to include women in trials and any consequential harm to their offspring. ${ }^{229}$

This is a day of synthetic living, when to an ever-increasing extent our population is dependent upon mass producers for its food and drink, its cures and complexions, its apparel and gadgets. These no longer are natural or simple products but complex ones whose composition and qualities are often secret. Such a dependent society must exact greater care than in more simple days and must require from manufacturers or producers increased integrity and caution as the only protection of its safety and well-being. Purchasers cannot try out drugs to determine whether they kill or cure. . . Where experiment or research is necessary to determine the presence or the degree of danger, the product must not be tried out on the public, nor must the public be expected to possess the facilities or the tech-

clotting risk in women taking oral contraceptives, once aware that women with type A blood experience disproportionate number of pulmonary embolisms).

2242 Marden G. Dixon \& Frank C. Woodside III, Drug Product Liability 14-68 (1991). 225 Hoffman v. Sterling Drug, Inc., 485 F.2d 132, 140-41 (3d Cir. 1973).

226 See, e.g., Tinnerholm v. Parke, Davis \& Co., 285 F. Supp. 432, 448 (S.D.N.Y. 1968), modified on other grounds, 411 F.2d 48 (2d Cir. 1969) (upholding negligence claim of child catastrophically injured by Quadrigen vaccine [subsequently withdrawn by the manufacturer] because vaccine "rushed to commercialization" without testing under market conditions).

22721 C.F.R. $\$ 314.50(5)(v)(1993)$.

22821 C.F.R. $\$ 201.57$ (c)(3)(i) (1993).

229 I was pleased to find that Ellen Flannery, partner in Covington and Burling in Washington, D.C., and a leader of the private pharmaceutical and medical device bar, concurs in this assessment of possible liability risk. "Drug manufacturers will likely find it increasingly difficult to prove that all-male studies of many drug products constitute state-of-the-art testing. There is growing recognition that the physiological differences between men and women make it scientifically inadequate in many instances to conduct clinical tests or epidemiological studies using only male subjects." Ellen Flannery \& Sanford N. Greenberg, Liability Exposure for Exclusion and Inclusion of Women as Subjects in Clinical Studies 9 (Mar. 11, 1993) (unpublished paper on file with author). 
nical knowledge to learn for itself of inherent but latent dangers. ${ }^{230}$

In Jones v. Ortho Pharmaceutical Corp., ${ }^{23 !}$ Cinderella Jones attempted to hold the defendant manufacturer liable for its failure to conduct clinical trials that could have established whether its combination sequential birth control pill, Ortho Novum SQ (since ordered off the market by the FDA), may have contributed to her development of cervical carcinoma in situ. Plaintiff relied on the theory that 21 C.F.R. $\$ 314.1$ (c)(12)(c) required Ortho to provide "adequate information" consisting of reports "of an adequate number of subjects, designed to record observations and permit evaluation of any and all discernable effects attributable to the drug . . . ." Essentially, her argument was that the company's failure to investigate this potential risk made it impossible for her to establish the causal link that would sustain her underlying claim for the cancer, and that therefore the burden to demonstrate the causal connection between the drug and her cancer should be considered presumptively met, subject to rebuttal from the company. ${ }^{232}$

The California intermediate appellate court dismissed Jones' ingenious strategy in short order, but it does have a certain logic. It is not realistic for injured individuals to undertake the kind of epidemiological or clinical research that is required to meet the heavy burden of proving the element, necessary to any recovery, of causation-in-fact: that it is more probable than not that the defendant's product was a substantial factor in the plaintiff's injury. Generally, drug manufacturers will be in a far better position to research the issue, at least in the negative sense of proving that few or no adverse experience reports attributing a similar problem to the drug have been submitted. ${ }^{233}$

Of the relatively few tort complaints that have attempted to hold drug companies responsible for harm on a theory of insufficient research, most focus their pleadings on the manufacturer's failure to warn of risks that it would have known about, had proper clinical research been conducted, rather than on the failure to test per se. That is, the manufacturer lacks information that could and should have been transmitted to the consumer (who in the case of prescription drugs is considered to be the prescribing physician) because it failed to conduct the research that would have developed that information.

Regardless of the legal rubric, however, the point is that occasionally

230 Dalehite v. United States, 346 U.S. 15, $51-52$ (1953) (Jackson, J., dissenting).

231209 Cal. Rptr. 456 (Ct. App. 1985).

232 This concept was derived from an accepted principle of tort law, enunciated in Haft $v$. Lone Palm Hotel, 478 P.2d 465 (Cal. App. 1970): when there is a substantial probability that a defendant's negligence caused plaintiff's injury, and when that negligence makes it impossible as a practical matter for the plaintiff to prove causation (in $\mathrm{Haft}$, it was the hotel's failure to provide a lifeguard at its pool, which meant there were no witnesses to the plaintiff's decedent's drowning), it is appropriate to shift the burden of proof from the plaintiff to establish causation to the defendant to disprove it.

239 Once a product is on the market and being prescribed, all testing can stop. To detect statistically rare outcomes, we rely entirely on the voluntary submission of Adverse Drug Experience Reports from physicians. Unfortunately, clinicians have nothing to gain but altruistic satisfaction from submitting these reports. They have to lose, at minimum, the time spent shuffling paper. At worst, they, as well as the pharmaceutical houses, may be implicated in a medical negligence action. The post-marketing surveillance program has been notoriously lax and spotty. 
drug companies face liability for not doing research. There is no obvious reason why this principle cannot be extended and applied to their failure to conduct research in women, including pregnant women, that would have revealed the specific risks which ultimately appeared in the female population when the drug was approved and became generally available.

The catch-22 of this element of the analysis is that it is only even theoretically applicable to those rampant harms that will become visible despite a lack of well-organized data collection. Less common adverse outcomes due to the inadequately researched drug may well occur, but their increased incidence may not be detectable against background levels without the rigorous data collection and biostatistical analysis characteristic of a well-run clinical trial. And even if highly persuasive evidence of adverse outcomes does emerge, it will still be difficult to establish the kind of causal link between the drug and the event necessary for legal action. As Cinderella Jones tried to argue, no one but the company itself has the resources and the interest to conduct postmarketing research on an approved product, and the company is hardly likely to invest in epidemiological or controlled studies that may reveal a genuine systematic problem, if instead it can dismiss whatever evidence has emerged as "anecdotal," "meaningless coincidental clusters," and the like.

The next hurdle would be to demonstrate that had the research been done and the information developed, this particular plaintiff (or plaintiff's physician) would have decided not to use the drug, and thereby been spared the harm. Obviously, if people had received the information about a risk, but still would have used the medication, the cause of their injury is not the company's failure to test or to warn.

Convincing a court to impose liability for failure to test drugs in pregnable and pregnant women will be a challenge and will be rare. My point here is to open up discussion of alternative sources of liability that research sponsors seem disinclined to consider.

\section{(b) Another basis for researcher liability: gender discrimination}

The Fifth and Fourteenth Amendments to the United States Constitution require that governmental actors refrain from denying "equal protection of the laws" to individuals because of their membership in what has been dubbed a "protected class" - usually an unchosen and immutable status that is legally irrelevant, such as race, ethnicity, or gender. ${ }^{234}$ In addition, gender discrimination in the private sector (with some overlap in the public sector) is

234 The Supreme Court did not establish this proposition with respect to gender until 1971. See Reed v. Reed, 404 U.S. 71 (1971). Five years later, it formulated the test for legitimate government differentiation on the basis of gender: "[C]lassifications by gender must serve important governmental objectives and must be substantially related to the achievement of those objectives." Craig v. Boren, 429 U.S. 190, 197 (1976). More recently, the test was reformulated to require "exceedingly persuasive justification" for the differentiation. Mississippi Univ. for Women v. Hogan, 458 U.S. 718, 724 (1982). But see Personnel Admin. Mass. v. Feeney, 442 U.S. 256 (1979) (if government action gender-neutral on its face, despite discriminatory results of its application, must demonstrate that discrimination is intentional to find Constitutional violation).

Many state constitutions also include Equal Protection provisions that may be interpreted more broadly than the federal clause. See, e.g., People v. Davis, 537 N.Y.S.2d 430, 434 (Sup. Ct. 1988). 
prohibited, or perhaps more accurately put, regulated by federal, state, and local enactments such as Titles VI and VII of the Civil Rights Act of 1964, 42 U.S.C. $\$ 2000 \mathrm{e}$. In addition, under the federal statute, "women affected by pregnancy, childbirth, or related medical conditions shall be treated the same for all employment-related purposes . . . as other persons not so affected but similar in their ability or inability to work . . . ."235

Could the refusal to include women and/or pregnant women in a protocol be considered illegal discrimination? In the rare circumstance that subjects are paid and their participation in research can be fairly characterized as a form of employment, ${ }^{236}$ it almost certainly could, and that protection would extend to pregnant women. ${ }^{237}$

With respect to protocols sponsored and conducted by governmental entities, the answer is probably also yes, both under the federal Equal Protection Clause and under most state antidiscrimination statutes which typically apply to discrimination not only in employment but in "places of public accommodation" - settings where goods or services are generally provided to the public on a first-come, first-served basis. ${ }^{238}$ Not only clinics and hospitals, but private doctors and dentists, have been so categorized and found guilty of discrimination for denying health care to patients on the basis of a protected status. ${ }^{239}$ While federal funding or federal regulation do not always suffice to

23542 U.S.C. $\$ 2000 \mathrm{e}(\mathrm{k})$ (1978). Outside the realm of Title VII, however, some courts have found that differential treatment of women because of their capacity to become pregnant is not an impermissible gender-based classification. See, e.g., Michael M. v. Superior Court, 450 U.S. 464 (1981) (upholding statutory rape statute applicable only to males because of state interest in limiting illegitimate pregnancies); Toomey v. Clark, 876 F.2d 1433 (9th Cir. 1989) (no violation of Equal Protection by state juvenile court's consideration of defendant's pregnancy in decision to waive jurisdiction and permit prosecution as an adult); United States v. Flores, 540 F.2d 432, 438 (9th Cir. 1976) (court may consider pregnancy in sentencing). It may be worthy of note that all these decisions involve criminal law and prosecution.

236 If we are talking about a nonpublic entity not subject to Constitutional standards, then only "employers" according to the statutory definition - employing more than a certain number of people, for example - would be covered.

237 Pregnancy discrimination in employment may also be covered by state anti-discrimination statutes. See, e.g., New York City Transit Auth. v. State Div. of Human Rights, 577 N.E.2d 40 (N.Y. 1991). Outside the employment context, discrimination based on pregnancy may not be deemed gender discrimination that violates the Equal Protection clause. Geduldig v. Aiello, 417 U.S. 484, $497 \mathrm{n} .20$ (1974) (permitting insurance system to distinguish between pregnant women and "nonpregnant persons"). Within the employment arena, courts must accept as defenses that may defeat discrimination claims, "bona fide occupational qualification" and "business necessity." Without elaborating on these complex legal doctrines, both permit differential treatment of men and women in the workplace upon a convincing argument that it is "necessary." E.g., Dothard v. Rawlinson, 433 U.S. 321 (1977).

238 E.g., N.Y. Exec. Law $\$$ 296(2)(a) (McKinney 1993):

It shall be an unlawful discriminatory practice for any person, being the owner, lessee, proprietor, manager, superintendent, agent or employee of any place of public accommodation ... because of the ... sex ... of any person, directly or indirectly, to refuse, withhold from or deny to such person any of the accommodations, advantages, facilities, or privileges thereof . . . .

Remarkably, the public accommodations provision of the federal civil rights law, 42 U.S.C. $\$ 2000$ a, does not apply to discrimination on the basis of gender. Seidenberg v. McSorley's Old Ale House, Inc., 308 F. Supp. 1253 (S.D.N.Y. 1969).

239 The most common recent context of these decisions has been the refusal of some healthcare providers to treat people with HIV infection. See, e.g., Doe v. Jamaica Hosp., N.Y.L.J., May 6, 
convert a private entity into a "state actor" for equal protection purposes, 240 or to subject a state or local agency to federal anti-discrimination statutes, ${ }^{241}$ a substantial share of the health science research dollar is derived directly from taxpayer funds, ${ }^{242}$ and thus legal (as well as moral) prohibitions on gender discrimination ought to apply. Research supported by NIH and ADAMHA contracts should have to adhere to Constitutional and statutory standards. ${ }^{243}$ But even in trials conducted in the private sector, in settings that clearly are neither places of public accommodation nor employment, where the choice of excluding potentially pregnable women is the result of the FDA and DHHS restrictions on conducting research with women of childbearing potential and/or pregnant women, arguably both those policies and the resulting exclusion from trial may be subject to an Equal Protection clause attack.

In that situation, even were it conceded that governmental policy may validly seek to protect the reproductive capacity of research subjects and/or the welfare of their potential offspring, exclusion only of women would fail the Craig $v$. Boren test ${ }^{244}$ of substantial relationship between means and ends. Women and men are similarly situated, in the language of the law, with respect to their genetic contribution to their offspring. As for pregnant women in a trial that may be teratogenic or fetotoxic, unless the research sponsor or the government can show that male subjects and their offspring are immune to any adverse effects of equal gravity of the intervention on trial - which hardly seems possible with the limited data now available - the equal protec-

1991, at 27 (alleged exclusion of HIV-infected pregnant woman from hospital's high-risk prenatal care unit could violate public accommodation section of New York Human Rights Law); Estate of Campanella v. Hurwitz, New York City Comm'n on Hum. Rights, July 31, 1991 (private dentist's office a place of public accommodation under New York City Human Rights Law). But see In re Sattler, 580 N.Y.S.2d 35 (App. Div.), appeal denied, 610 N.E.2d 388 (N.Y. 1992) ("one-chair" dental practice not a place of public accommodation under New York City Human Rights Law). The clear definition of public accommodation in the Americans with Disabilities Act, may, ironically, support a less expansive interpretation of the less clear provisions of some gender discrimination laws. 42 U.S.C. $\$ 12181$ (7)(F) (Supp. III 1991).

While a few state statutes do expressly state that places of public accommodation may serve only men or only women if the place "is in its nature reasonably restricted exclusively to individuals of one sex," e.g., N.J. Stat. ANN. $\$ 10: 5-12(f)$ (West 1992), it is hard to see how research protocols could meet that standard. The controversy over gender discrimination in private clubs has also spawned the concept of a place of apparent public accommodation that is deemed "distinctly private" and therefore exempt from the statute. See, e.g., United States Power Squadrons v. State Human Rights Appeal Bd., 452 N.E.2d 1192, 1204 (N.Y. 1983). But few settings that would be conducting a research protocol would qualify as anything like a private club.

240 See, e.g., Rendell-Baker v. Kohn, 457 U.S. 830, 840-42 (1982); Stanturf v. Sipes, 224 F. Supp. 883, 890 (W.D. Mo. 1963), aff d, 335 F.2d 224 (8th Cir. 1964), cert. denied, 379 U.S. 977 (1965).

241 Note that the federal statute, Title VI of the Civil Rights Act, does not prohibit gender discrimination in programs and activities receiving federal financial assistance. 42 U.S.C. $\S 2000 \mathrm{~d}(1988)$.

242 Of the almost $\$ 10$ billion devoted to health sciences research and development in the U.S. in fiscal year 1991, 78\% was dispensed by the federal agencies NIH and ADAMHA (Alcohol, Drug Abuse, and Mental Health Administration). Two-thirds of that sum was contracted out to private academic institutions. Funding Health Sciences Research, supra note 15 at 35, 77, 79.

249 Compare West v. Atkins, 487 U.S. 42 (1988) (prison doctors acting under contract to care for inmates are state actors).

244429 U.S. 190, 197 (1976); see supra note 234 for a description of the test. 


\section{tion claim must stand. ${ }^{245}$}

As I will discuss later with respect to the limitations of the current NIH antidiscrimination policy now codified in the NIH Revitalization Act, ${ }^{246}$ there is a significant risk that a male-dominated judicial system will accept too unskeptically the "scientific" rationale for exclusion of women from research, especially in view of judges' characteristic deference to the "professional judgment" of physicians and scientists. ${ }^{247}$ It will be more difficult, however, to support research subject discrimination (especially when subjects may be considered employees) on the "fear of liability" rationale in light of the Supreme Court's almost wholesale rejection of that rationale in the 1991 Johnson Controls decision. ${ }^{248}$

245 It should also be noted that many state courts have interpreted their own constitutions to offer greater protection of individual liberty than the United States Constitution offers in view of the present federal bench. See, e.g. , Committee to Defend Reprod. Rights v. Myers, 625 P.2d 779, 799 (Cal. 1981) (California Constitution prohibits Medi-Cal exclusion of reimbursement for abortions); In re T.W., 551 So. 2d 1186, $1192-93$ (Fla. 1989) (Florida Constitution prohibits requirement of parental consent to minor's abortion); Doe v. Director of Dep't of Social Servs., 468 N.W.2d 862, 869 (Mich. Ct. App. 1991) (Michigan Constitution prohibits Medicaid exclusion of coverage for abortions not necessary to save mother's life), rev'd, 487 N.W.2d 166 (1992).

246 National Institutes of Health Revitalization Act of 1993, 42 U.S.C.A. $§ 201$ (West Supp. 1993); see infra text accompanying note 276.

247 See, e.g., Youngberg v. Romeo, 457 U.S. 307, 323 (1982) (decisions about adequacy of care of developmentally disabled in state institutions "presumptively valid if made by a professional"); Parham v. J.R., 442 U.S. 584 (1979) (no need for due process protections for children committed to mental hospitals by their parents or by the State, since admission decision made by team of mental health professionals).

248 Int'l Union, United Auto., Aerospace and Agric. Implement Workers of Am., v. Johnson Controls, Inc., 499 U.S. 187, 207 (1991). Because of its.significance in this area, and because the issuance of this decision from this Supreme Court was frankly amazing to most opponents of gender bias, Johnson Controls merits some extended discussion.

The management policy challenged was quite typical of the fetal protection policies adopted by dozens of major American corporate employers. See Elaine Draper, Risky Business 200 n.13 (1991) (study of 198 large chemical and electronic companies in Massachusetts found nearly one in five - 37 companies - restricted women's work options on the ground of potential fetal risk, while ignoring male reproductive hazards). Johnson Controls had never hired women on its production line before the Civil Rights Act of 1964 outlawed patent sex discrimination. Initially, its policy was to inform women workers about the known risks of lead exposure during pregnancy and to tell parents (of both genders) that they were responsible for the health of their unborn children. In 1982, it revamped its policy to mandate exclusion of all fertile females from jobs that would expose them to certain levels of lead. As a result, at least one female worker was sterilized. She, along with a $\mathbf{5 0}$ year-old divorced female employee who had been involuntarily transferred to a lower-paying job, and a male employee who was denied an unpaid leave of absence prior to becoming a father, charged that Johnson Controls had violated Title VII. 499 U.S. at 192.

The Supreme Court found this policy biased against women. Id. at 199-00. To justify "facial" discrimination - a policy that on its face treats women differently from similarly situated men - an employer must show a "bona fide occupational qualification, reasonably necessary to the normal operation of the business or enterprise (BFOQ)." Id. at 200-03. While injury to a potential fetus is a "deep social concern," the safety of an employee's offspring is not an essential component of that employee's ability to do the job: pregnant women have the same skills and aptitudes for the Johnson Controls jobs as nonpregnant employees. "Decisions about the welfare of future children must be left to the parents who conceive, bear, support and raise them rather than to the employers who hire those parents." Id. at 206.

The Court was not unmindful of the liability concerns that had been raised by Johnson as a defense. Id. at 208-09. Acknowledging the risk of lawsuits for prenatal injury, the Court majority stated that employers who adhere to OSHA standards (provide blood tests, proper ventilation, 
It is important to stress that my argument does not depend on the notion of a "right" to become a research subject. However, even though no one has a "right" to hold a particular job or to live in a particular apartment or to attend a particular school, discrimination in employment, housing and education against members of protected groups still can be prohibited. An individual may have no "right" to sit as a juror in a particular case, yet have a right not to be excluded from the venire. ${ }^{249}$ An individual woman may not be able to insist on access to a particular protocol, but that does not legitimize the wholesale exclusion of all women. The claim here would be very similar to the denial of an "opportunity to compete." 250

Would a pregnant woman also be able to utilize these anti-discrimination statutes? Well, on the federal level, the policy embodied in the Pregnancy Discrimination Act, ${ }^{251}$ which rejected the Supreme Court's absurd dichotomization of pregnant women and nonpregnant people in Geduldig v. Aiello, ${ }^{252}$ strongly supports an affirmative conclusion. While the Pregnancy Discrimination Act is limited to protection of employment rights, its analysis ought to hold in this context. Any other stance inevitably reduces pregnant women to the status of "fetal container." 253 State statutes also offer protection against

safety equipment, etc.) should face no liability. Id. In concurrence, Justice White noted that OSHA compliance is not always a defense to tort liability; that parents can't waive their children's claims and that parental negligence can't be imputed to children; and that strict liability, rather than negligence, might in fact become the basis for successful legal action in some instances. Id. at 213-14. Nonetheless, he did not deem this possibility of future liability a sufficient counterweight to the protected interest of women in equal treatment, and the majority responded that the incremental cost of hiring women was not so high as to "threaten survival of the employer's business." Id. at 210-11.

As I try to show here, given the sources of potential liability that remain even if researchers continue to exclude women subjects, the incremental cost of the necessary insurance or self-insurance likewise does not "threaten survival" of the research enterprise.

For a less rosy view of Johnson Controls, and a persuasive argument that it represents a "limited" and perhaps "short-lived" victory for women, see Jennifer Morton, Comment, Pregnancy in the Workplace - Sex-Specific Fetal Protection Policies - U.A.W. v. Johnson Controls, Inc. - A Victory for Women?, 59 TENN. L. REv. 617,634 \& passim (1992) (noting that several concurring Justices would uphold sex-specific fetal protection policy based on employer's concern for potential fetus, and/ or (in dicta) extra costs associated with employing women, and Justice Marshall's replacement by Justice Thomas subsequent to this decision).

249 See J.E.B. v. Alabama ex rel. T.B., 1994 WL 132232 (Apr. 19, 1994); Taylor v. Louisiana, 419 U.S. 522 (1973); Strauder v. West Virginia, 100 U.S. 303, 308 (1879); see also Batson v. Kentucky, 476 U.S. 79, 87 (1986); U.S. v. DeGross, 913 F.2d 1417, 1420-23 (9th Cir. 1990).

250 Shurberg Broadcasting of Hartford v. F.C.C., 876 F.2d 902, 917 (D.C. Cir. 1989); see also Carol Levine, Has AIDS Changed the Ethics of Human Subjects Research?, 16 L. MED. \& HealTh Care 167, 172 (1988):

[I]f there is a right to be a research subject, and again that is arguable, it is not a general right to enter whatever trial one may choose but the right to be offered an equal opportunity to be considered for all trials that are appropriate, given one's medical condition and other scientifically relevant characteristics.

My partial rejection of Levine's analysis in this piece stems from my inability to muster much confidence in the use of terms such as "appropriate" and "scientifically relevant."

25142 U.S.C. $\$ 2000 \mathrm{e}(\mathrm{k})$ (1978).

252417 U.S. 484 (1974). Geduldig's "continuing vitality" has recently been reaffirmed by the Court. Bray v. Alexandria Women's Health Clinic, 113 S. Ct. 759, 760 n.3 (1993).

253 George Annas, Protecting the Liberty of Pregnant Patients, 316 New Enc. J. Med. 1213, 1214 (1987). For full development of this contention see Merton, Ethical Obstacles, supra note 79. 
policy or action that "singles out pregnant women for [different] treatment ... solely because they are pregnant." 254

\section{(c) Institutional Review Board Liability for failure to ensure "equitable selection of subjects"}

Another legal avenue for challenging the exclusion of women is more indirect. Since the mid-seventies, Federal ${ }^{255}$ and in some jurisdictions state $^{256}$ law requires that virtually all ${ }^{257}$ human subjects research be conducted only after protocol review and approval by entities called institutional review boards ("IRBs"), which must include a few non-scientists and community representatives who are independent of the entity conducting the research. ${ }^{258}$ The responsibilities of these boards include assuring the informed consent of subjects and a reasonable risk-benefit ratio of potential harm to subjects and the potential value of the research; and, most germane to the present discussion, enforcing the federal regulatory and general ethical mandate for the equitable selection of subjects. ${ }^{259}$

254 Elaine W. v. Joint Diseases North General Hosp., Inc., 613 N.E.2d 523, 525 (N.Y. 1993).

25542 U.S.C. \& $2891-3$ (1974).

256 See, e.g., N.Y. Pub. Health Law $\$ 2444$ (Consol. 1987) (Protection of Human Subjects). This statute largely tracks the National Research Act of 1974, Pub. L. No. 93-348, 88 Stat. 852 (codified as amended in scattered sections of 42 U.S.C.), but it does not explicitly require the "human research review committees" it mandates to seek equitable selection of subjects.

257 Initially the National Research Act mandate applied not only to research done with federal funds but to all research conducted at or sponsored by an institution receiving federal funds. 45 C.F.R. $\$ 46.101$ (a) (1977). The original regulations of the Secretary of the Department of Health, Education and Welfare specifically limited the requirement of IRB review to "activities supported under grants or contracts from DHEW." 45 C.F.R. $\$ 46.102$ (a) (1977). The requirement of IRB review now applies to all research "conducted, supported, or otherwise subject to regulation by any federal department or agency" that has adopted the new Federal Policy for the Protection of Human Subjects. 56 Fed. Reg. 28,002, 28,012 (1991). In practice, most institutions that receive any federal funds (and most research institutions do) review all protocols through the same process and generally do not differentiate those that are federally funded. Note, however, that the New York state law, for example, applies to all research conducted in the state, regardless of funding source. N.Y. Pub. Health Law $\$ 2444$ (Consol. 1987).

258 See, e.g., 45 C.F.R. $\$ 46.107$ (b) (1992). See generally Robert A. Greenwald et Al., Human Subjects Research: A Handbook for Institutional Review Boards (1982); Levine, Ethics and Regulation, supra note 22, at 321-28. Interestingly enough, the original flat requirement that an IRB could not consist entirely of one gender has been revised to mandate merely "every nondiscriminatory effort to ensure" that no IRB consists entirely of men or women. See 45 C.F.R. $\$ 46.107$ (1992). From the perspective of the role IRBs could play in changing exclusionary research practice, this seems an unfortunate and unnecessary regression.

${ }^{259}$ Federal regulations have always required IRBs to determine that "selection of subjects is equitable," taking into account the purposes of the research and the setting in which it will be conducted. See, e.g., 45 C.F.R. \$ 46.111(a)(3) (1992). A provision added to section 46.111 of the Federal Policy for the Protection of Human Subjects, "Criteria for the Approval of Research," requires IRBs to be "particularly cognizant of the special problems of research involving vulnerable populations, such as children, prisoners, pregnant women, mentally disabled persons, or economically or educationally disadvantaged persons" and to ensure additional safeguards to protect the rights and welfare of these "subjects . . . likely to be vulnerable to coercion or undue influence." See also the parallel provision of the Food and Drug Administration at 56 Fed. Reg. 28,029 (1991).

The good news is that this new provision suggests that pregnant women can be research subjects; the bad news is that it defines them as inherently vulnerable, requiring special protec- 
It is not impossible to imagine an excluded potential subject seeking redress not only from the researcher (who may be shielded from liability on various grounds), but also from the IRB members. "IRB members may be personally liable to subjects and investigators for 'malpractice' or negligence in discharging their IRB functions."260 While most lawsuits against IRBs, and there have not been many, have involved challenges to their approval of inclusion of vulnerable subjects, ${ }^{261}$ that is merely an artifact. In theory there is no reason why violation of their legal duty to ensure the equitable selection of subjects by approving unjustified exclusionary criteria would not be just as actionable.

The greatest hurdle for a plaintiff would be proving the indispensable element of "causation" - that is, but for the IRB's failure to require more inclusive subject selection, the plaintiff would have entered the protocol and as a result, benefited either from the innovation on trial or merely from the superior care and monitoring that subject status may entail. ${ }^{262}$ Courts might be quite reluctant to find foreseeable benefit from the innovation itself after all, the myth of the null hypothesis endures. ${ }^{263}$ They would be harderpressed, however, to reject as a matter of law the claim that a plaintiff had lost something of value when access to a trial was denied because the IRB permitted unjustified exclusionary criteria to stand. Even if the would-be subject could not establish that she definitely would have been among the chosen, the law increasingly recognizes the concept of "loss of a chance"264 as compensable harm. Plaintiffs who cannot show that they definitely would have recovered from cancer if diagnosed earlier, for example, can still recover for loss of a significant chance of remission from the physician who negligently missed the diagnosis. ${ }^{265}$

tions from and raising special "problems" for researchers. This is not the place, but the implications and premises of this provision warrant more examination.

260 National Commission for the Protection of Human Subjects of Biomedical and Behavioral Research, Report and Recommendations: InStitutional. ReVIEW BoARds 82 (1978); see also Greenwald et al., supra note 258, at 25. For a different view, see Angela $R$. Holder, Liability and the IRB Member: The legal aspects, IRB: Rev. Hum. Subjects Res., June-July 1979, at 7.

261 Purcell v. Zimbelman, 500 P.2d 335 (Ariz. 1972); Nielsen v. Regents of the Univ. of Cal., Civ. No. 665-049 (Sup. Ct. Cal. Cty. of San Francisco, Sept. 11, 1973); Bailey v. Mandel, Civ. No. K-74-1 10 (D.C. M.D. 1974); see also Mason v. Institutional Review Bd. for Human Research, Medical Univ, of S.C., 953 F.2d 638 (4th Cir. 1992) (seeking injunctive relief to compel IRB to continue terminated protocol); Head v. Colloton, 331 N.W.2d 870 (Iowa 1983) (seeking injunctive relief to compel amendment of a protocol, but not with regard to selection of subjects). Recently, a Quebec court held not only the investigator and the hospital, but the hospital's research committee (the functional equivalent of an IRB) responsible for the death of a research subject due to cardiac arrest after fluorescein angiography. Weiss v. Solomon, R.J.Q. 731 (1989). The court suggested that the Research Committee had failed, among other things, to insist on adequate screening of subjects for the kind of cardiomyopathy that made this subject especially at risk for this procedure. (1978).

262 See John Robertson, The Law of Institutional Review Boards, 26 U.C.L.A. L. REv. 484, 531

269 See supra note 28.

264 See discussion supra notes 249-50 and accompanying text. See generally, Joseph H. King, Causation, Valuation, and Chance in Personal Injury Torts Involving Preexisting Conditions and Future Consequences, 90 YALE L.J. 1953 (1981); John D. Hodson, Annotation, Medical Malpractice: Loss of Chance Causality, 54 A.L.R.4th 10 (1987 and Supp. 1990).

265 See, e.g., Evers v. Dollinger, 471 A.2d 405 (N.J. 1984); Herskovits v. Group Health Coop., 


\section{A PROPOSAL FOR FULL PARTICIPATION IN RESEARCH BY ALL PEOPLE, INCLUDING THE PREGNABLE AND THE PREGNANT}

The policy I propose will no doubt be criticized on many fronts, but it does have the virtue of simplicity. I propose that all research protocols include women, without any presumptive exclusion for women of child-bearing capacity, on precisely the same terms that they include men; that is, that eligibility criteria define subjects as people, not by their gender. Women may not be excluded or terminated from a study on the basis of their hormonal status (as a result of menstrual cycle or hormonal therapy) or their reproductive status, unless the hormonal fluctuations and potentially reproductive behavior of the male subjects is monitored to the same degree. Presumably, with regard to trials of therapies for health problems that seem to affect only men, such as testicular cancer, women will generally not qualify because they will not fulfill the gender-neutral eligibility criterion of being at risk for the relevant condition. Because of the need to make a clean break with prior exclusionary practices, however, it is important to break the habit of reflexively categorizing subjects by gender. If a chromosomal female with the requisite condition ever does appear, her anomalous gender identity should not be a barrier to her participation.

The first challenge is to change the discriminatory rules; the next is to strive for substantive rather than merely formal equality. It is at that next level that one would decree outcomes: the participation of women subjects in proportion to their number in the relevant population and provision of child care and other facilities needed to achieve that goal. To compensate for past injustice, gender-specific and gender-comparative research should receive preferential support.

Uniformly, protocol design should include systematic analyses of gender as a variable. ${ }^{266}$ This should be the case not only when gender differences have already been recognized or are anticipated, for example research on drugs metabolized by pathways influenced by sex steroid hormones. We cannot assume that the questions that would detect such patterns have been asked and answered. ${ }^{267}$ The development of every new drug ought to require pharmacokinetic screening and pharmacodynamic studies in women

664 P.2d 474 (Wash. 1983); see also Falcon v. Memorial Hosp., 462 N.W.2d 44 (Mich. 1990) and authorities cited therein; Perez v. Las Vegas Medical Ctr., 805 P.2d 589 (Nev. 1991). Aware of the besieged sense of many clinicians, I feel obliged to note that these decisions do not stand for the proposition that missing a diagnosis automatically amounts to malpractice. The doctor who merely makes a mistake is not liable - only the doctor whose mistake is attributable to an unexcused departure from a reasonable standard of professional care.

266 See Jean Hamilton, Avoiding Methodological and Policy-Making Biases in Gender-Related Health Research, in U.S. Dep't Health \& Human Servs., Pub. No. (PHS) 88-50206, Women's Health: Report of the Public Health Service Task Force on Women's Health Issues IV-54, IV-57-60 (1987).

267 See Eve K. Nichols, Expanding Access to Investigational Therapies for HIV Infection and AIDS, 1991 INST. OF MED. 69-71 (1991). Unfortunately, the FDA's Proposed Guideline, while acknowledging this problem, is guilty of just this fallacy. See Proposed FDA Guideline, supra note 97, at 39,410 (emphasizing pharmacokinetic rather than pharmacodynamic by-gender analyses because "the number of documented gender-related pharmacodynamic differences of clinical consequence is at this time small"). 
and men, and reproductive studies in female and male animals that can determine the incidence of adverse reproductive outcomes through both parents.

This policy goes far beyond current federal regulations, and the proposed revision of the FDA Guidelines. The latter should be redrafted to raise identical concerns about the participation of both male and female subjects of reproductive potential, and to allow women to decide for themselves, as men do, about the relative risks and benefits of participation in Phase I or early Phase II trials. Food and Drug Administration regulations require researchers to inform subjects "when appropriate" that the research may involve "risks to the subject (or to the embryo or fetus, if the subject is or may become pregnant) which are currently unforeseeable."268 This section should be amended to require researchers also to inform male subjects who are or may become involved in reproductive activity of the state of knowledge about male-transmitted birth defects and/or effects on male germ cells. ${ }^{269}$ In many cases the current knowledge will be nil; nothing will be known because the intervention has not been tested on this parameter. Subjects should be told this, and told also that while instances of adverse reproductive effect for or through the male parent have occurred, too little is yet known to permit quantification of the risk. If women are required to use contraception, then so should men. ${ }^{270}$

The most efficient method of changing researcher behavior would be to amend the substantive provisions of FDA regulations to mandate complete testing of new drugs in relevant populations, specifically women of child-bearing age, pregnant women, and nursing women. ${ }^{271}$ At a minimum, the FDA ought to ensure that drug labels state that evidence of both safety and efficacy is lacking for these populations whenever that is the case, and that nothing is known about reproductive hazards for men, which will almost invariably be the case.

The only major change in the Federal Policy for the Protection of Human Subjects would be in the section on equitable selection of subjects, Section .111. "Pregnant women" should either be removed from the category of "vulnerable populations" or replaced by "men and women actively engaged in reproduction." To amplify the definition of "equitable," helpful language may be borrowed from a fine consensus document, the product of a working group on principles and policies for clinical research on HIV-infection, which concluded that:

26821 C.F.R. $\$ 50.25(\mathrm{~b})(1)$ (1988).

269 On December 15, 1992, a coalition of the HIV Law Project of the AIDS Service Center of Lower Manhattan, the National Organization for Women Legal Defense and Education Fund, the AIDS Project of the American Civil Liberties Union, and other AIDS-activist organizations petitioned the FDA for just such amendments, pursuant to 21 C.F.R. $\$ 10.30$. See Citizen Petition (Dec. 15, 1992) (petition sent to FDA, on file with author). The FDA's response - the Proposed FDA Guideline - is completely inadequate in this regard. See discussion supra notes 118-28 and accompanying text.

270 On the need for careful monitoring of male compliance with such restrictions, see infra note 287.

271 A concomitatii of this change would be for FDA regulations to mandate completion of animal reproduction studies prior to human testing. See Citizen Petition, supra note 269, at 6-7; supra note 107-08 and accompanying text. 
No group should be categorically excluded, on the basis of age, gender, mental status, place of residence or incarceration, or other social or economic characteristic from access to clinical trials or other mechanisms of access to experimental therapies. Special efforts should be made to reach out to previously excluded populations.

It is inequitable and discriminatory to exclude women, including women of reproductive age, from clinical trials. ${ }^{272}$

The last component of federal regulations that would need revision is Subpart D. Here, the best option would be to delete Section 46.207, the provision dealing with "Activities directed toward pregnant women as subjects." Its language is ambiguous and confusing, the subsection requiring paternal consent is surely unconstitutional even under present standards, and given that about all it permits is activity intended to "meet the health needs of the mother," depending on one's view of the purposes of clinical research, either it is tautological or it describes a null set. ${ }^{273}$ The bulk of the other provisions of Subpart B, which govern fetal research, suffer from various infirmities and illogicalities that ought to be corrected, but do not in themselves pose any particular barrier to women's participation in protocols.

\section{HOW THIS COULD HAPPEN: STRATEGIES TOWARD CHANGE}

The problem defined in this paper has begun to receive some attention from researchers and others. Several different efforts are underway to move the biomedical community toward a more equitable and, for women, more useful model of clinical research. None of these efforts is incompatible with the others; people concerned with this issue could profitably pursue them all. I will identify some of the advantages and disadvantages that each approach presents.

\section{A. Legislative/Regulatory Action: Politics}

\section{Federal legislation}

The American way to fix most problems is to pass a law. In this area, that impulse has found expression in proposed national legislation. In July 1990, in the wake of substantial publicity about a Government Accounting Office report on NIH's limited success in enforcing its own policy, ${ }^{274}$ the Women's

272 Carol Levine et al., Building a New Consensus: Ethical Principles and Policies for Clinical Research on HIV/AIDS, IRB: Rev. Hum. Subjects Res., Jan.-Apr. 1991, at 1, 14, 16. The working group that developed this consensus document included prominent clinical AIDS researchers and ethicists, as well as representatives of potential subject populations. Their recommendations depart from mine in continuing to treat pregnant women as different from men engaged in reproductive activity, although they do require that pregnant women be permitted access to Phase II/ III trials or treatment INDs if a drug is potentially life-saving, and would create a rebuttable presumption that pregnant women are eligible for all trials. See id. at 16 . While the context of this report is AIDS research, the merit of its analysis is not confined to that.

279 See supra notes 131-32 and accompanying text.

274 In 1986, NIH and ADAMHA promulgated the Policy Concerning Inclusion of Women in Study Populations. NIH, Policy Concerning Inclusion of Women in Study Populations (1991) (hereinafter NIH PoLICY). "Clinical research findings should be of benefit to all persons at risk of the 
Health Equity Act, a package of 22 bills and "sense of Congress" resolutions designed to guarantee women greater equity in medical research, health care and preventive services, was introduced by the co-chairs of the Congressional Caucus for Women's Issues, Representatives Patricia Schroeder and Olympia Snowe. Subjects ranged from mandated appropriations for research aimed at breast cancer, ovarian cancer, and female HIV-infection to reimbursement for mammograms and bone mass measurement.

One bill in particular, the Clinical Trials Fairness Act, targeted the inclusion of women in research protocols, essentially by codifying the NIH policy that the composition of the study population must be considered when determining the scientific merit of a research proposal. The bill was reintroduced in the 102d Congress (February 1991) and actually was passed by both the House and Senate as part of the NIH Reauthorization Act, only to be vetoed by then-President Bush. ${ }^{275}$ In 1993, another version of this appropriations legislation finally became law: the NIH Revitalization Act of 1993.276

There is much that is positive in the NIH Revitalization Act. It directs the Director of the National Institutes for Health to ensure that women (and members of racial and ethnic minority groups) are included as subjects in each research project conducted or supported by the National Institutes of Health. ${ }^{277}$ It requires the creation of Clinical Research Equity Subcommittees, including members with expertise in health conditions of particular relevance to women, within each of the national research institutes. But the bill leaves a great deal to be desired from the standpoint of rectifying the historic imbalance in access to clinical research because of its broad and vague exceptions. None of the bill's provisions apply if the inclusion of women in a re-

disease, regardless of gender." Id. at 1 . The Policy requires evaluation of the gender composition of each study proposed for funding, and a statement of reasons for excluding members of one gender or for "a disproportionate representation" of one gender. Gender representation should be "appropriate to the known incidence/prevalence of the disease or condition being studied," and reasons for exclusion of one gender must be "well explained and justified." The justification must be "compelling," but it may consist of "a strong scientific rationale" or "a need to protect the health of the subjects." Id.

A 1990 Government Accounting Office report concluded, however, that the Policy had virtually no impact because no mechanism of institutional enforcement had been set up. Applicants for NIH grants were not advised about it, and the grant application reviewers did not utilize it as a factor in evaluating the merit of competing proposals. The Policy did not even apply to the NIH's own intramural projects. See National Institutes of Health: Problems in Implementing Policy on Women in Study Populations, Hearings Before Subcommittee on Health and the Environment, House of Representatives, 101 st Cong., 2d Sess. 47 (1990) (testimony of Mark V. Nadel, Associate Director, National and Public Health Issues, Human Resource Division). See further discussion of the NIH Policy infra notes 281-87 and accompanying text.

275 See Women's Health Equity Act, S. 2961, 101 st Cong., 2d Sess. (1990); Clinical Trials Fairness Act, S. 2945, 101 st Cong., 2d Sess. (1990) and H.R. 2507, 102d Cong., 1st Sess. (1991) (vetoed).

27642 U.S.C.A. \& 201 (West Supp. 1993).

277 Id. at $\$ 131$. This 'is a serious limitation in itself; although NIH supports and conducts a great deal of research, one wonders why the legislation is not at least as broad in scope as the federal regulations discussed above - applicable to all research conducted, funded, or regulated by any federal agency or department. Other bills have been introduced that would require attention to women's health interests in the investigation of all drugs prior to FDA approval. See Pharmaceutical Interaction Safety Act, H.R. 2694, 103d Cong., Ist Sess. (1993); Pharmaceutical Testing Fairness Act, H.R. 2695, 103d Cong., 1st Sess. (1993). 
search project is "inappropriate": 1) with respect to the health of the subjects; 2) with respect to the purpose of the research; or 3) under such other circumstances as the Director of the National Institutes for Health may designate, such circumstances to be defined in regulations. ${ }^{278}$

"Inappropriate" is the kind of legislative language that keeps lawyers in fancy cars and fur coats. "Inappropriate with respect to the subjects' health or the purpose of the research" alone would cover the waterfront in terms of authorizing exclusion for just about any of the reasons discussed above. ${ }^{279}$ To give the Director of the NIH, an Executive Branch appointee with a definite political mission, absolute discretion to ignore the inclusion requirement whenever she or he thinks inclusion "inappropriate" is really to vitiate the entire statutory scheme. ${ }^{280}$ It may be that nothing more than this is possible in the current political climate, and it is a step in the right direction, albeit a small step. But anyone who genuinely wants to change the exclusionary practices of researchers should urge Congressional sponsors to return to the

278 Section 131. Requirement of Inclusion in Research Sec 492B.(a).

(1) In conducting or supporting clinical research ..., The Director of NIH shall, subject to subsection (b), ensure that-

(A) women are included as subjects in each project of such research; ...

(2) The Director of NIH . . . shall conduct or support outreach programs for the recruitment of women . . . as subjects in projects of clinical research.

(b) The requirement established in subsection (a) . . shall not apply to a project of clinical research if the inclusion, as subjects in the project, of women ... .

(1) is inappropriate with respect to the health of the subjects;

(2) is inappropriate with respect to the purpose of the research; or

(3) is inappropriate under such circumstances as the Director of NIH may designate.

Id. at $\$ 131$. Cost is not to be considered as a factor in defining "inappropriate." Regulations, intended to explicate "inappropriate," were issued on March 28, 1994, effective June 1, 1994. NIH, NIH Guidelines on the Inclusion of Women and Minorities as Subjects in Clinical Research, 59 Fed. Reg. 96598. The regulations address only Phase III clinical trials and require nothing more than a review of existing data to ascertain whether they suggest significant clinical differences between women and men. If so, then the Phase III trial must be designed to elucidate those differences. However, in Subsection VI(c), the Guidelines state that in most studies, approximately equal numbers of men and women should be subjects unless different proportions are "appropriate" because of known epidemiological differences. 59 Fed. Reg. 14508, 14512. Thus, "inappropriate" is somewhat circularly defined as "not appropriate," but at least it would appear to exclude factors such as risk to offspring. Researchers are not required to inclicate how they propose to comply with this legislation until fiscal year 1995. Id. at $\S 131$ (d)(2)(A)(i), (e)(1), (2).

279 Scientists who want to find a way around this statute will argue that the hornogeneity rationale fits neatly within the "purposes of the research" exception; that concern for that "vulnerable" group, pregnant women, warrants exclusion of those who are or may unwittingly be pregnant "for their health"; and so on. Surely exclusions suggested by FDA Guidelines or apparently required by other federal regulation render contradictory inclusion "inappropriate," and I am afraid that the Director's regulations, which were to have been issued by December 10, 1993, will declare exactly that.

280 Another example of this ubiquitous vagueness: the one federal statute that currently mandates the inclusion of women as subjects is the National Commission on Acquired Immune Deficiency Syndrome Act, 42 U.S.C. $\$ 300 \mathrm{cc}-16(\mathrm{a})(3)$ (1991), the authorization for the Secretary of HHS to distribute grants and contracts for AIDS research: "The Secretary shall ensure that, as appropriate, clinical research programs [for AIDS centers] include as research subjects women, children, hemophiliacs, and minorities." (emphasis added) As of this writing, no regulations interpreting "as appropriate" have been issued. 
drawing board and restart the process of political organization and education - or perhaps, consider an altogether different route.

\section{NIH interpretation of "compelling justification"}

The National Institutes of Health can, through the implementation of its own policy, ${ }^{281}$ dramatically influence the pattern of excluding women from biomedical research. But to do so, more specific standards than are contained in the current policy are necessary. The NIH Policy appears to establish a firm presumption that women shall be included in protocols. However, that presumption may be rebutted by showing either: 1) that it would be "inappropriate" to include women in a given study; or 2) a "compelling justification" for the exclusion of women. In conjunction, these criteria for exemption from the policy are quite capable of swallowing it whole - as with the language of the legislation discussed above, the proverbial Mack truck would have no trouble navigating these holes.

For example, the NIH Policy states that "appropriateness" of inclusion of women is in part a function of the "known incidence/prevalence" of a condition among women. Yet one of the major consequences of the exclusion of women from research has been enormous gaps in existing knowledge about the epidemiology of many conditions in women. As the members of the Women in Research Task Force, a bioethics working group in which I participated, wrote in a letter to Dr. Kirschstein, then-Acting Associate Director of the new NIH Office of Research on Women's Health, "women could end up being excluded from a study based on data from studies which excluded women in the first place." 282 Moreover, women must be leery of terms like "appropriate" when those who will be deciding what they mean remain overwhelmingly products of the mindset and worldview that has so often found subordination, denigration, and paternalistic protection of women "appropriate."

Likewise, with respect to the required "compelling justification" for exclusion of women, the fear is that the three justifications reviewed above ${ }^{283}$ need only be recited to exempt a protocol from the NIH Policy. In its Memorandum OER 90-5, NIH refers to only two situations that qualify as "compelling": 1) the condition to be studied occurs only in men; or 2) inclusion of women would "jeopardize the health and safety" of a class of subjects. Without clarification, it is not hard to imagine that fetal protection may be the hidden meaning of the latter. I find disquieting, rather than comforting, Dr. Kirschstein's response to the Women in Research Task Force letter, in which she states:

A list of situations that comprehensively accounts for all such justifications for "compelling" exclusion is very difficult to create. ...

One potential basis ... is the case in which the financial and human costs of conducting research trials are significantly increased

281 See supra note 274.

282 Letter from Karen L. Hagberg, Coordinator, Women in Research Task Force, to Ruth L. Kirschstein, M.D., 2 (June 28, 1991) (on file with author).

283 See supra part II.B. 
or unduly burdensome in comparison to the benefit gained by including a representative number of both genders in the study population for a disease or condition in which the incidence is lower in one gender than in the other. . .

Another potential basis for rebuttal is the situation in which violation of the established legal rights of a child or potential rights of a fetus are a foreseeable possibility as a result of the mother's participation in a clinical trial. . . . [C]ases in which studies on animals measuring teratogenic or other significant adverse effects are incomplete or inconclusive warrant exclusion justification review and may serve as sufficient grounds for rebutting the inclusion presumption. ${ }^{284}$

Several questions are raised by this response. First, when Dr. Kirschstein speaks of "financial and human costs of conducting research trials," I wonder whose costs, or costs to whom? For women as a class, the costs of their involuntary nonparticipation in research always outweigh the benefits to them. Second, what "potential rights of a fetus" (or for that matter, established rights of a child) are violated when a woman chooses to take an unapproved drug? Surely those same rights, whatever they may be, are violated when the same woman now takes an approved drug that has never been tested in women, or in pregnant women, but is available on the market. Or when the woman fails to follow a doctor's orders, or to exercise regularly, or to do a thousand other things that are "good" for her - as once upon a time, thalidomide, diethylstilbestrol, routine Caesarean section, and minimal weight gain were deemed "good," indeed necessary, for women by their physicians. With this language, I am afraid Dr. Kirschstein and the Office of Research on Women's Health, the putative bastion of women's rights and liberties in this process, inadvertently reinforce the coercive, intrusive model of "maternal-fetal (or child) conflict" discussed above. ${ }^{285}$

As for "incomplete or inconclusive" animal studies of teratogenicity or "other significant adverse effects [upon reproductive outcomes]," so far as I am aware there is nothing but incomplete, inconclusive data in this area. For a start, the absence of such studies with respect to male-mediated effects on offspring render them all, by definition, partial and inconclusive. If Dr. Kirschstein's statement is taken literally, hardly any research should be permitted. There is an alternative approach: requiring adequate animal studies of adverse reproductive effects both in male and female animals. Such studies would have to test for all potential male routes of prenatal impact. ${ }^{236}$ And if $\mathrm{NIH}$ is serious about avoiding risk to the offspring of research subjects, the only effective method will be either to permit participation only of nonfertile men and women - difficult for large-scale studies, and unlikely to be clinically representative - or to impose much more rigorous controls on repro-

${ }^{284}$ Letter from Ruth L. Kirschstein, M.D., Acting Director, Office of Research on Women's Health, to Karen L. Hagberg, Coordinator, Women in Research Task Force 3 (Oct. 23, 1991) (on file with author).

285 See supra notes $137-38$ and accompanying text.

286 See supra notes $140-46$ and accompanying text. 
ductive behavior by human study participants, both male and female. ${ }^{287}$

3. Protection for researchers: immunity from liability through waiver or compensation system

In our society, we often try to encourage behavior we want to foster or protect, but which has major associated costs, by eliminating or limiting the costs. So, to address the carnage in the American workplace, we adopt a system of workers' compensation, which protects employers from liability for the actual costs of employment-caused disease and injury; to encourage pharmaceutical companies to continue producing vaccines despite the inevitable occasional deaths or injury they cause, we enact a parallel system of compensation for vaccine-related injuries. ${ }^{288}$ In New York and elsewhere, there is much support for creating a compensation system for people injured by medical negligence or iatrogenesis.

In each instance, the system is touted as beneficial to the putative victims, because it will provide quicker, if much smaller, recoveries and will relieve them of the burden of proving fault or another theory that would give rise to liability in the judicial system. The track record of these alternative systems has not lived up to their advance press. Most worker advocates agree that workers' compensation has turned out to be a nightmare for all but the worker who sustains a relatively minor traumatic injury on the job. For the tens of millions who have been maimed and killed, or suffer from occupational diseases or more subtle effects of working conditions, "comp" is a slow, unreliable, frustrating, debilitating experience of haggling, hassle, and hotly contested litigation (albeit administrative rather than judicial). Even when "successful," the process culminates in a meaningless pittance and begrudging provision of medical benefits - usually much too late, long after the worker has lost a home or missed out on medical care that could have made a difference. Overall, workers' compensation has turned out to be an excellent deal for employers and a very poor bargain for employees. ${ }^{289}$ When I hear,

287 Since it is more difficult to monitor male compliance with protocol restrictions on im. pregnation than to require routine pregnancy tests, more stringent limitations on the mobility and privacy of male subjects may be necessary for the duration of their study participation, and substantially thereafter, until it is established that their sperm are free of any contamination or mutation.

28842 U.S.C. $\$ 300 \mathrm{aa}-11$ (1991); see discussion of National Childhood Vaccine Act of 1986 and the California AIDS Vaccine Victims Compensation Fund in Wendy Mariner \& Robert Gallo, Gelting to Market: the Scientific and Legal Climate for Developing an AIDS Vaccine, 15 L., MED. \& HEALTH Care 17, 24 (1987).

289 On the failure of American workers' compensation systems to enhance safety incentives or to make employers accountable for the cost of hazards in the workplace, see DaniEL BERMAN, DeATH ON THE Joв 54-73 (1978) (workers' compensation replaces less than 10\% of income lost by victims; e.g., life of a Puerto Rican worker is worth as low as $\$ 11.34$ per week in compensation system); Keith N. Hylton \& Steven E. Laymon, The Internalization Paradox and Workers ' Compensation, 21 Hofstra L. Rev. 109 (1992) (demonstration of the incomplete internalization of cost); OfFICE of Technólocy Assessment, Pub. No. OTA-H-256, Preventing Illness and Injury in the WorkPlace 302, 309 (1985); Glen M. Shor, Workers ' Compensation: Subsidies for Occupational Disease, l J. Pub. Health Pol'y 328 (1980).

On the inefficiencies, delay, and consequent harm to claimants, sce The Final. Report of the State of New York Temporary State Commission on Workers' Compensation and DisaBILITY BenEfits 15-19, 29-72, 79-83, 101-03, 121-25.(1986); Kenneth C. Crowe, Workers' Comp: In 
then, proposals to alleviate the exclusionary practices of clinical researchers by creating a "no-fault" model of compensation for research-related injury, ${ }^{290}$ my enthusiasm is tempered by the history of similar grand experiments.

Another option might be to institutionalize anticipatory waiver of future claims in the informed consent documentation that subjects execute prior to enrollment in research protocols. As a practical matter, this largely already happens, through the operation of the legal doctrine of consent and "assumption of risk." Typically, in the informed consent process the subject learns (or is told, at least) about the variety of risks inherent in participation, including the risk of the unknown. Under the common law, by expressly agreeing not to hold the researcher responsible and/or by proceeding with the research, the subject consents to and "assumes" these risks - like the boxer who climbs into the ring knowing someone is about to try to hurt him - and will have no legal claim later if those very risks, including the undefined "unknown" risks, materialize, whatever the degree of the investigator's culpability. ${ }^{291}$

This uniform practice is the principal reason that legal claims against re-

NY, I''s Hurting, NEwSDAY, June 27, 1988, at III-1; Hearings Before the Temporary State Commission on Workers' Compensation and Disability Benefits, Dec. 10, 1984 (testimony of licensed representative Marilyn S. Brook) (on file with the author); Lawrence White, Workers' Noncompensation, in Human Debris 74-112 (1983); Lawrence White, Living the Nightmare, in Human Debris 74 112 (1983); Jerry L. Mashaw, Lessons for the Administration of Workers' Compensation from the Social Security Disability Insurance Program, in New Perspectives in Workers' Compensation 97 (John F. Burton, Jr. ed., 1988); W. Kip Viscusi \& Michael J. Moore, Workers' Compensation: Wage Effects, Benefits Inadequacies, and the Value of Health Losses, 69 REv. Econ. \& STAT. 249 (1987); John F. Burton, Jr., Compensation for Permanent Partial Disabilities, in SAFETy and the Work Force 18 (John D. Worrall ed., 1983).

On the attitude of industry toward workers' compensation as protecting their interest, see the following quotation from the physician for a large chemical company: "Indusiry doesn't worry much about workers' compensation because those awards are so pitifully small. The lawsuits that frighten them are those that don't have the protection of workers' compensation." Quoted in Elaine Draper, Risky Business 148 (1991).

290 See, e.g., Hayley Gorenberg \& Amanda White, Off the Pedestal and Into the Arena: Toward Including Women in Experimental Protocols, 19 N.Y.U. REv. L. \& Soc. Change 205, 228-29 (1992); Judith Areen et al., Clinical Research Involving Women as Subjects: Legal Considerations: A Monograph Commissioned by the Office for Protection from Research Risks of the National Institutes of Hialth 25-26 (1992) (unpublished monograph on file with the author). For years there has been debate about taking biomedical research out of the common law tort liability system.' See, e.g., President's Commission for the Study of Ethical Problems in Medicine and Biomedical and Behavioral Research, Compensating for Research Injuries: The Ethical and Legal Implications of Programs to Redress Injured Subjects (1982); Bernard R. Adams \& Marilyn Shea-Stonum, Toward a Theory of Control of Medical Experimentation with Human Subjects: The Role of Compinsation, 25 Case W. Res. L. Rev. 604 (1975). The idea has never become concrete, probably because there have been virtually no legal claims by subjects against researchers - reflecting either that participation in clinical research is extremely safe or that the waiver clauses in informed consent documents are artfully drawn.

291 See KeEton, ET AL., supra note $150, \S 18, \S 68$. A release or waiver may be subject to attack if it is not "unambiguous and understandable," or if it fails to make clear that it applies not only to the inherent dangers of the enterprise, but to those harms caused by negligence. See Gross v. Sweet, 400 N.E.2d 306, 309 (N.Y. App. Div. 1979)(waivers of liability strictly scrutinized; "should not compel resort to a magnifying glass and a lexicon"); Boll v. Sharp \& Dohme, 120 N.E.2d 836 (N.Y. App. Div. 1954) (blood donor's covenant not to sue construed to permit lawsuit 
search sponsors have been exceedingly rare, and confined to instances of serious misrepresentation to the subject of quality and magnitude of risk. Why then, do not researchers rely on assumption of risk doctrine to avoid liability? Because of the fundamental misconception: ${ }^{292}$ when researchers think of women, they automatically think of children, and when they talk to their lawyers, they are told that consent and assumption of risk are defenses only to claims by the person giving the consent (and those claiming derivatively through her or him). The concern of research sponsors is the prospect of liability not to the subject but to the subject's offspring, and the issue about women in protocols becomes whether the female parent's consent, either pre-conceptual or prenatal, will insulate the researcher from that liability. Researchers simply do not perceive this same question arising from the participation of male subjects in their protocols.

The answer? On first analysis, most lawyers will say that the parent's consent to risk on behalf of a child is ineffective. ${ }^{293}$ While parents can consent to their children's participation in all manner of fairly dangerous and nonbeneficial activities outside the medical arena, generally they can consent to medical intervention for their children only if the intervention is intended and expected to be beneficial to the individual child. ${ }^{294}$

for negligence because it included commitment to use "customary procedures" and did not exonerate defendants from liability for departure from those procedures).

Express waivers, such as those executed at amusement parks and stables, are quite often deemed "contrary to public policy" and not enforceable under certain circumstances, usually when the signer is considered to be in an unequal bargaining position. See, e.g., N.Y. Gen. Oblic. LAw $\S \S 5-321$ to 5-326 (McKinney 1989 \& Supp. 1993) (liability waivers obtained by landlords, garage-owners, caterers, etc. void). Although the researcher-subject relationship might seem to lend itself to that kind of analysis, to my knowledge express assumption of risk in the medical context has never been voided as a matter of public policy. However, see 21 C.F.R. $\$ 50.20$ (1993): "No informed consent, whether oral or written, may include any exculpatory language through which the subject ... is made to waive or appear to waive any of the subject's legal rights, or releases or appears to release the investigator, the sponsor, the institution, or its agents from liability for negligence." Waiver and release, of course, are not quite the same as assumption of risk through operation of law. Also, it is not the subject's legal rights that concern researchers.

292 See supra notes 83-85 and accompanying text.

293 For an argument that in the analogous case of work-related harm to offspring, waiver would be unenforceable, see Nicholas A. Ashford \& Charles C. Caldart, The Control of Reproductive Hazards in the Workplace: A Prescription for Prevention, 5 Indus. REL. L.J. 523, 556 (1983). Ashford and Caldart believe that the public policy favoring a healthful workplace and the inequality of bargaining power between employer and employee would combine to void a waiver of liability required as a condition of future employment, and argue that just as divorced parents cannot bind their children to a custody agreement or particular level of support without court approval, worker-parents should not be able to waive a future child's right to sue for fetal damage. Id. at n.158. But see, Katherine Swinton, Regulating Reproductive Hazards in the Workplace: Balancing Equality and Health?, 33 U. Toronto L.J. 45, 67 (1983) (United Kingdom Law Commission recommends, and Parliament adopts, statute making binding mother's contractual waiver of liability and assumption of risk on future child's behalf).

294 See Angela Holder, legal. Issues in Pediatric and Adolescent Medicine 151 (2d ed. 1985). If the research presents only minor risk and does hold out promise of benefit, then one parent may consent. IRBs also may waive the requirement of parental permission. See generally, James M. Morrissey et al., Consent and Confidentiality in the Health Care of Children AND ADOLESCENTs 22, 90-91 (1986). One sui generis situation that severely strains this precept is the case of a child who needs a bone marrow or kidney transplant that could best be supplied by a minor (or mentally impaired adult) sibling. May the parent consent to the healthy sibling's organ 
The traditional view, therefore, has been that parents lack capacity to consent to their child's participation in research not intended to be therapeutic, and therefore, ipso facto, to assumption of the risks of the child's participation in such research. ${ }^{295}$ This view has led to conclusions that researchers must find highly disquieting, such as this observation in the first edition of Professor Holder's superb text on legal issues in pediatrics:

It is, however, quite clear that if nonnegligent damage results from a non-therapeutic experiment, the child would have a good cause of action against the investigator. There are numerous precedents for the conclusion that a parent cannot waive a child's rights under the law.... If a parent consented to a non-therapeutic experiment on a child and real damage occurs, in addition to the potential criminal liability for child abuse on the part of both the investigator and the parent, it is quite clear that the child would not be bound by the consent signed by the parent. ${ }^{296}$

However, in 1983 the U.S. Department of Health and Human Services promulgated extensive regulations about children as research subjects that clearly contemplate and authorize parental consent to a broad range of research with children. ${ }^{297}$ This includes research that presents "an opportunity to understand, prevent, or alleviate a serious problem affecting the health or welfare of children" and research that involves greater than minimal risk and no prospect of direct benefit to the subject, but that is likely to yield "generalizable knowledge about the subject's . . . condition that is of vital importance for the understanding or amelioration of [that condition]."298 It is hard to imagine that the lengthy, detailed provisions of these regulations that describe the quality of consent necessary for such research will be treated as nugatory in any future liability litigation, rather than as the source of public policy they obviously are. I predict that research carried out in accordance with these regulations will be considered as subject to the principles of assumption of risk as any other research, and that parental consent that is not patently unreasonable ${ }^{299}$ will be given effect. ${ }^{300}$

donation? Courts have permitted such procedures on theories of psychological benefit to the sibling or under the rubric of "substituted judgment" - the legal fiction that the child, if able to exercise judgment, would consent to the donation. See, e.g., Hart v. Brown, 289 A.2d 386, 388 (Conn. Super. Ct. 1972); Strunk v. Strunk, 445 S.W.2d 145, 149 (Ky. 1969). Other courts, however, have refused to honor the parents' wishes. See, e.g., In re Richardson, 284 So.2.1 185, 187 (La. 1973).

295 However, the one attempt to obtain a judicial declaration that parents have no right either to permit or to compel their children's participation in nontherapeutic research did not succeed. HoLDER, supra note 294, at 153-54, n.16.

296 Holder, supra, note 294, at 170-71. In the second edition, Professor Holder revises this assessment somewhat: "There are numerous precedents for the conclusion that a parent cannot waive a child's rights under law. ... If a parent gave permission for research on a child and real damage occurred, the child would not be bound by the waiver signed by the parent." Id. at 160 .

297 Additional Protections for Children Involved as Subjects in Research, 45 C.F.R. $\$ 46.401$ (1983).

298 Id. at $\$ 46.406-07$. Instead of the term "consent," the regulations speak of parental permission and the child-subject's assent. IRBs may waive the requirement of parental permission and/or minor assent altogether.

299 It is possible to go overboard. I recall one protocol submitted to the IRB I chaired that 
In any case, parental assumption of risk for born, living children who are themselves the subjects of research is not an instructive analogy to the defense of a sponsor from responsibility for harm to unborn or unconceived children because of their parent's consensual participation in a protocol. Just as the HHS regulations distinguish research directed toward pregnant women from research directed toward fetuses in utero, ${ }^{\mathbf{3 0 1}}$ it is fair to anticipate that the law of assumption of risk will not confound what parents should be allowed to do on behalf of their children and what they must be able to do on their own behalf, despite potential implications for future children. ${ }^{302}$

But assuming that it is legally possible for researchers to avoid liability through enforceable subject consent, would that be right? I find this a diff-

contained language amounting to a release of the sponsor from responsibility for intentional physical assault by the investigator. The IRB, I hasten to add, did not approve the protocol.

300 For an intriguing argument that the effect of the federal regulatory scheme and IRB review is legally equivalent to judicial authorization of medical intervention for an incompetent, i.e. an unborn or unconceived child, and therefore would constitute a "consent" that would immu. nize a researcher, see Hazel Sandomire, Women in Clinical Trials: Are Sponsors Liable for Fetal Injury?, 21 J. L., MED. \& ETHICs 217, $221-23$ (1993).

301 Compare 45 C.F.R. $\$ 46.207$ with $\$ 46.208$.

302 Aside from assumption of risk, another potential defense to researcher liability is contributory negligence: when an injured party "contributes" to his or her own harm through unreasonably risky conduct, the claim against a third person may be either precluded or proportionately reduced. See generally, KEETON ET AL., supra note 150, at 65. (I will dispense with the full complexity of the comparative negligence system, which in some jurisdictions permits recovery only if the injured party's "contribution" is assessed as less than $50 \%$ and in others will permit some recovery even if the contribution amounts to $90 \%$; it has no bearing on the present topic.) It would be unusual to find "negligence" on the part of a research subject - perhaps departure from the protocol in taking unauthorized concomitant medications might be an example - but one can imagine the allegation that it was negligent for a prospective parent to participate in a protocol with unknown risks to offspring.

This defense would be of little avail to the researcher, however, because in almost every state, contributory negligence on the part of a parent is not imputed to a child injured in part because of that negligence, and so the child's recovery is not barred or reduced. See KEETON ET AL., supra note 150, at $\$ 74$; Int'l Union, United Auto., Aerospace and Agric. Implement Workers of Am., UWA, v. Johnson Controls, Inc., 499 U.S. 187, 199 n.3 (1991) and authorities cited therein. Recovery for mental or emotional distress of the parent occasioned by the harm to the child might well be abrogated, but that is not the major element of damages feared by researchers. See, e.g., City of Louisville v. Stuckenborg, 438 S.W.2d 94 (Ky. Ct. App. 1968); Davila v. Bodelson, 704 P.2d 1119 (N.M. Ct. App. 1985). (In theory, a researcher held liable could also seek indemnification from the negligeni subject-parent, but given the financial status of the typical research subject, this is an almost frivolous observation.)

As discussed previously, the real significance of being able to attribute negligence to the research subject-parent in this context is to sever the causal link between the researcher's conduct and the harm to the child by interposing the subject's contributory negligence as a superseding cause. See supra notes $149-89$ and accompanying text. As may be evident from what I've said so far, the law of intervening or superseding causation is a true morass, and its application in this context would require another full-scale article, but Prosser provides a useful illustration of how it can work to relieve a putative wrong-doer from responsibility: if someone gives a child something dangerous, like dynamite caps, and the child's parent becomes aware of the danger, but allows the child to retain the dangerous item, "it is at least possible to conclude that from that point forward the responsibility is the parent's rather than the defendant's." KEETON ET AL., supra note $150, \& 44$ at 318 . Likewise, if the parent-to-be is fully apprised of potential risk, including unknown risk, to future offspring from participation in a research protocol, and enters the protocol anyway, arguably "the responsibility is the parent's" rather than the researcher's. See supra note 175 . 
cult question. In terms of moral calculus, it is important to realize that waiver and compensation schemes do not reduce costs; they merely distribute them differently than, in theory, the common law liability model would. Under a compensation or waiver system, the costs largely remain with the unfortunate few who suffer injury, rather than being imposed on those who direct the activity that produces the costs, and indirectly on consumers of the product or service generated by the activity. When a President says that failure to enforce workplace health and safety standards for six months saves $\$ 20$ billion, he means that it saves the owners and operators of business that amount; it may cost workers and their families a great deal more than that in the currency of limbs, senses, organs, and sometimes their lives. The cost of nonregulation or nonresponsibility does not disappear into the ether.

In an analysis of the limits of autonomy in clinical research, Alvin Novick has developed a strong argument against allowing subjects to waive the rights and protections guaranteed them by the regulatory system because, as he puts it, "each subject's waiver would be like a leak in a dam. The damage would not be easily detected or repaired at first but would threaten to sweep away our carefully constructed regulatory wisdom."303 To permit waiver, he says, is to "affirm that human subjects may be treated with disrespect and that safeguards can be consciously bypassed simply because the investigators and the subjects agree to do so." 304 Novick is referring more to problems of research design than to the issue of who bears the risk of harm, but his notion that widespread individual waivers can undercut basic principles -- such as that those who stand to gain from an activity should shoulder its costs deserves serious consideration. My expectation, and fear, would be that because researchers are so reluctant to recognize' the fact that male exposure can endanger progeny, only women would be required to execute these special consents; just as often now only women are required to undertake reliable contraception - creating yet another special obstacle (would legal advice be required? at whose expense?) to women's participation in research.

Proposals to protect researchers by finding ways to immunize them from tort liability could, in one swoop, eliminate an important rationale for the exclusion of women from research. That is an inviting prospect. The trouble is, it could also mean that the clinical trials women would finally get to participate in would become incrementally more dangerous, and that they, their injured offspring, and the injured offspring of male subjects, would have to absorb whatever injury was entailed. It remains hard for me to see the justice of eliminating liability for those who sponsor and conduct research, unless they are willing to share their profits, in the broadest sense. Liability is an important disincentive, and at present one of few, for the kind of callous disregard for human health and life that has been all too prominent a feature of drug development and other kinds of biomedical research. ${ }^{305}$ Perhaps we

${ }^{903}$ Alvin Novick, May a Human Subject Waive the Right to Be Treated as A Human Subject?, 5 AIDS \& Pub. Pol'y J. 45, 48 (1990).

304 Id.

305 In addition to the classic horror stories of Tuskegee, MER/29, DES, Dalkon Shield, and thalidomide, other examples, including the resistance of aspirin manufacturers to labels that would warn of the risk of Reyes' Syndrome; the failure of Eli Lilly to reveal deaths associated with the arthritis drug Oraflex; the criminal charges against company officials for concealing the liver 
have progressed to the point where such deterrence is no longer necessary, but without more evidence, to jettison this one proven mechanism of preventing harm seems rather reckless.

\section{B. Litigative Action: Law}

It is conceivable that the best way to bring about change in this area will be through litigation on behalf of individual and/or classes of women, utilizing some of the theories of liability outlined above. In one case, involving a woman with HIV-infection denied entrance to a tat-inhibitor trial because its entrance criteria limited enrollment to women who had been surgically sterilized or were one year post-menopausal, a letter from a lawyer seems to have persuaded the research sponsor to offer that woman a slot in the trial. ${ }^{306}$ (The sponsor did not, however, change the general criteria. How is that for good science?)

Because the fear of litigation seems to play such a large role in the exclusion of women, counter-litigation - perhaps the threat more than the turtlepaced reality - may be the only effective means of persuasion. After all, it has been the near-universal experience of public-interest lawyers that even the most successful legislative reform campaigns, culminating in well-crafted legislation, turn out to be hollow delusions without enforcement from the private sector to give the legislation teeth. That is why it is imperative that poor people have lawyers who have the will and the means to litigate on their behalf.

But the drawbacks of the litigative approach cannot be denied. It is excruciatingly slow, and the time frame for those who want to enter trials is usually short. It will require the enlistment of experts in the design and conduct of research, who however strongly they believe in the need to change research practice may be reluctant to become involved with anything that smacks of the courtroom. The practical reality is that many research sponsors, including the government, have essentially unlimited resources to expend in opposing and appealing judicial remedies. And, as happened in the case described above, the remedy too often may be of benefit to particular individuals, but not produce an overall change of policy or of heart. Like the 2" x 4" that gets the mule's attention, litigation may be a necessary tool to induce researchers to focus on the need to do clinical trials with subject pools that more accurately reflect the clinical population, but it seems unlikely to accomplish the whole task.

\section{Professional Education: The Role of Scientists, Scholars, and IRBS}

On balance, the best option to overcome the obstacles to women's fullfledged participation in biomedical research may be the most laborious: to try to incorporate into the various mechanisms of professional socialization a

damage associated with Selacryn, are described in Teresa M. Schwartz, The Role of Federal Safety Regulations in Products Liability Actions, 12 J. Prod. Liab. 305 (1989). See generally, John Braithwaite, Corporate Crime in the Pharmaceutical Industry (1984).

306 Memorandum on FDA's Proposed Guideline, supra note 128, at 1-2. 
new ethos of biomedical research. ${ }^{307}$

Regulations and funding criteria that require researchers to include women in protocols ought to be instituted, and those that exist need to be made far more specific and effective. But I doubt that these will suffice. The other forces that operate on researchers must be brought into play. The leaders of the research establishment, the people who command respect and control resources, need to reinforce the message that research that fails to include subjects of both genders is no longer acceptable. It has to become clear that exclusionary research will not be rewarded by the prestige and recognition within their own community that is of such paramount importance to those who consider themselves scientists.

The Office of Protection from Research Risks (OPRR) and the Office of Research on Women's Health (ORWH) can and should take a leading part in this enterprise. Educational material should be generated and distributed in consensus conferences, workshops, and with applications for research support. Articles should be submitted to the major medical journals; a "Sounding Board" in the New England Joumal of Medicine and an editorial in Clinical Research would probably accomplish more than ten lawsuits. OPRR and ORWH could undertake outreach to educational institutions: it is always a tough fight to insinuate any new issue into the already-overcrowded professional curriculum, but the medical schools, public health schools, and graduate programs that train future researchers - not to mention the law schools that produce those researchers' future lawyers - have a responsibility to make their contribution to redressing the injustice of current research practice $^{308}$ The professional organizations could be mobilized; a few, like the American Public Health Association, have already gone on record supporting adequate representation of women in all research populations and exhorting researchers to analyze all study results by gender to detect differential patterns of risk or response to intervention. ${ }^{309}$ An endorsement of the inclusion of women as an aspect of the equitable selection of subjects from a policy committee of the American Society for Clinical Investigation would be highly significant, not so much because American scientists automatically conform to such judgments, but because of the debate within the profession it would occasion and the thinking it would provoke. Unquestionably, the recently released report from a special committee of the Institute of Medicine will forward this process. ${ }^{310}$

Then there is the next circle: the bioethicists and social scientists who comment on and criticize scientists' behavior. The Hastings Center, the Kennedy Institute, the Center for Biomedical Ethics in Minnesota, the Center for

307 An excellent summary of the variety of sources of influence within the research community can be found in Mark S. Frankel, Human Experimentation: Social and Professional Control, in ENCYClopedia of Bioethics 702 (Warren T. Reich ed. 1982).

308 On the importance of transmission of norms and ideals in the process of professional education, see Jay Katz, The Education of the Physician-Investigator, 98 DAEDalus 480 (1969); see also, The Student-Physician: Introductory Studies in the Sociology of Medical Education 7677 (Robert K. "Merton et al. eds., 1957).

${ }^{909}$ See Governing Council of the Am. Pub. Health Ass'n, Interim Policy Statement L.B1, Support for Women's Health Research, 81 Am. J. Pub. Health 260 (1991).

\$10 See supra note 8. 
Clinical Ethics in Chicago, the Center for the Study of Society and Medicine at Columbia's College of Physicians and Surgeons - all these institutions could air the issues associated with exclusionary research, a process already in progress to some extent but not yet as systematic and comprehensive as it could be. Perhaps OPRR and ORWH could sponsor a national meeting that would bring together representatives of these centers and researchers.

Institutional Review Boards are major sources of influence on the design and conduct of protocols. In carrying out their function of assuring the equitable selection of subjects, ${ }^{311}$ IRBs can assist researchers who encounter difficulty in designing gender-neutral studies. My experience as Chair of the IRB of the Community Research Initiative of New York suggests that an IRB can work as a partner with researchers in a collaborative, problem-solving mode that seeks to enlighten researchers rather than impose conditions on them. ${ }^{312}$ But first, the members of IRBs themselves need to become versed in the issues and achieve clarity about their own interpretation of the equitable selection requirement. ${ }^{313}$ OPRR, in particular, can foster this process and inform IRBs of their duty (and self-interest, given the liability questions raised above $)^{314}$ to carefully examine the justifications for protocols that, for example, limit the participation of potentially child-bearing women but express no interest in the potentially reproductive status or conduct of male subjects.

Still other entities than those I have named - foundations, for example - could help create a textured, subtle, persuasive discourse about subject exclusion that would be heard and taken seriously throughout the halls of academic medicine and governmental research centers. My point here is not to draw a precise blueprint but to suggest a general strategy which would be less an Operation Desert Storm assault, more a guerrilla movement focused on the "hearts and minds" of those who plan, fund and do clinical research.

\section{CONCLUSION}

The exclusion of women from clinical research must end. A variety of justifications offer superficial support for the practice, but on close examination they have scant validity. These shibboleths must be abandoned, and research practices must change, through whatever combination of political, legal, and social pressure is necessary. Nothing less than the health of my daughter's generation of women, and the generations beyond, is at stake.

311 See discussion supra 259 and accompanying text.

812 Merton, Community Based, supra note 109, at 524.

${ }^{313}$ A survey of all IRB chairpersons at institutions with NIH approval, conducted in the fall of 1991 , found that $80-90 \%$ of the 329 responding IRBs had no policy in place with respect to equitable selection of subjects relative to gender; that fewer than half the IRBs routinely ask investigators to justify a proposed exclusion of female subjects; and that $73 \%$ routinely require women subjects to use contraception during a trial, while $93 \%$ did not have a parallel requirement for male subjects. Surprisingly, several of the IRB chairs indicated that equitable selection of subjects was not a legitimate concern for an IRB. Many more respondents volunteered categorical statements about the requirements of federal regulation, the likelihood of liability, and the supremacy of the value of fetal protection as a value above all others, that reflect the misinformation and inaccurate analysis of these issues criticized throughout this article. Ada Sue Selwitz \& Daniel P. Wermeling, IRB Policies and Practices: Review of Subject Population, 20-33 (undated) (unpublished monograph prepared as NIH background paper, on file with author).

314 See discussion supra notes 255-65 and accompanying text. 


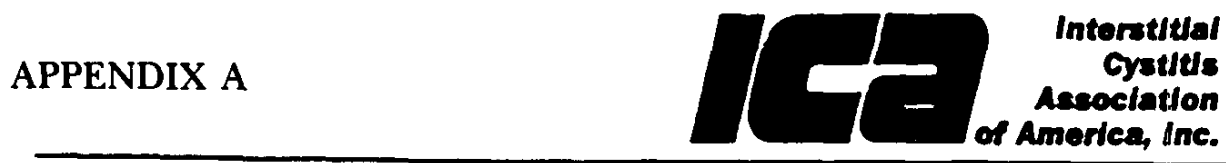

P.Q bar 1stars, son Ologa ca patrs

\section{THE GENDER GAP IN UROLOGY RESEARCH \\ At least 100 million dollars are needed to provide parity for female urologic diseases}

Urologic Disease

Incidence per Year

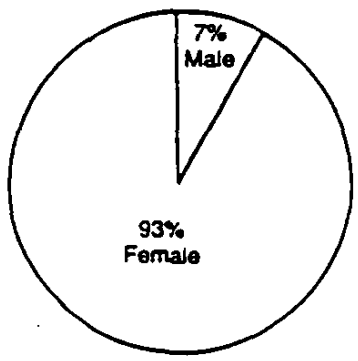

PREDOMINANTLY MALE

\begin{tabular}{lcc} 
Disease & s & $\begin{array}{c}\text { Incidence } \\
\text { por year }\end{array}$ \\
\hline $\begin{array}{l}\text { Benign Prostatic } \\
\text { Hypentrophy } \\
\text { BPH }\end{array}$ & 482,000 \\
\hline Stones. & 1 million \\
\hline $\begin{array}{l}\text { Male Sexual } \\
\text { Oystunetion \& }\end{array}$ & Unknown \\
\hline Orner Male & & $1,482,000$ \\
\hline Total & $\$ 9,623,832$ & \\
\hline
\end{tabular}

Twice es many men are hosortalized lor stones than women a 85\% of all outpaberm cases are mave. Source - NKUDAB Long-Pange Plan.

\section{ANNUAL EXPENDITURE $\$ 6.49$
PER PERSON}

NIH Funding Breakdown for Urologic Diseases (except cancer)

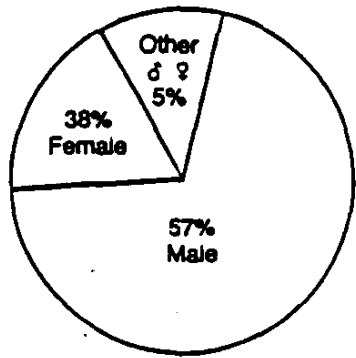

PREDOMINANTLY FEMALE

\begin{tabular}{|c|c|c|}
\hline Dleange: & s & $\begin{array}{l}\text { Incldence } \\
\text { per year }\end{array}$ \\
\hline $\begin{array}{l}\text { Imerstitial } \\
\text { Cystutis }\end{array}$ & & 500,000 \\
\hline Infection & & $\begin{array}{l}\text { Chronic } \\
6 \text { million }\end{array}$ \\
\hline Incontinence & & 12 million \\
\hline $\begin{array}{l}\text { Urothral } 4 \\
\text { other fermale } \\
\text { disorders }\end{array}$ & & $\begin{array}{c}\text { Unienown } \\
\text { but } \\
\text { substantial }\end{array}$ \\
\hline Total & \& $6,437,715$ & $18,500,000$ \\
\hline
\end{tabular}

NOTE: Our figures are ditterent this year because they are not limited to the NIDDK Urology Oivision.

\section{EXPLANATIONS:}

- The disease incidence was based on NIH provided epidemiological data and is in agreement with data in the National Kidnoy and Urologic Diseases Advisory Board Long-Range Plan. A disoase has been classified as Male/Female if it aftects one sex at the $70 \%$ level or higher.

- FUNDING - The breakdown does not include urinary cancer because that comes under the heading of oncology and is tunded by the Cancer Institute. How ever, it does inctude all urology specific research from all NIH Institutes. We have not inclucied, however, 24.8 million in research dollars orovided by NIH from NIAID, NINDS, NICHD, NIEHS, NCRR and NCNR because intormed sources have told us that these figures are not urology specific. Instead, these figures were derived simply by prorating total budgets. For example. the 519.7 million provided by NLAID is as relevant to the lower urinary tract as to infection of the big 100.

- So as not to inctude occasional UT's. we attempted to guesstimate the rumber of chronic infections and used a lower 6 million figure. Each year, there are 1.6 million hospital admissions for UTI's. We know that these are chronic cases and wo atso know that for every hospital casa there are several chronic outpattent cases. There fore we belleve that our estimate of 6 miltion chronic UTi's is probably conservative.

- BASIC RESEARCH - All basic research on urologic digenses is included in this tabulation. Assignnerts were made based on primary area of interest. For example: Basic research on the smooth muscte was put under male seanal dysturction if this was the stated objective of the research. Othenvise, wel put all emooth muscie research into temale urology giving NIH the benefit of the doubt.

- OtHER MALefFemale Research - The Other MalefFomalo" category reters to research that bs not gender specific it inctudes 6 projects for a total amount of 5701,938. A prime example of this category bo one project that NIH has designated as IC resoarch, Le. Central \& Peripherd Mechaniems of fjtadder Pain: Since this proiect is as relevant to IC as to any other bladder condition with pain, tt was moved into tht gender neutral category. We also want to point out of this time, that 6 projects dealing with kildney disanse are beling tunded with urology monoy. We did not include these, and that is why our total funds do not add up to the total NIDOK \& NIA Urokggy budgets. 


\section{TOWARD A WOMEN'S HEALTH RESEARCH AGENDA}

This is a still incomplete list of health conditions, issues, and problems that: 1) appear with greater incidence or prevalence in women; and 2) have been sparsely researched and are poorly understood. In the case of those conditions that have been the focus of significant clinical investigation, research has involved predominantly or exclusively male subjects. There is virtually no information available about the natural course, use of conventional therapies, or special implications of most of these conditions in pregnant or lactating women. In the rare event that research has been done on a condition in pregnant or lactating women, the purpose of the research has generally been to evaluate the safety or efficacy of an intervention for the embryo, fetus or child, not for the mother.

This list is based on a preliminary review of: 1) the testimony of witnesses representing a broad array of professional and community organizations at the 1991 hearings of the NIH Task Force on Opportunities for Research on Women's Health; 2) reports generated by the recently formed Society for the Advancement of Women's Health Research; and 3) legislative committee and conference reports on the proposed Women's Health Equity Act. All statistics are U.S. only unless otherwise indicated. The order is quite arbitrary. Additional suggestions would be appreciated.

1. Cardiovascular/coronary heart disease (women twice as likely to die from heart attack as men; 1 in 3 women has clinical cardiovascular disease at age 65 and older; \# 1 killer of women over 50 ; more women than men die each year)

- diagnosis, risk stratification, prevention, efficacy of medical and surgical therapies and lifestyle measures in women

- protective effects of exogenous gonadal hormones on coronary arteries, vasoactivity, or lipid disposal mechanisms

- establishing norms of circulating lipids and lipoproteins in women and understanding reasons for differential as predictors of coronary risk

- relationship between oral contraceptive use and other cardiovascular risk factors

- reasons that diabetes is such a potent predictor of prognosis in women

- factors in poorer myocardial infarcation (MI) outcomes in women

- impact of age-associated/stress-associated factors on prevalence of CVD

- hypertension: gender differences in incidence of isolated systolic hypertension; hormonal-antihypertensive drug interactions; factors in threefold increased risk of stroke and mortality in hypertensive women

2. Risk-benefit ratio of hormone replacement therapy (HRT); effective alternatives to HRT 
3. Breast cancer (fewer than $3 \%$ of women with breast cancer are or have been in clinical trials; 175,000 new diagnoses/year; $70 \%$ of all diagnoses with no known risk factors; 45,000 deaths per year; increasing incidence, no decrease in mortality rate)

- basic research on causes, progression, links to environmental, occupational, dietary, metabolic and genetic factors: hormone replacement therapy, hormone-based contraception, infertility treatment, etc.

- relationship between radiation therapy and distant bone metastasis

- investigation of access barriers to high-quality screening

- identification of tumor markers for very early detection

- psychosocial management

- improved educational methods for breast self-examination

4. Ovarian cancer: causes, progression, genetic factors, basic processes of ovarian aging, early detection (20,500 new diagnoses, 12,400 deaths/ year)

5. Cervical cancer: new screening modalities (13,000 new diagnoses, 5000-7000 deaths/year; second most common cause of cancer deaths in women worldwide)

6. Uterine cancer: (34,000 new diagnoses, 4000 deaths/year)

7. Improved efficacy of mammography and pelvic transvaginal ultrasound

8. Endometriosis (5-10 million women; most common disease among women under 50 )

9. Osteoporosis (19 million women; $35-50 \%$ of all postmenopausal women; 1.5 million fractures per year, leading to 50,000 deaths and $25 \%$ of all nursing home admissions; lifetime risk of osteoporotic hip fracture equal to combined lifetime risk of breast, uterine and ovarian cancer)

- evaluation of bone mass measurement technology

10. Autoimmune disease and immune dysfunction disorders: need to research basic pathology, genetic/sex-linked etiology, and treatment of:

- Multiple Sclerosis (70\% women)

- Systemic lupus erythematosus (500,000 people, 90\% women, 65\% African-American, Asian-American, Native American; 5,000 deaths/ year)

- Myasthenia gravis (85\% women)

- Rheumatoid arthritis (2 million people, $75 \%$ women)

- Sjogren's syndrome (2-4 million people, 90\% women)

- Scleroderma (80\% women)

- Diabetes (65\% women)

- Mononucleosis (65\% women)

- Inflammatory bowel disease (55\% women) 
11. Thyroid disease (hyperthyroidism 5 times more frequent in women, hypothyroidism 4 times more frequent in women)

12. Gastrointestinal disease:

- gastroparesis and irritable bowel syndrome (3 times more common in women)

- gall bladder disease (65\% women; women under 50 develop 4 times as often as men)

- differential hepatotoxicity of alcohol in women

13. HIV infection and transmission to women (in major American cities, leading cause of death for women aged $20-40 ; 11.5 \%$ of all U.S. adult AIDS cases per CDC criteria are women, 73\% African-American and Hispanic; life expectancy of AIDS-diagnosed woman is six months; worldwide, $1 / 3$ infected adults are women and in Africa rate of new infection of men and women is equal):

- safety and efficacy of already approved drugs (e.g., linkage of AZT to vaginal cancer?) and new interventions in women

- impact of use of oral contraceptives in HIV-infected women and interaction of AIDS drugs and contraceptives

- gynecological opportunistic infections

- AZT and dysmenorrhea

- transmission barrier methods that are female-controlled and may be used without detection by sexual partners

- relationship of immune decline markers to female genital tract and reproductive organ infections and pre-cancerous lesions

- interaction of HPV and HIV

- investigation of case definition and need to incorporate genderspecific clinical assessment techniques in routine evaluation of HIV patients

14. Occupational hazards of workplaces that are predominantly female (including the home)

15. Metabolism and pharmacokinetics/pharmacodynamics of drugs and alcohol in women, especially older women; variation in drug metabolism, especially antihypertensives and antidepressants, during menstrual cycle and pregnancy

16. Pathological and therapeutic effects of sex steroids:

- natural history of endocrine system in menopause

- RU486 and other antiprogestins

- effects on insulin sensitivity, clotting and plaque

17. Urinary tract disease and dysfunction:

- interstitial cystitis (500,000 people, 90\% women; described in Campbell's Urology as a "hysterical female condition" until 1980) 
- changes in bladder function and urinary incontinence, especially in menopause and postpartum (12 million people, $90 \%$ women; $1 / 3$ of all women over age 55; leading cause of nursing home admissions for women)

- urinary tract infections (8 million people, $30: 1$ female/male ratio; $6 \%$ entire female population every year; $20 \%$ all prescribed antibiotics; linkage to fetal intrauterine growth retardation)

- complications of hysterectomy and pelvic floor surgery

- "urethral syndrome:" catch-all diagnosis requires investigation

\section{Uterine fibroid disease}

\section{Lactation:}

- effect on postpartum anovulation: method of fertility control

- long-term consequences on obesity and maternal energy balance

- effects on maternal calcium stores

- protective effects on breast cancer

20. Pre-menstrual syndrome: patterns and relationships of ovarian steroids, autonomic nervous system arousal indicators, and psychosocial and environmental factors in symptomatic women

21. Menopause as normal life process $(25 \%$ of women who seek medical advice for menopause-related symptoms are prescribed tranquilizers; one-third of average woman's lifespan is postmenopausal)

- need to identify markers to track changes in endometrial tissue

22. Pelvic inflammatory disease $(420,000$ outpatient visits, 200,000 hospitalizations each year)

23. Post-hysterectomy vaginal/pelvic reconstruction and breast implants

24. Polycystic ovarian disease; premature ovarian failure

25. Amenorrhea, dysmenorrhea

26. Iron-deficiency anemia

27. Nutritional needs, especially in lactation and pregnancy: understanding of metabolic adjustments that redirect nutrient use to milk synthesis and secretion

28. Chronic migraine/headache (16-18 million people: $70 \%$ women)

29. Hyponatremia (post-surgical low blood sodium leading to death/brain damage) (90\% woman)

30. Health risks of cosmetic surgery 
31. Vascular and genitourinary complications in paralyzed women with spinal cord injury/disease, including menorrhagia and amenorrhea, autonomic dysreflexia

\section{REPRODUCTIVE HEALTH}

32. Safer and more effective contraception and fertility control for women and men, including female-controlled barrier contraceptive/STD preventive devices (half of all abortions result from contraceptive failure)

33. STDs: chlamydia, human papilloma virus (associated with cervical cancer)

34. Chronic miscarriage and recurrent spontaneous abortion

35. Ectopic pregnancy (fourfold increase in incidence since 1970)

36. Etiology of pre-term labor/membrane rupture (leading cause of infant morbidity/mortality)

37. Toxemia, pre-eclampsia, eclampsia (pre-eclampsia occurs in $10 \%$ of all white pregnancies, 20\% African-American pregnancies)

38. Effect of greater participation and control by birthing women and traditional birth attendants in prenatal care and birth process decisions

39. Gestational diabetes

40. Effects on mother of exercise/physical stress in pregnancy

\section{Immune responsiveness and immunosuppression in pregnancy}

42. Gametotoxicity and other adverse reproductive effects in men of toxic exposures, pharmaceuticals, food additives and hormones, etc.

\section{PSYCHOSOCIAL/BEHAVIORAL/MENTAL HEALTH}

43. Antiwoman violence: etiology, prevention, treatment for rape, sexual abuse and domestic violence (battering most frequent reason for female presentation to ER; 4 women killed/day; 3-5 million assaults on women/year)

\section{Postpartum stress/depression}

45. Affective disorders, especially depression (7 million women; women's risk for depression twice that of men)

46. Impact of gender roles on health-promoting behavior/health status

- effect of caregiver role: exposure to children's diseases, stress of elderly parent care, occupational hazards of nurses/health aides

- effect of multiplicity of roles on health status (role overload) 
- effect of role as family medical mediator: responsible for diet and clothing of family members, arranging access to health care, purchase and administration of OTC and prescription mediations, etc.

47. Impact of gender role on sexual function/dysfunction, susceptibility of STDs, ability to utilize contraception, etc.

48. Incest/sexual, physical and emotional abuse of children (rate of childhood sexual assault on women $22-37 \%$ )

49. Multiple personality disorder

50. Anorexia, bulimia, eating disorders

51. Factors affecting the onset, continuation, and cessation of tobacco, alcohol, and other substance use/abuse behaviors in women

- treatment modalities that do not impair maternal-child relationships

- treatment modalities for pregnant and lactating women

52. Pornography and media images as factors in antiwoman violence

\section{LONG-TERM PROJECTS:}

53. Review and revision of the Diagnostic and Statistical Manual of Mental Disorders and the International Classification of Disease to promote more accurate diagnosis and treatment of women

54. Investigation of new specialty in women's health 